\title{
Nuclear Power Plants Are Not So Safe: Fluid Transients I Water Hammers, Autoignition, Explosions, Accident Predictions and Ethics
}

\author{
Robert Allan Leishear \\ Leishear Engineering, Limited Liability Corporation, Aiken, USA
}

Email address:

leishear@aol.com

\section{To cite this article:}

Robert Allan Leishear. Nuclear Power Plants Are Not So Safe: Fluid Transients / Water Hammers, Autoignition, Explosions, Accident Predictions and Ethics. International Journal of Philosophy. Vol. 9, No. 1, 2021, pp. 11-51. doi: 10.11648/j.ijp.20210901.13

Received: December 7, 2020; Accepted: February 1, 2021; Published: February 20, 2021

\begin{abstract}
Due to misdiagnosed hydrogen explosions and ethically flawed publications, nuclear power plants are not as safe as published to be for decades. Previous publications inaccurately, unethically, and inappropriately assessed reactor safety with respect to other industries and natural disasters, where nuclear industry publications non-conservatively applied data to promote nuclear reactor safety, and published models skewed accident data to present nuclear energy as safer than it is. Major findings of this one-man study were calculated with 95\% confidence. 1) Explosions caused by fluid transients accompany nuclear power plant meltdowns. 2) A meltdown similar to Three Mile Island (TMI-2) has a 50\% probability before 2039, with a one in two probability of a radioactive release like Fukushima. 3) A large radioactive release like Fukushima has a 50\% probability before 2067. 4) Radioactive releases can be prevented by fluid transient control with the exception of Chernobyl type accidents, which are expected far into the future. 5) Nuclear power plant accidental deaths are not significantly less than other industries as claimed for many years, but are comparable to other industries. An improved explanation of nuclear power plant explosion safety is provided here to better control dangers in the radiation business. Items 1 and 2 were previously published, but are summarized here as proof of principle to support this new research, and items 3, 4, and 5 are new to the literature. These latter concerns are the thrust for this discussion of ethics, nuclear safety, and the prevention of loss of life, property damages, and catastrophic environmental damages. A personal history of the difficulties of being the first to invent new theory and the government obstruction and unethical cover up to thwart legitimate safety concerns are intertwined with statistical proofs for nuclear reactor disaster predictions. Such disasters explode radioactive dust clouds into the air to circle our planet, and spread radioactive contamination that radioactively rains down across parts of the earth following large accidental explosions. Although the ethical path to accomplish this task has great personal costs, such as difficulty, stress, complexity of thought, long hours, impacts on family life, and money, the rewards are that imminent nuclear power plant explosions and loss of life can be stopped!
\end{abstract}

Keywords: Chernobyl, Three Mile Island, Fukushima, Hamaoka, Fluid Transient, Autoignition, Hydrogen Explosions, Ethics

\section{Introduction}

\subsection{Nuclear Power Plant Explosions and Ethics}

This research paper provides a two-fold discussion of nuclear reactor safety. On the one hand, the dangers of an imminent nuclear power plant explosion are considered. On the other hand, the unethical misrepresentation of technical information in the nuclear industry for several decades by government agencies prevented earlier detection of this safety peril. Specifically, the Fukushima explosions could have been prevented, and impending similar explosions can be prevented.

With respect to nuclear power plant explosions, recent theory is briefly reviewed which proves that fluid transients, which include water hammers and steam hammers that depend on the primary system fluid at the time of the transient (Leishear [1]). These transients cause explosions in nuclear power plants. For example, pump startups and valve operations pressurize flammable hydrogen-oxygen mixtures 
to autoignite and explode during water hammers. The extremely complex mechanisms of fluid transient induced explosions caused major damages at Three Mile Island and Fukushima (Figure $1^{1}$ ). This mechanism also exploded 6 inch diameter pipes like paper firecrackers at nuclear power plants in Hamaoka, Japan and Brunsbuttel, Germany; and this mechanism caused many smaller explosions in nuclear power plants in the U.S. and abroad, which have been misdiagnosed as water hammers without explosions for decades.

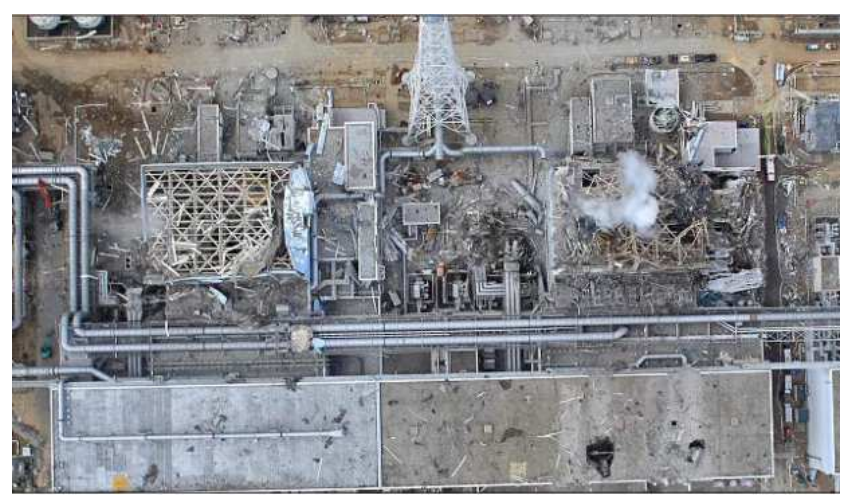

Figure 1. Preventable Fukushima explosions and fire damages following a tsunami, meltdown, and water hammer (NRC.gov).

Earlier government reports misrepresented the safety of nuclear energy by manipulating data to reach false conclusions. These reports also ignored the facts that proved that there was an explosion at Three Mile Island in 1979, rather than a fire as reported in government studies. Accordingly, there was no reason to question nuclear reactor safety. However, the invention of new theory on why nuclear power plant explosions occur called these previous reports into question, and more thorough study showed that reports misrepresented the facts.

Once safety reports were questioned, new research opened. Specifically, water hammer explosions were shown to be a common thread to nearly all of the so-called nuclear accidents, except Chernobyl. With this understanding in hand, the probabilities of the next meltdown and next explosion are predicted in this publication. There is a $50 \%$ probability of a meltdown in the present nuclear reactor fleet before 2039, and there is a $50 \%$ probability of an explosion during that meltdown. If actions are taken, this potential explosion can be prevented.

In summary, new ideas scrape against the status quo of conventional thought. This publication is the next step to save lives by changing the way that engineers think about nuclear power plant explosions, both ethically and technically. With respect to technology, this work clearly proves that the next nuclear power plant explosion is likely to occur within 20

\footnotetext{
${ }^{1}$ Figure 1 was planned to be a dramatic photo of a large fire that was shown on Japanese television following the Fukushima explosions. When permission was requested to use that photo for this paper, NHK television station conceded that the photo was a chemical plant fire used on the news since they were not allowed to access Fukushima. Was this action a question of ethics, economics, or public information? That 2011 photo and video were withdrawn from the internet immediately after this request.
}

years. With respect to ethics, government agencies have promoted a false sense of security through the misrepresentation of facts. The next Fukushima type explosion can be prevented, where regulators and plant operators promised that explosions at Fukushima were technically impossible. The goal of this research is to change the thoughts of other engineers to make the world around us a safer place to live.

\subsection{Research Topics}

A primary goal of this original research is to improve nuclear power plant safety by convincing others that the next nuclear power plant explosion is imminent and that nuclear power plants are as safe as other industries, although not as safe as previously thought. New explosion predictions are the crux of this research, and corollary ethical considerations are secondary, but extremely important with respect to how earlier conclusions with respect to rector safety were reached. The questions of ethics presented here are not accusations of wrong-doing, but observations that principals of ethics have been violated by omission or rationalization. In efforts to do well, the facts are sometimes side-stepped. As a matter of fact, this paper drastically changed through different revisions as this author's sense of ethics evolved with respect to very complex issues of concern. Guilt or blame is not the issue - the issue is that reactor safety conclusions are unethically, and therefore incorrectly, presented and addressed in the nuclear industry. Reactor safety and explosion predictions are the predominant issues considered here.

By considering the history of nuclear power plant accidents, predictions of future accidents and explosions can be statistically determined. The most important of these findings is that the next meltdown is expected before 2039, and that there is a one in two probability of a large scale radioactive release to the air and across the globe during that event. To predict future nuclear accidents and explosions, in-service nuclear power plant accidents must be considered.

For nuclear power industry explosions there are also two primary ethics issues that are considered, which are intertwined with nuclear power plant safety. The first ethics concern is related to the Three Mile Island nuclear reactor meltdown, where pertinent technical data was excluded from investigation reports. Specific evidence to prove that an explosion occurred at TMI-2 has been available in U.S. government reports since 1979, that evidence has been ignored in support of an opinion that a fire occurred at TMI-2 (Leishear [1 and 2]), and that previous evidence is challenged here. In fact, the intentional oversight of facts which prove that explosions occurred at TMI-2 has prevented the understanding of nuclear power plant explosions for decades.

The second ethics concern is related to probability theory that was used in earlier research by others to incorrectly evaluate and misrepresent the safety of nuclear power plants, and this study works to use that same probability theory to prove that reactor safety is improperly presented in previous literature. First of all, graphic accident frequency publications for single reactor operations are used to imply that the same 
frequencies apply to the world-wide reactor fleet, but the accident frequencies for the fleet are much higher than publicized. Second, frequencies are used throughout the nuclear industry to publicize reactor safety, but risks are appropriate instead of frequencies, and risk evaluations prove that previous publications are faulty and misleading. The following discussion supports these opinions, which will be controversial to some engineers, scientists and politicians, and care is therefore taken here to competently prove these opinions. The issue of ethics is seldom discussed with respect to engineering publications, and this issue deserves attention. After all, safety is paramount.

To understand these complex interrelated issues, accidental meltdowns, accidental radioactive material releases, and accidental deaths require consideration. Although data from numerous reactor accidents support this research, the primary reactors of discussion are Three Mile Island, Unit 2 (TMI-2), Chernobyl, Unit 4, and Fukushima Daiichi, Units 1 through 4, where the prevention of major accidents can drastically improve safety in the nuclear industry (Leishear [1]). Reactor criticality accidents are discussed briefly in the Addendum, where large-scale nuclear power plant accidents and resultant accidental deaths primarily bound this study.

\section{Methods}

\subsection{Major Findings and Literature Review}

The major findings considered by this study are based on an extensive literature review and calculations that were performed with a 95\% confidence level, using Excel spread sheets.

The claims made in this paper challenge long-held beliefs of engineers, scientists, regulators, and plant operators throughout the nuclear industry since the 1950s, and accordingly the credentials of this author are of significant importance to forge this research. Ordinarily, this much detail on an author's background is not presented in a paper, but the stakes are high, and credentials are extremely important to the success of this research. To pursue this nuclear power plant explosions research, this author has spent most of the past five years performing full time voluntary research - at a personal cost of more than $\$ 140,000$ - to prove the technical conclusions that are presented in this paper. To document this research, this author wrote 13 peer reviewed publications on nuclear power plant explosions. To prove these publications, the author's research included completion of all of the courses required for a Ph.D. in Nuclear Engineering in addition to a previous Ph.D. in Mechanical Engineering at the University of South Carolina. As part of Ph.D. course work, this author also studied risk analysis for nuclear reactor systems.

This author also completed many other supporting courses for the specific purpose of investigating nuclear power plant explosions. These courses included 10 combustion courses taught by the Combustion Institute at Princeton University and by CEFACS from Paris; 18 finite element courses for combustion, explosions, fluids, and structures that were taught by Fluent/Ansys/Autodyne; 9 nuclear reactor design courses that were taught by the U. of Barcelona, the U. of Illinois, the Organization of Economic Cooperation and Development (OECD) in Paris, Oak Ridge National Laboratory, and the U.S NRC; 9 corrosion courses taught by the National Association of Corrosion Engineers; an International Nuclear Engineering Law course taught by the OECD at the U. of Singapore; and an International Radiological Protection School (IRPS) course taught by the OECD at the U. of Stockholm. Also self-studied were recommended textbooks on combustion, reactor water systems, and corrosion. All of the courses served as an overarching and detailed literature review for this research, where the sole purpose for attending these courses was to ensure the validity of this research. Also, threads to hundreds of background references are available through the References, but few references parallel this breakthrough research.

\subsection{Prior Supporting Research and Background}

Prior to this research, the author wrote a book for the American Society of Mechanical Engineers on the topic of piping failures that briefly discussed nuclear power plant explosions, while working as a Research Engineer and Principal Investigator for Savannah River National Laboratory (SRNL). Many of the author's credentials are specifically tailored to this research. Since this research is hinged on statistical analysis, the author's credentials in that field deserve mention. This author worked as a Fellow Research Engineer, or Principal Investigator for SRNL, using statistical analysis to document experimental research, and was trained to be a Metrologist and Quality Assurance Engineer for a NIST certified instrument calibrations laboratory at SRNL, where one duty was to perform statistical uncertainty analysis to calibrate nuclear process instrumentation, using the Guide to Uncertainty Measurements in accordance with NQA-1 Quality Assurance requirements. This author worked as a Shift Technical Engineer, and responsibilities were the application of Safety Analysis to operational and emergency operations, where he trained full time for a year to pass the Oral Board Examination to secure this position, and he is also an ASME Fellow, a NACE Senior Corrosion Technologist, and has worked as a piping engineer, pump engineer, pressure vessel inspector, and welder.

Moreover, intensive volunteer study over the past years has been paralleled by few, if any, other engineers, where this extensive and exhaustive research was performed for the sole purpose of proving the common cause for nuclear power plant explosions, gas pipeline explosions, and piping breaks. Essentially, this author serves as an extensively well-trained engineer to solve complex engineering problems that have not been previously understood.

This paper is part autobiography, part philosophy, and part engineering fact, making this paper unique with respect to presentation and results. Bringing together these parts forms a coherent discussion to prove that nuclear power plants are not as safe as previously believed, and that their safety can be 
vastly improved. Numerous topics support research conclusions, and a summary of nuclear accidents is first required to introduce accident frequencies, accident risks, probabilistic safety analysis (PSA), statistical models, and ethics.

\section{Results}

\subsection{Nuclear Power Plant Explosions}

Nuclear power plant explosions are central to this study. Three of the primary accidents of concern to this study merit a brief summary, i.e., TMI-2, Chernobyl, and Fukushima. These accidents and their causes were detailed in a previous paper, supported by extensive references (Leishear $[1]^{2}$ ). That paper is the technical basis for the following conclusions with respect to these accidents.

1. These accidents had independent causes, but each experienced reactor meltdowns. Chernobyl involved the only reactor of these three accidents to experience a criticality, which is a major release of energy during uncontrolled nuclear fission. These accidents are described in detail in a series of papers (Leishear [3-7]), where this paper is essentially one more paper in a series of papers that present ongoing explosions research. With respect to quality assurance, excellence is the target of this research, since excellence is an accident if the target is mediocrity. These papers are part of an intricate series of 14 peer reviewed papers series that prove a well detailed and comprehensive case that the cause of all nuclear power plant explosions, except Chernobyl, were the direct result of pump and valve operations (The Leishear Explosion Theory: Fluid transients ignite explosions). This paper represents the turning point between proof of theory and the prevention of future nuclear power plant explosions, which include hundreds of ongoing small explosions and large explosions like those that occurred at Fukushima and Three Mile Island. a. The TMI-2 accident had multiple contributing causes, e.g., an inadequate safety analysis, inadequate lessons learned processes since a similar accident was successfully averted at the Davis-Besse nuclear power plant at an earlier date, inadequate operator training where the operators responded in accordance with U.S. Navy nuclear training that was inappropriate, a stuck open valve that emptied the coolant system while the indicators showed that the valve was closed, and inadequate engineering support where the Shift Technical Engineer position was later developed to provide full-time technical support during all operations. In spite of difficulties, operators brought the accident under control before a complete meltdown occurred where the fact that a partial meltdown occurred was unknown for six years until

\footnotetext{
2 This section on Primary Accident Descriptions is paraphrased from an earlier reference (Leishear [1]). Other accidents could also be described in detail, but these three accidents provide an overview of accident complexities and similarities.
}

the reactor vessel was opened for dismantling. Many changes were incorporated into the nuclear industry following studies of this accident.

b. The Chernobyl accident had multiple contributing causes, e.g., inadequate training where the operators did not understand their actions when a control rod was improperly extracted to result in a nuclear criticality that multiplied the 950 MWe power by a factor of 100 to 500 , inadequate engineering training where the engineer in charge of special turbine tests did not understand the effect of engineering tests on reactor operations, and incompetent management and engineering decisions that were performed to bypass safety interlocks. Managers were sentenced to 10 year prison terms for authorizing those bypasses to meet schedules.

c. The Fukushima accident had multiple causes, but primarily a 12 meter wave caused by a tsunami swamped the plant and incapacitated normal and backup electrical power sources. Meltdowns occurred in Units 1, 2, and 3, and explosions occurred in Units 1 through 4. The Safety Analysis assumed that a tsunami wave would be 9 meters in height, which was dwarfed by the actual tsunami wave. Accordingly, there were no emergency response plans for this type of accident. Although extensive accident investigations have been performed, repercussions to the nuclear industry are still being addressed, while some nuclear industry changes have already been incorporated.

2. Reactor system explosions occurred during all three accidents that were related by hydrogen autoignition generated from several sources, which included thermolysis, radiolysis, and Zircaloy corrosion.

a. Thermolysis breaks water down into explosive hydrogen and oxygen when coolant water is added to molten reactor components or a criticality increases reactor water temperatures. Radiolysis breaks water down into hydrogen and oxygen through the interactions of radiation with water. Zircaloy creates large volumes of hydrogen without oxygen when the fuel rod cladding that contains the uranium dioxide fuel pellets chemically reacts with high temperature steam. Hydrogen and oxygen are formed to varying extents from each of these sources in each accident, and sufficient oxygen is required to burn all of the generated hydrogen.

b. Hydrogen autoignites as a function of temperature and pressure in the dieseling process, similar to a diesel engine. When this autoignition temperature and pressure are achieved, hydrogen explodes when sufficient oxygen is present. Different explosions occurred in each accident and the extent of each explosion depended on the quantity of oxygen and hydrogen that was present at the time of the various explosions.

c. Chernobyl experienced two explosions that were 
separated by seconds. The first explosion was due to the autoignition of hydrogen and oxygen that were generated by thermolysis and radiolysis, which were generated by a criticality. When this first explosion ruptured the reactor vessel - that was not designed for high pressure containment - a large volume of hydrogen mixed with the air in the reactor building to ignite on contact with molten fuel. This second explosion was on the order of ten times the magnitude of the first explosion, and the blast was calculated to be equivalent to 14 metric tons of dynamite.

d. Fukushima explosions consisted of two types. The first type of explosion occurred when coolant water was added to the molten reactor cores, and thermolytic hydrogen and oxygen exploded immediately negligible hydrogen from radiolysis was present. The second type of explosion occurred due to thermal-fluid transients and excess unburned hydrogen from Zircaloy corrosion when coolant water was added to the reactor to control the meltdown. Large quantities of unburnt hydrogen from Zircaloy corrosion were exhausted to the reactor building that was not effectively designed for accident containment, and continued pumping of water into the reactor system then compressed residual hydrogen gas inside the piping to heat those gases above their autoignition temperature. When this heated gas was exhausted to the reactor buildings, the buildings exploded and fired radioactive dust to form a radioactive cloud that circled the globe.

e. In terms of the explosion ignition cause, TMI-2 explosions were nearly identical to Fukushima explosions. When coolant water was added to the reactor during the meltdown, a thermolytic explosion initially occurred that damaged the fuel rods in the core, and this initial explosion did not breach the reactor like Fukushima thermolytic explosions. The TMI-2 core was only partially melted and Fukushima cores are believed to have completely melted. As the TMI-2 coolant pumps were started, a large volume of Zircaloy corrosion generated hydrogen that was released to the reactor containment building. As the pumps continued to operate three different explosions occurred, but both the second and third explosion were caused by thermal-fluid transients - gas was heated by compression and was exhausted to the pressurized relief tank piping to later burn those explosive gases. The second explosion created an open path to the containment building by bursting a rupture disc in preparation for the next explosion. The third explosion autoignited the reactor containment building hydrogen that had mixed with air $^{3}$. In fact, a safety valve on the reactor coolant water system

\footnotetext{
${ }^{3}$ There may have been other small explosions inside the TMI-2 reactor system, but these three explosions are the most important with respect to the explosion in the reactor containment building.
}

(RCWS) opened at the same time as this last explosion, which was incorrectly considered to be a flame front in the reactor building for the past forty years (Leishear [1 and 2]).

f. Since one out of two power plant meltdowns cause explosions and one out of two power plant explosions are caused by fluid transients, preventing the transients by venting reactor systems before and during the startup of pumps may prevent half of the predicted large radioactive releases. Injecting helium or nitrogen into the RCWS is also expected to be partially beneficial for explosion prevention following meltdowns, where nitrogen injection into the reactor building is presently used. Even so, nitrogen was ineffective at Fukushima, and more research is required to evaluate these methods.

g. Additionally, using high frequency transducers to monitor RCWS pressures due to small explosions will provide insights into the many small explosions that continue to occur in reactor systems worldwide and in the U.S.

\subsection{A Discussion of Ethics ${ }^{4}$ with Respect to Past Accidents}

A different technological perspective (ethics) is presented here that establishes a threatening danger to the public. Goals of this paper with respect to ethics are to consider the ethical implications of new research, to question the ethics and use of previous publications by others, to question the ethics of government organizations, and to inspire engineers to question their own ethics in day to day operations. Poor ethical decisions that engineers make, either intentionally or by rationalization, are the reason that ethics discussions are included in this paper.

To prevent future meltdowns and explosions engineers must not only consider technology, but must consider the ethical process of how they make decisions. Some previous power plant decisions may have been made in the absence of the new explosion theory that is presented here, but explosions

\footnotetext{
${ }^{4}$ An IRPS course sparked parts of this paper. Topics from different instructors included ethics in the radiological protection industry and safety in that industry. This author questioned the ethics and validity of using past publications to establish safety in the nuclear reactor industry (Figures 10 and 13). The instructor's response was that the use of consequence instead of risk levels the playing field, but this author believed that response to be unethical since data was improperly manipulated in those publications. That single, original question was the next step in technical research needed to bring this paper to fruition as this author's knowledge progressed through continuing studies. That is, this author had seen these two figures in earlier nuclear engineering courses, and accepted them as-is but learned new information as research continued.

Additionally, a TMI-2 discussion was not included in the first draft of this paper. Even though the title of this paper concerned ethics, a direct confrontation with the NRC was not initially pursued. This dilute version of an ethics discussion prompted reviewers to comment that there did not appear to be an ethics issue at all and that the ethics issue was not adequately proven. The NRC is the primary stakeholder to ultimately correct these safety hazards, and an affront to their authority is not the smoothest way to gain their cooperation, but a more amiable approach has failed to yield NRC action and cooperation for years. The NRC and DOE have consequently been directly affronted here for their previous decisions and communications or lack thereof.
} 
research and nuclear reactor safety were thwarted by the fact that essential information has been misrepresented and eliminated from safety evaluations. The practice of ethical engineering decisions is essential to nuclear safety.

With respect to ethics, one question is whether or not the ethics of previous research should be questioned at all. After all, a primary tenet of engineering publications is that authors do not directly confront one another on questions of ethics. A common refrain is that we agree to disagree. This approach minimizes potential animosity between researchers for the higher purpose of advancing technology. However, part of this research is based on previous works that misrepresent the facts by neglecting conventional wisdom that was available at the time of publications.

If the facts are misrepresented, how can that work be ethical? For this author to not challenge the ethics of incorrectly promoted research would be unethical. In other words, a different view of nuclear technology challenges the status of ethics. That is, engineers are responsible to identify ethical concerns and take action to address those concerns. This publication challenges previous ethical decisions to advance technology and nuclear safety. Simply publishing technical information for others to decide what is right or wrong falls far short of engineering excellence, integrity, honesty, and ethical conduct.

One may argue that ethics is not the issue at all for previous papers, and that the publication problems identified in this paper are the simple progression of technical knowledge. This author disagrees since the appropriate knowledge was available at the time of those publications, and that knowledge was not used. One may argue that the scientific community and society itself will ultimately judge which, if anything, is correct, but this opinion is fundamentally flawed in that the free exchange of ideas about ethics is essential to improve research publications. Why engineers make decisions is as important as the decisions themselves, since engineers are the stewards of nuclear safety and the lives of our neighbors. One may also disagree with this work, and ethics would not be a problem at all, but this paper proceeds as if the work presented here is correct, since remarkable efforts have been taken to ensure that this work is correct. Accordingly, ethics issues are identified in cases where the information was at hand for others to perform better research to not skew data to yield inappropriate and unsafe conclusions.

Accordingly, specific research conclusions that are unethical need to be identified before an overarching discussion of ethics can be presented, since new research is intertwined with the ethical conclusions of previous research. The new research interests are the facts that explosions occur during all nuclear power plant meltdown accidents, and explosions also occur during routine operations of nuclear power plants (Leishear [1]). Even so, discussions of these recent discoveries by themselves do not raise ethical concerns, where fluid transients have been identified to be a common cause of most explosions in nuclear power plants. Transient pressures due to pump and valve operations compress flammable gases in nuclear reactor systems to cause autoignition and explosions in nuclear power plants.

As discussed in detail below (Flawed Ethics Investigation), this discovery was hindered by previous government reports that intentionally disregarded data, which would have proved that an explosion occurred at TMI-2, where these actions were unethical. New research has been further hindered by government organizations such as the U.S. NRC and the U.S. Department of Energy (DOE). Essentially, the U.S. government has hindered explosions research for forty years and continues to do so. This challenge to the government will hopefully turn their direction to accept the fact that nuclear power plant explosions can be stopped and that actions need to be taken, where their lack of action is a continuing ethical concern as discussed below.

\subsection{False Reporting of TMI-2 Explosions}

False reporting raises ethics concerns, and specific incidents of false reporting follow. Immediately following the 1979 TMI-2 reactor core meltdown, there was great fear of an explosion of a large hydrogen bubble in the reactor building after the meltdown, as expressed by the Governor of Pennsylvania and others as reported by the press. Nobody knew that explosions had already burned most the hydrogen in the reactor containment building. In a subsequent U.S. Nuclear Regulatory Commission (NRC) report (Henrie and Postma [8]), a conclusion was stated that there was not an explosion during the accident, and nobody knew that there was an explosion prior to this contemporary research.

Were politics for future nuclear plants the driver behind the intentional suppression of 1979 TMI-2 data that proved explosions had already occurred? Regardless, the TMI-2 accident had a devastating effect on nuclear power plant production and resulted in remarkable safety improvements to the reactor fleet.

\subsection{TMI-2 Explosions Data}

Discovered during this ongoing research, three facts were intentionally omitted from the original TMI-2 accident analysis. First and most importantly, an explosion was measured during this accident and reported in an NRC report, where two reactor building pressures were measured during the accident. The first pressure peak went off the scale, and the second pressure peak was consistent with the occurrence of a fire or smaller explosion. The first explosion pressure was then discarded by the accident investigators, and the lower pressure was used to perform complex calculations to falsely prove that only a fire occurred. All subsequent NRC accident descriptions failed to mention the observed explosion pressure, and referred only to the pressure that supported a false conclusion that a fire rather than an explosion occurred during the TMI-2 accident.

Second, the accident investigators reported that temperature indicators, or thermocouples, documented the path of a fire through the TMI-2 reactor containment building. Thermocouples were reported to collect data every 15 seconds, which lent great credibility to the temperature data to prove 
that a fire occurred. However, the 15 second interval was associated with a complete set of thermocouples spread throughout the building. Applicable discrete thermocouples actually reported data every two minutes, which entirely discredits the temperature reporting since a reading every two minutes provides negligible data to track a high velocity explosion wave. Consequently, the use of thermocouples to prove that a fire occurred is discredited here.

Third, there were three explosions during the TMI-2 accident - this theory is a recent addition to the engineering literature (Leishear [1]). The first explosion occurred inside the reactor at the time of meltdown, and the operators did not know that there was a meltdown in process. The second explosion occurred while refilling the reactor system with coolant water - the accident was caused by accidentally dumping the cooling water from the reactor, which caused half of the nuclear fuel inside the nuclear reactor to melt. This second explosion occurred inside piping that connected the reactor to the reactor containment building. When this explosion occurred, water in the pressurized relief tank was blown out of the tank through a rupture disc that burst open during this explosion (Figure 2). A level indicator showed that the tank was in fact empty after the accident, which would have assisted in the proof of an explosion, However, the final $\mathrm{NRC}$ reports concluded that the tank could not be empty since there was no explosion, and the NRC therefore concluded that the instrumentation did not work properly - there was no validation of whether or not the gauge worked. That is, more crucial evidence was discarded, which supported a conclusion that an explosion rather than a fire occurred. Then, hydrogen from the melting core was dumped from the RCWS safety valve, into the connecting piping, through the rupture disc, and into the building - an explosion was waiting to happen. A subsequent explosion occurred in the reactor building, which was falsely reported as a fire for 40 years, and a recent publication clarifies this mistake (Leishear [1]).

Now to the question, were the TMI-2 reports unethical? The answer is unequivocally, yes. Although the intent to perform technically competent work is evident in the detailed report calculations, the end result of the selective choice of evidence represents a breach of ethics that yielded false conclusions. However, there may not have been a conscious effort to act unethically, and this author does not claim that there was intentional deceit. The claim is that data was disregarded if that data did not conclude that a fire rather than an explosion occurred. Effectively, experimental data was selectively considered to prove a specific and false conclusion. Was data deleted to cover up an explosion as part of a political agenda to promote rector safety? Perhaps, but an intentional, or criminal, 1979 cover up cannot now be conclusively proven. All that can be proved at this late date is that pertinent data was intentionally omitted from final reports, and that a TMI-2 cover up continues. Again, a fire did not occur at TMI-2, but an explosion did occur at TMI-2, where misleading conclusions prevented this explosion discovery for many years. Rationalizations that facts are inapplicable is unacceptable, where these facts ignored explosion pressures that were measured, a rupture disc that exploded open and emptied a tank was dismissed, and piping temperatures that indicated an explosion were also dismissed. Whether an intentional cover up occurred or not, the intentional deletion of pertinent data from reports that could have prevented the explosions at Fukushima certainly constituted an irresponsible and dangerous cover up.

\subsection{Recent History of TMI-2 Explosions Research}

Since 2011, this author has conducted a series of discussions with the NRC in response to this cover up to stop nuclear power plant explosions through this ongoing voluntary research. Initial concerns expressed to the NRC were summarily dismissed. Persistent communications with the NRC resulted in the assignment of a NRC engineer to address nuclear reactor safety concerns. In an effort to prove that safety concerns were incorrect, he provided a copy of Henrie and Postma's report [8].

That report provided sufficient information to discuss that the so-called fire at TMI- 2 was caused by the opening of a safety valve to autoignite a reactor building hydrogen fire, where 705 pounds of hydrogen were inadvertently dumped to the reactor containment building. Hydrogen then burned until sufficient oxygen to support combustion was depleted.

In accordance with this NRC report, this author incorrectly believed that a fire occurred at TMI-2, and published an ASME Mechanical Engineering Magazine article on the TMI-2 hydrogen fire (Leishear [9]). This magazine article was then incorrectly used as a technical background to address the TMI-2 fire concern and explosion concerns during other accidents, such as Fukushima. Since the original TMI-2 report stated that there was a fire, this author believed that there was a fire. This author then submitted a request for the NRC to further investigate fires and explosions, based on this article. In other words, the NRC provided technical information to counter the author's safety concerns (Leishear [10]), but that information further fueled this author's evolving explosion theory. A Generic Issue was submitted to the NRC for further consideration, and the NRC dismissed this safety concern, based on the 15 second intervals of temperature measurements, an empty pressurizer tank, and a stated lack of explosion data. As noted above these NRC opinions for dismissal were based on published false facts. The NRC acted ethically in good faith, but earlier ethical violations were fundamentally flawed, which resulted in the NRC rejection of a correct autoignition theory to explain the hydrogen burn at TMI-2.

Five years later, this author discovered that an explosion occurred rather than a fire (Leishear [1]). While performing the extensive research noted above, new facts were uncovered. A comparison of explosions at Chernobyl, Fukushima, and TMI-2 concluded that there were remarkable similarities between Fukushima and TMI-2. In fact, these two accidents had such significant similarities that explosions had to have occurred at TMI-2. Further intensive study of the TMI-2 accident was then performed to uncover the facts that an explosion had occurred, but that applicable data was ignored 
during the NRC investigation to support a conclusion that a fire rather than an explosion occurred. In other words, new findings supported a conclusion that 1979 research was unethical since pertinent technical data was intentionally neglected. Even though the intent of this neglect by the NRC may not have been dishonest or malevolent, this neglect of facts during scientific investigations of reactor safety was certainly unethical. In response to these findings, the NRC was again contacted. Flawed NRC rebuttals and unanswered allegations demonstrate a pattern of NRC refusal to acknowledge a severe safety problem for the U.S. reactor fleet.

In other words, this author determined that there was a common cause for reactor fires and explosions, and a NRC rebuttal provided the information to prove this work was competent. Specifically, Pre-GI-015 was written to encourage the NRC to take action on hydrogen fires and explosions, the NRC rebutted that request, and further research proved that the rebuttal was incorrect and proved that an explosion rather than a fire occurred at TMI-2.

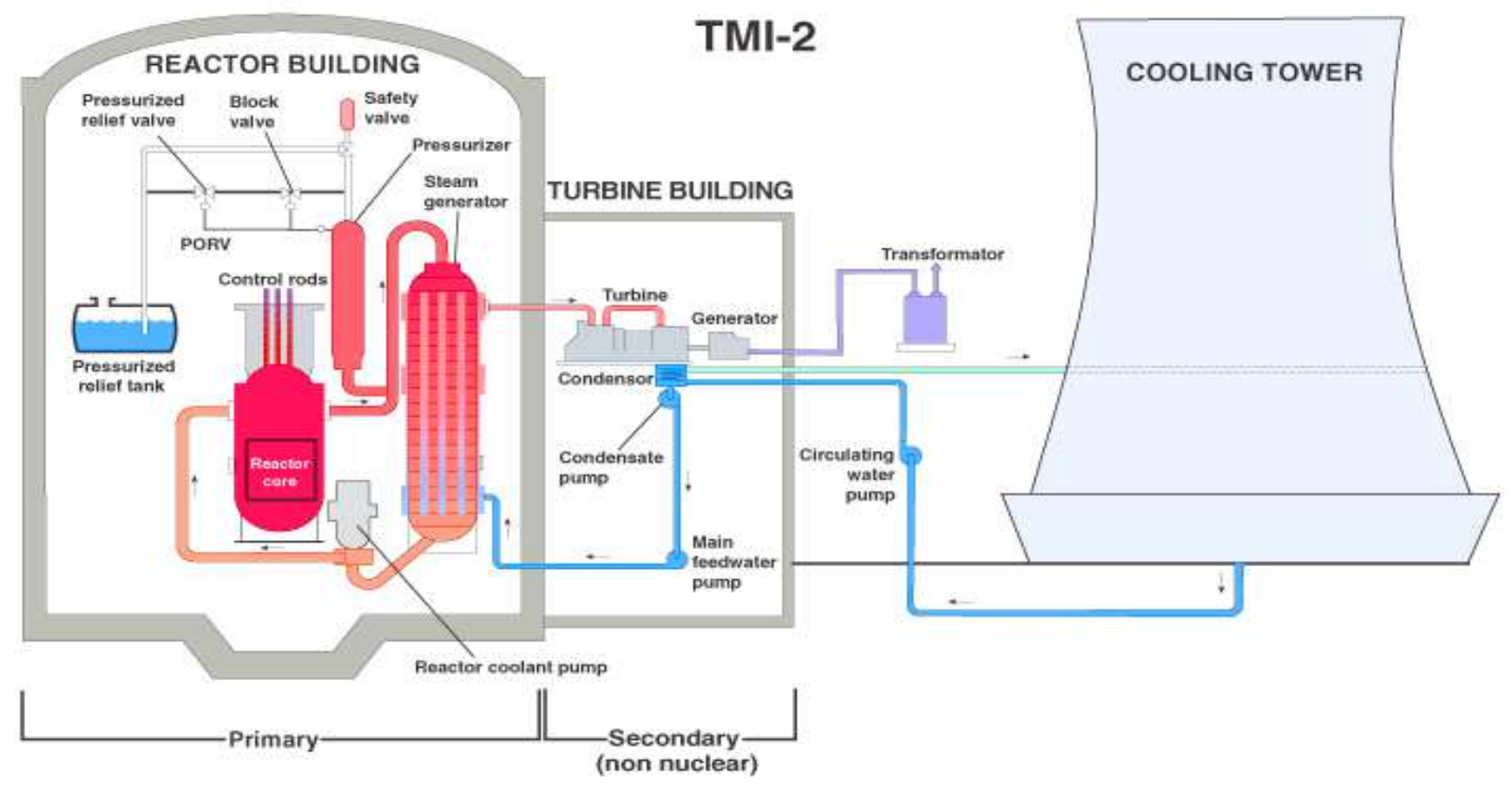

Figure 2. TMI-2 configuration (U.S. NRC).

\subsection{Ethics and the NRC Cover Up}

The following letters were written by R. A. Leishear to the $\mathrm{NRC}^{6}$, and the $\mathrm{NRC}$ failure to respond to new safety information challenges the ethics of the NRC nuclear power regulators ${ }^{7}$. Ignoring safety problems that affect the entire U.S. reactor fleet is, in itself, an unethical act by the NRC. A bureaucracy, in itself, cannot be attributed to be unethical, but the actions of its individual members results in unethical behaviors that affect the safety of the public by thwarting new technology. Specifically, the NRC did not comply with their procedures (NRC [11]), which state that the NRC shall comply with the following directives. Failure of the NRC to evaluate safety concerns when lives, property, and the

\footnotetext{
${ }^{5}$ Specific accusations are mandatory to demonstrate ethics violations, and this author had to step up to make those accusations so that important issues of nuclear safety can be addressed and corrected. Accordingly, this paper may bring about important engineering discussions between engineers and regulators.

${ }^{6}$ Emails to the NRC are permanently stored on U.S. government computer backups and the original copies of NRC and DOE emails are available through the Freedom of Information Act. NRC emails are also available as-written from leishearengineeringllc.com.

${ }^{7}$ The naming of specific government employees who were contacted is inappropriate for this work, and their names have been redacted.
}

environment are at stake constitutes malfeasance, where Merriam-Webster defines malfeasance as "wrongdoing, especially by a public official".

1. "It is the policy of the U.S. Nuclear Regulatory Commission that allegations associated with NRC-regulated activities are properly documented, assigned for evaluation, assessed for safety significance, and evaluated in accordance with this management directive".

2. "Ensure that individuals making allegations are treated professionally, are encouraged to provide information, and receive timely feedback by way of correspondence, telephone discussions, and visits, as appropriate".

3. "Ensure that safety-significant allegations are promptly reviewed and take any actions necessary..."

4. "Ensure that allegations concerning NRC licensees, license or certificate applicants, or other affected organizations are reviewed..."

Since the NRC did not respond to the following emails, there is no evidence that any of the following safety significant, and safety class, issues were addressed with respect to nuclear power plant safety, and the NRC violated their own policies. 


\subsection{1. “The NRC Cover Up” (To: allegations@nrc.gov, 3/7/2019)}

"Although I have written numerous unanswered emails to the NRC on nuclear power plant fires and explosions, I have realized that the NRC has intentionally neglected facts that resulted in a cover up of the 1979 Three Mile Island explosions. I published a series of [13 papers since 2010], where I believed that NRC reports were technically incorrect but competent. However, as I work toward the final phases of my research, I realized that Fukushima and Chernobyl each experienced explosions, and that Three Mile Island must have also experienced explosions due to accident similarities. Having reached this conclusion, I reevaluated other NRC reports, and I learned that NRC investigations ignored the facts that conclusively prove that there was a Three Mile Island explosion, rather than a fire. These findings are in review for publication [Findings are now published]. Perhaps the NRC will consider a response to this allegation, since many NRC documents are technically unsound, and false, as a result of this finding."

\subsection{2. "Safety Concern - Hydrogen Autoignition" (To: allegations@nrc.gov, 10/12/2018)}

"Current NRC regulations are apparently inadequate with respect to safe design requirements for the U.S. nuclear reactor fleet. This letter is the latest in a series of communications with the U.S. NRC. In fact, the NRC previously responded to safety concerns through "Auto-ignition of a Hydrogen-oxygen Mixture in the Reactor Coolant System, Memo - ML15191A397" [12]. Since that memo was released, numerous publications have refuted the NRC opinions presented in that memo. The attached article summarizes those new publications and demonstrates that regulations are incorrect.

... "Probabilistic risk assessment (PRA) applies the probability of failure for the components of a system to determine the overall failure probability of that system. According to the NRC (NRC [13]), the risk of a core accident, which includes meltdowns, should be less than once in ten thousand years (1/10,000 years), and the risk for a large radiation release to the public must be less than once in a hundred thousand years (1/100,000 years)." [More recent calculations change the LRF to 1 in $1,000,000$ years, (NRC [14])].

"Considering a PRA, the new theory presented here questions accident frequencies of the NRC with respect to this technology. That is, the research presented here shows that the probability of an explosion following a large meltdown is $100 \%$ (1.0). Also, two out of three (2/3) of the accidents at Chernobyl, TMI, and Fukushima resulted in large releases of radioactive materials. Therefore, the probability for a large, random radiation release" approximately "equals $1.0 \mathrm{X}(1 /$ 10,000 years) $X(2 / 3)=6.7$ times in 100,000 years $>$ $1 / 100,000$ years."

Note that the probability of a radiation release exceeds the probability that is permitted by NRC regulations. Many U.S. reactors may be safely designed if the Operator used a lower frequency than required by the NRC in their Safety Analysis calculations, but the NRC regulations governing safety calculations appear to be incorrect".

\subsection{3. "Inspector General Audit - Fires and Explosions in Nuclear Power Plants” (To: allegations@nrc.gov, 5/29/2018)", Safety Concerns}

"I participated in an audit conducted by the Inspector General's Office, which concerned a request for a generic issue, i.e.., "PRE-GI-015, Hydrogen Fires and Explosions in Nuclear Reactors, ML15245A508 [10]. ... Although the audit should be favorable to the NRC, the NRC response for this nuclear reactor safety issue was fundamentally flawed.

The auditors introduced the Audit by stating that they were interested in how the audit was conducted, rather than whether or not the audit was effective. The audit was very professional and addressed issues with respect to how Generic Issues are processed. The auditors considered my statements that the NRC response to this request was denied without further discussion. Consequently, I recommended that those who submit requests for Generic Issues be allowed to rebut the NRC response, which, of course, is not presently allowed. Otherwise, the audit met its limited scope.

Addressing this limited scope of the Inspector General Audit, I responded with the following comments.

1. The NRC response presented in ML15245A508 [10] was incorrect, and did not adequately address nuclear reactor safety concerns.

2. NRC regulations are currently incorrect, and allow Safety Analyses to be incorrectly written, which in turn potentially allows reactors to operate unsafely. Accordingly, all accident analyses for U.S. reactors are incorrectly performed.

3. Hundreds of explosions have occurred in U.S. nuclear power plant piping systems and will continue to occur, where these accidents have been misdiagnosed as water hammer accidents since the 1950s.

4. As an expert in water hammer, I am aware that the conditions that the NRC attributes to piping water hammer damages actually reduce the water hammer induced pressures in the piping system. That is, trapped gas pockets in the system do not increase pressure surge magnitudes, but decrease the magnitudes of those pressure surges. As a result, fatigue failures in piping continue, and they will progressively increase in frequency until the [explosion] problem is addressed.

5. The NRC response to ML15245A508 [10] was well considered, but was incorrect, where I was not allowed to challenge the [incorrect] NRC conclusions.

6. As part of my ongoing research, I published five ASME Conference publications in 2017 to challenge the ML15245A508 NRC responses [10] and to clearly state the errors that were provided in the NRC conclusions.

7. In short, NRC regulations are incorrect, U.S. reactors are operating unsafely, and reactor system piping damages will continue unless corrective actions are taken.

8. The NRC has refused to even acknowledge these serious safety issues and cost concerns". 


\subsection{4. "Fires and Explosions in Nuclear Power Plants" (To: allegations@nrc.gov, 5/26/2018)}

"The ... paper, ANS 22950 [7] (supported by other [referenced] 2018 technical publications) contradicts an NRC request for a Generic Issue, where I raised Safety Analysis concerns about the operations of U.S. commercial nuclear reactors. The NRC provided a formal response per PRE-GI-015, Hydrogen Fires and Explosions in Nuclear Reactors, ML15245A508 [10]. I disagreed with the NRC response at the time, and I have continued research since that time. There is no doubt that the hydrogen explosion at Three Mile Island, the explosions at Fukushima Daiichi, and an explosion at Hamaoka were all caused by the detonation of hydrogen due to fluid transients. Pump and valve operation compressed hydrogen and oxygen to ignite these accidents. Not only were these accidents ignited by fluid transients, but gas accumulation events have been incorrectly diagnosed since the 1950s. The current NRC position is that trapped gas compression causes piping damages. To the contrary, trapped gases reduce water hammer pressure waves. The actual problem is that when pumps are started, the trapped hydrogen and oxygen from radiolysis compresses, autoignites, and explodes or burns depending on the amount of flammable gas present at the time of ignition. In other word, there have been hundreds of explosions in nuclear reactor systems that have been misdiagnosed for many decades".

\subsubsection{NRC Neglect of Safety Concerns}

Neglect of safety concerns raised to the NRC certainly constitutes a breach of ethics ${ }^{8}$. According to an NRC Directive (NRC [11]), "It is the policy of the U.S. Nuclear Regulatory Commission that allegations associated with NRC-regulated activities are properly documented, assigned for evaluation, assessed for safety significance, and evaluated in accordance with this management directive (MD). In implementing this $\mathrm{MD}$, responsible NRC staff will respond immediately to an allegation involving an overriding safety issue (An issue that may represent an actual or potential immediate, significant, or immediate and significant threat to public health, safety, or security, warranting timely action by the licensee to evaluate and address the issue.)". The NRC has not responded to any of these correspondences over the past two years, and the topics of these letters present a significant threat to public health and safety.

\subsection{Safety of the Existing Reactor Fleet}

Having reviewed the technical aspects of nuclear power plant explosions, the relevance of these explosions to nuclear power plant safety can be discussed along with evaluations of previous publications. Plant safety is typically analyzed in

\footnotetext{
8 Numerous companies and agencies refused to acknowledge email correspondence about this research and the dangers of nuclear power plant explosions. They included Chubu Electric and its parent company Tokyo Electric Power Company, the IAEA, the NEA of the OECD, and the Nuclear Regulatory Agency of Japan (formerly the Nuclear and Industrial Safety Agency, which was disbanded since they promoted a policy that a Fukushima type accident was absolutely impossible).
}

terms of PSA for the world-wide fleet. Flaws in previous PSA evaluations predict reactor operations to be safer than they are.

\subsubsection{A Brief PSA History}

PSA became an important part of nuclear power plant safety and reliability following the TMI-2 accident. Prior to that accident, a PSA calculation showed that a meltdown accident similar to TMI-2 was likely in the reactor fleet, and the resulting PSA prediction was ignored at that time. Consequently, PSA methods were validated by the TMI-2 accident experience. PSA now plays a mandatory role in the safety analysis for nuclear power plants per U.S. Nuclear Regulatory Commission (NRC) regulations, and NRC regulations are adopted by many countries. PSA uses statistical failure data for specific components and probability theory to combine statistical failure analysis to predict the overall safety of a nuclear plant.

PSA is currently applicable to nuclear reactors that include Generation I, II, and III designs. Many Generation II designs are still in-service, but their production stopped in the late 1990's. Generation II designs include the TMI-2 pressurized water reactors (PWR's), the RBMK at Chernobyl that is a Russian designed pressure-tube graphite reactor, and the boiling water reactors (BWR's) at Fukushima. A majority of the 441 operating reactors are Generation II designs. Generation III designs (Figure 3) are presently under construction or planned for later construction, and Generation IV designs are future designs, which are not yet under construction. All of the designs ultimately produce steam by different methods to drive steam turbines to create electrical power, with an average power of 1150 MWe (1.15 GWe) European Nuclear Society [15]). The 2012 number of in-service Generation II and III reactors is shown in Figure 3.

PSA applies probability and statistics to model the risks associated with accidents. PSA calculated risks equal the frequency times the consequence (Modarres, et al [16]), such that

$$
\begin{gathered}
\text { Risk }=\text { The accident frequency multiplied times the } \\
\text { consequence of the accident }
\end{gathered}
$$

To continue this discussion, some terms require clarification. Reactor design frequencies or risks are associated with discrete, individual reactors. Fleet frequencies or risks are associated with the world-wide fleet of nuclear reactors. Fleet and reactor design risks are further delineated by the adjectives PSA and in-service - PSA frequencies or risks are associated with theoretical, statistical calculations for accidents, and in-service, or cumulative, frequencies or risks are associated with actual accident conditions that express real conditions, or historical trends for the entire fleet. In other words, PSA risks describe the potential for an accident to occur for any discrete reactor, and in-service risks describe the potential for an accident to occur anywhere in the world. Since a nuclear power plant explosion anywhere around the globe would be catastrophic, the in-service risks are the risks of primary concern to this study. 
Nuclear power plants, Nuclear power capcity, 1996-2015 (IAEA, 2016)

Total number of reactors: 450; OECD plants: 324

8 Generation III, 8 Generation III+, 434 Generation II reactors

Number of reactors

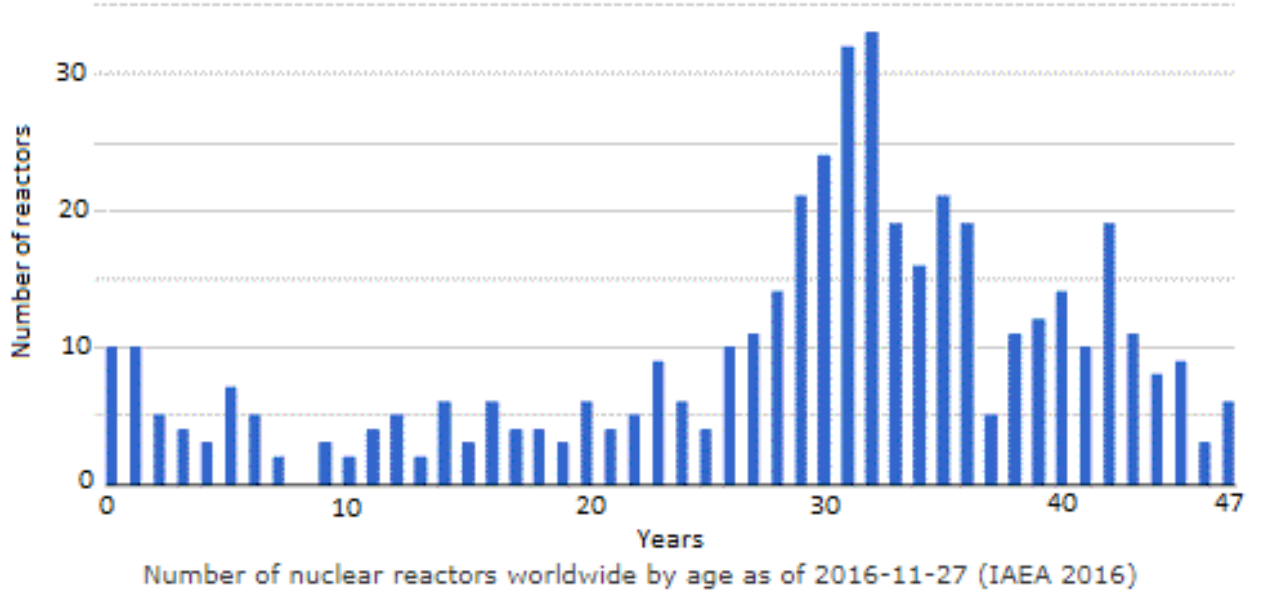

Figure 3. Operating nuclear reactors (Adapted by permission of the European Nuclear Society [15]).

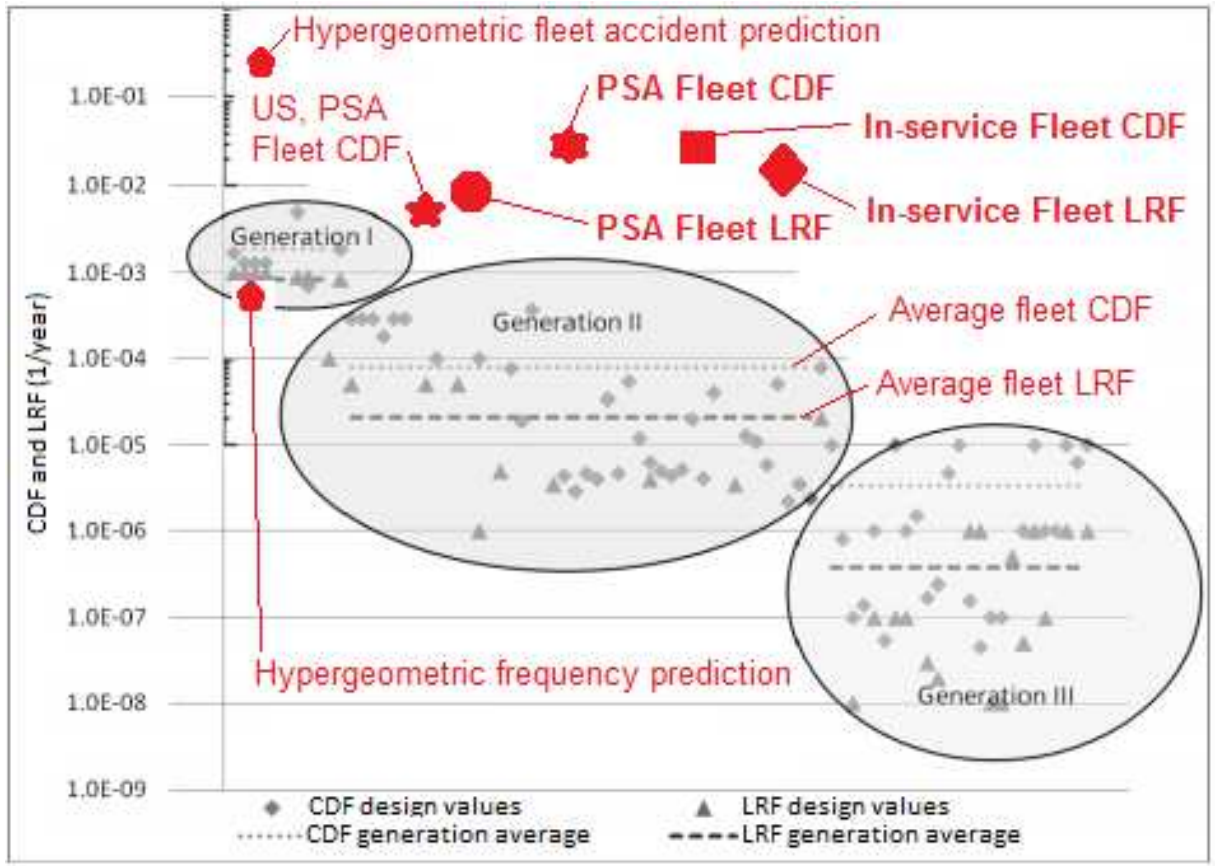

Figure 4. Generation II, nuclear reactor core damages (meltdowns) and large radioactive releases (Adapted from NEA [17]).

\subsubsection{PSA, Reactor Design Accident Frequencies}

As one factor of risk, frequencies are considered next. Important accident frequencies are expressed in terms of the large release frequency (LRF, sometimes reported as the large early release frequency) and the core damage frequency (CDF), or meltdown frequency. The LRF equals the frequency of large scale radioactive particulate releases, or contamination, to the environment, and the CDF equals the frequency of reactor power plant meltdowns, which include discrete fuel rod melting, graphite channel melting, partial meltdowns, and complete meltdowns. Reactor CDFs and
LRFs are compared in Figure 4 (NEA [17]), using an approximation that is affected by the age of the data, since the original plotted values are less than the CDF and LRF frequencies that are used today, due to safety modifications implemented after the TMI-2 and Fukushima accidents. This approximation is reasonable given the accuracy of other calculations in this work ${ }^{9}$, where calculation accuracies vary depending on source material.

\footnotetext{
${ }^{9}$ A detailed analysis for all of the uncertainties associated with all of the graphs in this paper is outside the scope of this work. Even so, published graphs by others that are used in this paper are sufficient to perform this study.
} 
Then from Figure $4^{10}$ the average values for the CDFs or LRFs of Generation II reactors (most of the fleet as shown in Figure 3) equal

$$
\begin{gathered}
P S A, \text { Reactor design } C D F(\text { Average })=8 \cdot 10^{-5} \\
\text { core } \\
\text { damages / year } \\
\begin{array}{c}
\text { PSA, Reactor design } L R F(\text { Average }) \\
\text { releases / year }
\end{array}
\end{gathered}
$$

\subsubsection{PSA, Reactor Fleet Accident Frequencies}

Since reactors operate independently, CDFs and LRFs are statistically independent probabilities. Consequently, the CDFs and LRFs for the reactor fleet do not equal any one of the specific frequencies or the average frequency plotted in Figure 4. Probabilistically, the CDFs and LRFs equal the sum of their individual probabilities, such that PSA, Fleet CDF

$$
\begin{aligned}
& =450 \text { reactors } \cdot 8 \cdot 10^{-5} \frac{\text { accidents }}{\text { reactor } \cdot \text { years }}= \\
3.6 \cdot 10^{-2} \frac{\text { accidents }}{\text { year }} & \rightarrow 27.8 \text { years until the next meltdown }
\end{aligned}
$$

$$
\begin{array}{r}
\text { PSA, Fleet } L R F=450 \text { reactors } \cdot 2 \cdot 10^{-5} \frac{\text { accidents }}{\text { reactor } \cdot \text { years }} \\
9 \cdot 10^{-3} \frac{\text { accidents }}{\text { year }} \rightarrow \\
111 \text { years until the next radioactive release }
\end{array}
$$

These values are plotted in Figure 4 as "PSA Fleet CDF and LRF". Note that the PSA fleet frequency significantly exceeds the average reactor design values shown in Figure 4. Using PSA, the expected time between accidents for the reactor fleet is once every 27.8 years rather than once in 12,500 years, and the time between radioactive releases equals once in 111 years for the fleet rather than once in 50,000 years for a single reactor. Therein lies an ethical problem - a non-rigorous interpretation of this figure, in the absence of the fleet frequency, can erroneously conclude that nuclear reactors are remarkably safer than they actually are, where statistics can be easily misunderstood.

In fact, a NEA /OECD report [17] stated that Figure 4 proves that the "predicted frequency for a large release of radioactivity from a severe nuclear power plant accident has been reduced by a factor of 1600 between the early Generation I reactors and the Generation III/III+ plants being built today." While this statement may be true for a single reactor design, the global fleet reduction of severe accidents per year is only reduced by a factor of $3.55=1600$ reactors / 450 reactors. The NEA statement confused probabilities to yield a misrepresentative and misleading statement. NEA analyzed calculations using an average probability rather than a cumulative probability, which yielded an error due to a fundamental misrepresentation of the data.

To be clear, the data from this figure proves that a severe

\footnotetext{
${ }^{10}$ Revisions to this figure are new to the literature. Uncertainty analysis is preferred, but was not provided by the original authors. This figure is provided in the NEA document, but their references to the IAEA source document are incorrect.
}

accident in the world-wide reactor fleet is expected once in every 27.8 years - not once in every 12,500 years. To greatly understate the problem, interpretations are sometimes confused with respect to this graphic depiction of reactor accidents. Note that fleet frequencies for accidents around the globe are more applicable to an accident that may occur in any country with nuclear power operations, even though the PSA frequency for individual reactors is necessary for the safety analysis for each of those reactors. For this research the PSA fleet frequencies, or probabilities, are applicable. This conclusion is consistent with NUREG-2201 [18], which states that the CDF is approximately 0.005 for the U.S. reactor fleet (Figure 4, US, PRA fleet CDF) with an uncertainty equal to an order of magnitude, and this NUREG also states that risk based information is not the sole basis for decisions. This recent work of the NRC moves toward a more appropriate representation of core damage risks. That is, some of the misrepresentations of WASH-1400 [22] are starting to be resolved.

\subsubsection{Is This Error an Ethics Concern}

While this error certainly misrepresents the facts, one could argue that this error may be more of an oversight due to a lack of understanding, rather than a conscious effort to ethically mislead others. Even so, the intent of the OECD publication that presented this data was to promote nuclear energy, and in that spirit the data was not properly screened and understood. These latter actions cross the line into unethical behavior, and this discussion may be considered to be a thorny issue that may lead to significant debate - so be it, the discussion is important. In fact, this step into unethical behavior is one of the most important lessons to be learned by engineers about ethics.

An engineer needs to be on guard against a natural tendency to bias technical information to his own beliefs. For example, this author worked as a troubleshooter to solve complex fluid flow problems in piping systems for many years. In troubleshooting complex industrial problems, interviews with operators, engineers and managers are an essential tool that yields much information to solve problems. However, employees occasionally, without intent, filter information that they know to be true when they are interviewed. Basically, they leave out facts that do not agree with their conclusions of what they already think happened during a specific problem the same can happen to one's own thoughts in an effort to achieve success.

\subsubsection{The Personal Cost of Ethics}

Also, the pressures of cost and schedule are always an issue in research. Engineers want more money and time, and managers want less in this perpetual divide between management and engineering.

As a specific example, this author ${ }^{11}$ conducted a $\$ 1.5$

\footnotetext{
${ }^{11}$ This example is one of several examples of management disagreements that risked career damage while employed at Savannah River Site. The details matter little to this paper, but difficult decisions were made to do what was believed to be right. These decisions often came with a cost like high stress and severe management disapproval and perceived risk of potential loss of employment, but in retrospect the cost has always been worth the conflict. Looking back on those conflicts is quite comfortable - integrity and honesty wear well over time. Early
} 
million mixing research project at Savanah River Site to investigate the times required to mix nuclear waste in million gallon tanks for further processing. As the research budget increased, project management wanted research to be curtailed by demanding that this author provide conclusions and a signed report. This author did not believe that the data was sufficient to do so for this safety class research, and this author refused to write or sign a report, which elevated the issue to upper management. Anger and frustration ensued as the research report was blocked by this Principal Investigator, but management yielded, and research funding continued. More importantly, new information was found during the additional research that was essential to mixing success in a nuclear waste processing plant.

As a result of refusing to sign an inadequate report, management repeatedly stated in several meetings that this author needed personality training to learn how to get along with people. After continued badgering to learn how to get along, and tired of severe criticism for doing what was right, a firm statement was made to management that if this badgering persisted, a meeting would be requested with the SRS President to discuss management pressure to perform incompetent work for a Safety Class research project that could affect the health and welfare of the general public offsite of a nuclear processing plant. Management personality discussions stopped - ethics was confused with personality.

The anger dissipated later as everyone on the project took credit for doing a good job. This research was a great success, and all of the disagreeing parties were listed as coauthors to an ASME Magazine article [9]. In fact, the 5 author limit for the Magazine was waived by ASME on this author's demand so that all 10 parties could be credited with this success, even though the success hinged on the initial refusal to sign an inadequate report. All parties involved were very pleased with this personal accolade for each team member more than a year after the project ended. Team work can be hard.

As time passes management and coworkers remember the success, and the discord associated with practicing ethics fades away. The practice of ethics can cause schedule delays, increased costs, and personality conflicts, but the probability of project success improves. In fact, ethics could be considered as an important part of Quality Assurance to ensure competent work.

Interestingly, the manager who advised personality training provided a reference for the explosions research that was turned down by DOE and discussed in this paper. In that reference, that manager wrote that "Dr. Leishear's engineering work and

career decisions to go along with management, and ignore that gut feel that something was wrong, do not wear so well over time. For example, as a younger engineer during a 1989 Westinghouse, U.S. Defence Department radar project, Management demanded that one of the review processes must be skipped during design to accelerate schedule. Compliance resulted in an error during later fabrication. Management then stated that they never made such a demand. Ethics was learned the hard way by this author. Doing the next right thing may be simpler, but not necessarily easier. Also, a more senior engineer refused to skip review steps at that time, and we finished our work within two days of each other. research performance has been with a fundamental belief that text books and existing theory are tools to develop new theory, rather than restrictive rules for design. Because of this belief, Bob frequently promoted singular dissenting opinions that turned projects around and led those projects to success. Resulting from these projects, numerous theories have been developed in areas of expertise to solve complex technical problems. In summary, extensive engineering education, technical training, and practical experience supported million dollars in cost savings to SRS, numerous innovative technical publications, including an ASME text book on Fluid Mechanics, Water Hammer, Dynamic Stresses, and Piping Design, and in teaching of the techniques he has learned and developed to 600 to 700 engineers and operators. He has consistently demonstrated the skills needed to identify new solution techniques to complex technical problems that were previously unsolved. Bob is a creative thinker, who carefully considers all aspects of technical challenges and many times proposed solutions that are considered "outside the box" and correct. He is committed to knowledge and technical accuracy and gives due considerations and thoughtful recommendations. $\mathrm{He}$ communicates effectively on all levels and provides customers with valuable, effective information that can be used to make key decisions. He is one of the hardest working engineers I have ever encountered and is never satisfied with anything less than complete success. In summary, Dr. Robert Leishear is clearly the best engineering resource I can recommend for research into nuclear facility safety as it applies to fires and explosions and he is well deserving of this grant. I give him my highest recommendation".

There were three lessons learned from this project. First of all, two or three years are required before people forget the arguments and remember the success. Secondly, success can be defined as the situation when everyone who works on a project believes that they were the sole reason for the project success, and the fact is that they are all correct. And third, if the author had been wrong his career would have been severely damaged.

Herein lies a critical problem with ethics, when should you risk your job to do the right thing? The ethical answer is all the time, but families need support, and the potential loss of employment is a factor that colors one's thoughts, since acting ethically may have less impact if your debts are paid. Sometimes jobs are lost even when ethics are practiced, and sometimes because ethical actions are practiced. Ethics is a matter of personal choice and responsibility, and the ethical choice is not always made in industry for reasons of cost, schedule, pressure by management and coworkers, pride, reputation, personal bias, and politics of course. When opinions differ, ethics serve as a resolution to conflict ${ }^{12}$. As a matter of fact, a job was quit at SRS due to such a conflict, and that action permitted the time needed to perform this research. In a letter to a Senior Vice President of SRS, the following

\footnotetext{
12 There is also a possibility that you are wrong and that your arguments only serve to alienate others, which can also happen when you are right. There is great sentiment throughout industry that one needs to go along to get along. Alternatively, you cannot argue with someone who does not care.
} 
statements were made.

\subsection{6. "The Rest of the Story, January 14, 2017}

The main reason that I left SRS was a management demand to perform work that I believed to be substandard, and incompetent in my opinion, at a time when the ... facility was in a state of Deliberate Operations. I had a terrific career at SRS, but it ended with some conflict. Overall, SRS was a great place to work, and consequently I struggled at whether or not I should write this letter at all. In fact, a year has passed since I retired, and my life is quite extraordinary. Even so, clarifying the reason for my abrupt retirement seems reasonable.

The issues at hand were schedule versus quality. Recurrent issues in some projects, engineers sometimes expect more technical investigation than management is willing to invest in The balance between these two requirements is important to the success of any engineering project, and engineers and management work to solve this problem to obtain a cost effective solution that provides a technically competent outcome. In most cases, effective compromises are reached, but on occasion compromise is not reached. That is, engineering and management do not reach the same conclusion about what needs to be done. In my career at SRS, I have had several such disagreements... I was pressured by management to perform work that I believed to be incompetent, and although I initially conformed to this request I finally decided to perform competent work in defiance of management demands... on a normally scheduled day off. My final calculations were used to provide recommendations to ... Operations management... On my own time, I published my new findings ..." after leaving SRS.

Related to this decision, two of the things that were learned during a long career were related to the explosions of the 1986 Challenger Space Shuttle and the 2003 Columbia Space Shuttle. In both cases, management for the U.S. space program put schedule and cost before quality and safety, and lives were lost. The failure causes differed -one was a failed gasket and the other was failed wing insulation - but in both cases the problems were identified before the Shuttles launched and destroyed the shuttles. The Challenger exploded seconds after liftoff, and the Columbia exploded on reentry into the atmosphere. Employees had the opportunity to exercise ethics and stop impending Shuttle disasters, but did not choose to do so.

The decision to challenge management at SRS was an exercise of ethical conduct to place quality before schedule. Proper equipment performance was the issue in a nuclear fuel reprocessing plant, and at the time the plant was in a state of deliberate operations to consciously slow work and carefully consider engineering decisions, where procedure compliance for nuclear criticality controls were questioned for this plant. I could have continued working at SRS, but I chose to work full time on this odyssey to improve nuclear safety, which started part time nearly 30 years ago. Yearly performance reviews were ongoing at this time, and I was given the worst performance review of my career for failing to put schedule first, where decades of performance reviews were rated in the top $10 \%$ to $20 \%$ of the engineering staff - my ethics decision affected my yearly raise and reduced a yearly wage increase.

Interestingly, the SRS Senior Vice President to whom this letter was written later provided a reference to support the turned-down DOE research proposal, which is a focus of this paper that could have investigated nuclear power plant explosions and safety. He wrote that "Dr. Leishear's work has been transformational and his innovative approaches to applied research have resulted in significant savings, and he is highly qualified to identify applied solutions for the nuclear industry. Dr. Leishear researched and developed a solution that would eliminate hundreds of piping failures, spanning over 40 years at the Savanah River Site. Based on his research, he authored an engineering textbook for the American Society of Mechanical Engineers. His innovative solution has the potential to eliminate water main failures, a multibillion-dollar problem in the U.S. Dr. Leishear also researched and implemented a pump design that saved twenty-five million dollars at the Savannah River Site. This was especially significant since these pumps were used in highly radioactive waste processing, and a failure represented a repair/disposal challenge. His work was documented in a Six Sigma project. Additionally, while working at the Savannah River National Laboratory, Dr. Leishear designed a robotic arm to drill and deliver radioactive samples. Sampling a radioactive million-gallon tank for regulatory closure required his innovative approach. His recent formal education advancements, i.e. Nuclear Engineering $\mathrm{PhD}$ and studies in Engineering Law, have strengthened his knowledge of reactor operations and design". Again, as time passes management remembers success, and the discord associated with practicing ethics fades away.

\subsection{Meltdown and Explosion Predictions}

With a new understanding of existing fleet safety in hand, future fleet safety can be considered. Specifically, the next reactor meltdown and the next nuclear power plant explosion can be predicted. In the nuclear industry, there have been 26 criticality accidents in nuclear process systems (See the Addendum) 5 nuclear submarine criticalities, 38 criticality accidents during experimental testing, and there have been additional meltdown and/or explosion accidents in commercial reactors, research reactors, and submarine reactors. This research is focused on nuclear power plant reactor accidents, and those accidents are listed in Table 1. In-service data from multiple countries represents power plant explosions and meltdowns due to the melting of single fuel rods, partial cores, or complete cores ${ }^{13}$.

Accident frequencies are assumed to be random events throughout the fleet, regardless of design. The primary thread that connects these accidents is that loss of coolant results in all accidents, even though the random initiating cause of each accident may drastically vary as detailed in other publications associated with this research (Leishear [3 - 7]. A second thread that connects these accidents is the fact that explosions occur

\footnotetext{
${ }^{13}$ Small piping explosions in nuclear plants are not included in this table.
} 
in every accident. The explosions may not cause damage as in the case of a partially melted fuel rod, or explosions can be large like the reactor breaches at Fukushima or Chernobyl.

Another common thread to every nuclear accident is the common belief that the design has been so well executed that an accident cannot occur. This belief occurs again and again, and is the most flagrant violation of ethics in the nuclear industry, since nuclear accidents continue their explosions into our world - again and again - as reactor safety is iteratively improved due to Lessons Learned from each accident. Overcoming this ethical dilemma is the purpose of this research to stop explosions, and the purpose of the following calculations is to predict the next meltdown and to predict the next preventable explosion so that action to stop explosions is taken.

\subsubsection{A Previous Accident Prediction}

A recent publication stated that the next nuclear accident is expected in approximately 10 to 20 years (Max Planck Institute [19]). The calculations were quite simple. The assumptions were that there have been 4 reactor meltdowns, which included 1 at Chernobyl and 3 at Fukushima. For the worldwide, civilian reactor fleet, the number of reactor years was divided by 4 to determine the number of hours to the next meltdown. Using reactor hours at the time of the 2011 Fukushima accident (14,500 reactor years of operation), and then and dividing by 4 , a prediction is graphed in Figure 5, such that

Accident prediction considering 4 accidents $=2019$ to 2031

Based on this number, those authors estimated that the next accident will occur 10 to 20 years after Fukushima. Note that the 8 year minimum prediction (2019) provided in Eq. 6 is slightly less than their 10 year minimum prediction for an accident, and this 8 year prediction is the sole calculation provided by the Max Planck Institute research to conclude that there will be 10 to 20 years between accidents. To augment their solution, a prediction of the maximum time between accidents is determined here by comparing the areas under the Figure 5 curve before and after the Chernobyl accident. Considering the nonlinear nature of reactor operating hours, this comparison of areas yields a relationship to yield a 20 year maximum prediction between accidents. Accordingly a model for the next accident is actually 8 to 20 years between accidents, i.e., an accident is predicted between 2019 and 2031.

Although not considered in their paper, the results are different if three accidents are considered, i.e., TMI-2 is neglected, Saint-Laurent is one accident, Chernobyl is one accident, and Fukushima is one accident. Then the accident prediction is 16 to 40 years between accidents. The revised method yields

$$
\text { Meltdown prediction considering } 3 \text { accidents }=2027 \text { to } 2051
$$

Note that this prediction will increase - more than double if the areas under the Figure 5 curve are considered before and after Saint-Laurent, rather than before and after Chernobyl.

If TMI-2 and Saint-Laurent are neglected ${ }^{14}$, and assuming

\footnotetext{
${ }^{14}$ Note that significantly different accident predictions are easily obtained, using Eqs. 6 through 8 . There is no ethical concern with respect to the Institute research,
}

that Chernobyl is one accident, and Fukushima is one accident, then the accident prediction for the revised method yields 12 to 30 years between accidents, such that

$$
\text { Meltdown prediction considering } 2 \text { accidents }=2023 \text { to } 2041
$$

Note that these equations assume that the hours of nuclear reactor operations will remain constant in future years, that uncertainties $(U)$ cannot be determined for these go - no go predictions, and that all of the reactor accidents before TMI-2 are negligible contributors to future accident predictions, which is a reasonable assumption due to the major fleet improvements after TMI-2.

Figure 5 shows this accident prediction in addition to the original accident prediction by the Max Planck Institute. That is, predictions are shown on this figure for the cases where the Fukushima explosions are considered as either one accident or three accidents. Consistent with analysis below, this author endorses the prediction that considers Fukushima to act as a single accident, although there were multiple meltdowns and explosions.

Also note that the Max Planck Institute researchers did not consider the frequency of nuclear power plant explosions, which is the focus of this research. This research can ensure that explosions and large radioactive releases cannot occur even if there is a meltdown.

\subsubsection{Predictions of the Next Accident Using Statistics}

Statistics are needed to evaluate reactor safety with respect to past and future accidents, where the use of statistics is defined by the Oxford dictionary as "the practice or science of collecting and analyzing numerical data in large quantities, especially for the purpose of inferring proportions in a whole from those in a representative sample." As such, statistics represents a mathematical description of facts to describe a random sequence of events (Coleman [21]. Simply stated, statistics are accepted in all scientific fields of study to explain physical processes to provide reasonable predictions.

Even so, inferred statistics are presented here, where future predictions are made, based on previous explosions. The methods presented are consistent with mathematical statistics as used with small sets of data. That is, if probability principles apply to thousands of interrelated components in a nuclear plant, then those same principles can be applied to small samples - pick and choose is not an option - either probability theory applies or it does not, where probability theory is integral to nuclear industry safety.

There are many statistical methods that provide different information. Multiple methods sometimes provide different answers to the same problem. Some of these methods follow and will be assessed for applicability to explosion predictions.

but a difference in engineering judgement affected the selection of accident predictions presented here. Note that these calculations (Eq. 6) predicted that an accident should have already occurred in 2019, and an associated, unsupported estimate predicted that an accident will occur in the next 10 to 20 years, i.e., 2021 to 2031 (Max Planck Institute [20]). 
Table 1. Power plant meltdown history, years between accidents.

\begin{tabular}{|c|c|c|c|c|}
\hline $\begin{array}{l}\text { All power plant meltdown accidents. } \\
\text { The magnitude of the meltdowns are not distinguished for these } \\
\text { accidents, i.e., core damage = meltdown for this table. }\end{array}$ & $\begin{array}{l}\text { Accident } \\
\text { number }\end{array}$ & $\begin{array}{l}\text { All } \\
\text { meltdowns, } \\
\text { years }\end{array}$ & $\begin{array}{l}\text { Post-TMI meltdowns, } \\
\text { including TMI-2, } \\
\text { years }\end{array}$ & $\begin{array}{l}\text { Future accident } \\
\text { predictions, mean time } \\
\text { between accidents, years }\end{array}$ \\
\hline First nuclear power plant, June, 1954 & 0 & 0 & --- & --- \\
\hline Sodium Reactor Experiment, July, 1959 & 1 & 5.083 & --- & --- \\
\hline SL-1, Jan., 1961 & 2 & 1.50 & --- & --- \\
\hline Fermi-1, Oct., 1966 & 3 & 4.583 & --- & --- \\
\hline Chapelcross, May, 1967 & 4 & 0.583 & --- & --- \\
\hline Lucens, Jan., 1969 & 5 & 1.75 & --- & --- \\
\hline Saint-Laurent, Oct., 1969 & 6 & 0.75 & --- & --- \\
\hline Jaslovske Bohunice, Feb., 1977 & 7 & 7.5 & --- & --- \\
\hline TMI-2, Mar., 1979 & 8 & 2.0833 & 2.0833 & --- \\
\hline Saint-Laurent, Mar., 1980 & 9 & 1 & 1 & --- \\
\hline Chernobyl, Apr., 1986 & 10 & 6.0833 & 6.0833 & --- \\
\hline Fukushima, Mar., 2011 & 11 & 24.916 & 24.916 & --- \\
\hline Meltdown prediction, conservative & 12 & --- & --- & 27.96 \\
\hline Meltdown prediction, non-conservative & & & & 50.26 \\
\hline Large release prediction, conservative & --- & --- & --- & 55.91 \\
\hline Criticality accident prediction, conservative, 4 accidents & --- & --- & --- & 111.83 \\
\hline $\begin{array}{l}\text { Large release prediction with corrective actions, conservative (Same } \\
\text { prediction value as the criticality accident prediction) }\end{array}$ & --- & --- & --- & 111.83 \\
\hline
\end{tabular}

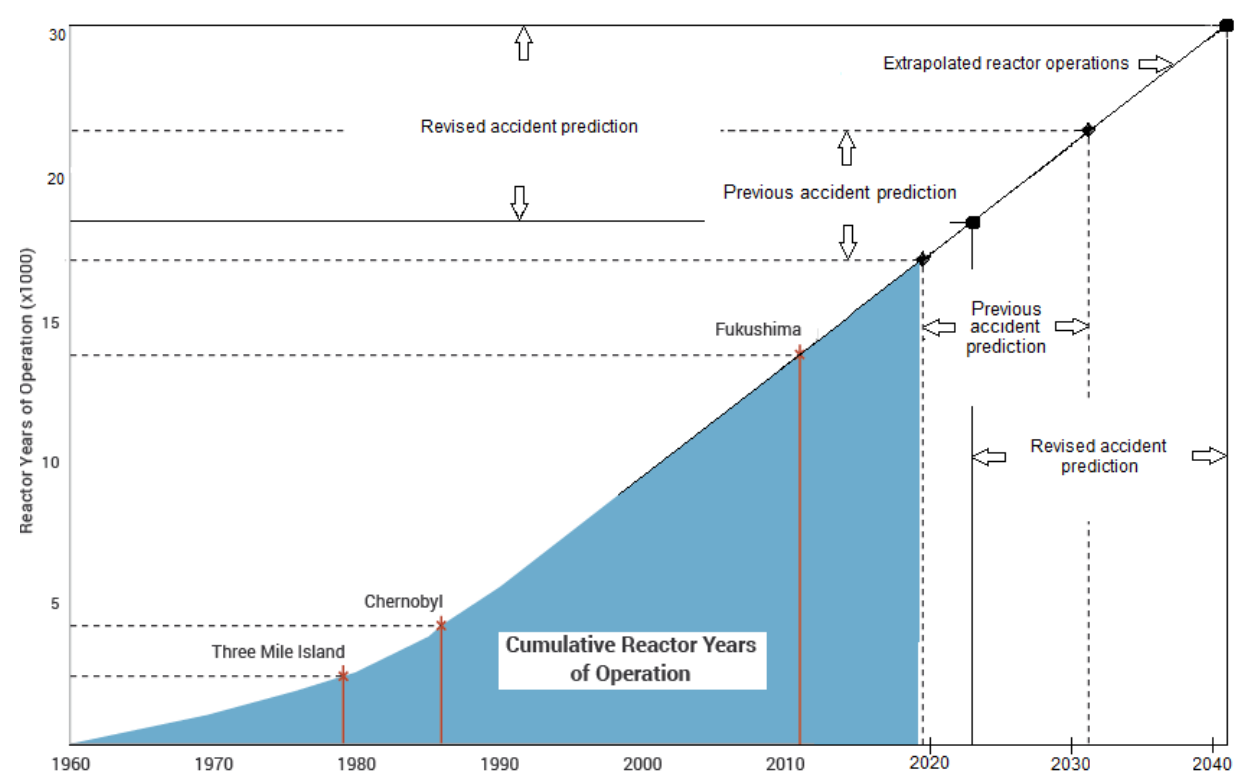

Figure 5. An accident prediction based on reactor hours of operation (Predictions from the Max Planck Institute [19] and Leishear [Eq. 8]. This figure was adapted from the World Nuclear Association [20]).

\subsubsection{An Accident Prediction Using a Hypergeometric Distribution}

A continuous statistical distribution can be used to predict whether or not a nuclear accident will occur, where the Hypergeometric model is such a distribution that is applicable to power plant explosions. This model is one of few models that account for a finite population without replacement, which assumes that damaged reactors are permanently removed from service (Modarres, et al [16]). Replacement of a reactor back into service may be permitted for small damages to fuel rods but not permitted for large damages such as those at Fukushima and TMI-2. The assumption of no replacement is an approximation.
Assuming that the changing population equals 450 reactors from Figure 2 (the number of in-service reactors varies due to new construction and decommissioning), and assuming that the number of previous accidents equals 11, the number of damaged reactors after the next accident equals 12 , and the number of undamaged reactors that are potentially included in the next predicted accident equals 439 , the hypergeometric probability is found to be $26 \%$ using Excel $^{\circledR}$.

Hypergeometric accident prediction $=0.26=26 \%$

Note that this value is an order of magnitude higher than the PSA fleet frequency shown in Figure 3, which predicts the twelfth nuclear power plant accident. 
Also note that there is a one in four chance that a reactor meltdown will occur. That is, a meltdown is expected in the existing reactor fleet, even though the probability of not having an accident is greater than the probability of an accident. Additionally, the accident probability of a meltdown at any specific reactor is one in 1733, given that 11 meltdowns have already occurred. This probability $\left(5.77 \cdot 10^{-4}\right.$ accidents per year $=$ hypergeometric frequency prediction) is more than an order of magnitude higher than the average fleet CDF shown in Figure 3. This conclusion is reasonable given that this CDF prediction considers the fact that there have been 11 earlier core damage accidents, while other predictions in Figure 3 do not account for earlier accidents by predicting the first accident occurrence.

While the probability of whether or not an accidental meltdown will occur is certainly of interest to this research, a prediction of when that accident will occur is far more important, and linear regression analysis is recommended and discussed as follows.

\subsubsection{Accident Predictions Using Linear Regression Analysis}

Linear regression analysis is a well-known statistical model (Coleman and Steele [21]), and that technique is used here to provide various predictions of the times to the next meltdown, the next explosion, and the next criticality. Both CDFs and LRFs are determined here, and calculation results are presented in Tables 1 and 2 and plotted in Figs. 6 and 7, where these results are new to the literature. Figure 6 shows greater technical detail to support discussions, and Figure 7 provides the results in an easier to read format with different supporting notations.

These bar graphs are set up so that the slope of any line equals the

(Time between accidents, Years) / (Accident) $=$ Years $/$ Accident $(10)$

Equations are determined from the bar graphs (Figures. 6 and 7), which extrapolate the twelfth meltdown accident from the earlier meltdown accidents. This extrapolation is similar to having stacks of quarters that are earned on 11 successive days. Rather than find an average to be expected on the twelfth day, the heights of the coin stacks are used to predict how much will be earned on the twelfth day. Similarly, plotted to the right hand side of the figures, bars are added to indicate the next large radioactive release and the next Chernobyl type criticality that may have a large radioactive release associated with that criticality, where probability calculations are used to predict these values.

To perform these calculations, linear regression is implicit in Excel $^{\circledR}$ models for graphing straight lines or parabolas, where regression equations are the mathematical basis for plotted displays. Excel ${ }^{\circledR}$ also has the ability to force curves to plot through zero, and this feature should not be used when considering statistical data. As noted by Coleman and Steele [21] and other authors, this practice skews the data through a theoretical point that was not experimentally validated. However, if there is a known point in a data set that equals zero, zero can be included as one of the plotted points to form a curve. For example, if a straight line or parabola is plotted for accidents after TMI-2, a zero value marks the time that TMI- 2 occurred, and this zero value can be used to provide an additional data point to be included in the data set that forms the straight line or parabola. An additional data point is important to minimize uncertainties that are calculated using student-T values.

Since scant data is available due to few explosions and meltdowns, student-T values (Coleman and Steels [21]) are used to determine the uncertainties of the linear regression results for rare and infrequent events. Basically, linear regression is used to provide a representation of reactor accidents with respect to time, and student-T values account for the limited data. This data can be represented as a straight line or any other continuous curve. For this work, explosions and meltdowns are coincident lines, noting that explosions can be small or large. Uncertainties for data points on these lines equal the standard deviation times the student- $T$, such that

$$
U=\sigma \cdot(\text { student }-T)
$$

Appropriate linear regression equations from the literature are used to determine uncertainties as required.

Excel ${ }^{\circledR}$ has the added benefit of providing $R$-squared values $\left(R^{2}\right)$ for each curve that is calculated. The $R^{2}$ values vary between 0 and 1 and provide a numerical description of how well a straight line or curve fits the data ${ }^{15}$. If $R^{2}$ equals zero, there is no correlation between a line and the data points. A zero $R^{2}$ value is the case for a single point, where the uncertainty is undefined. If $R^{2}$ equals one, there is complete correlation between a line and the data points, and the uncertainty is zero. This is the case when two points are theoretically exact and plotted with a straight line between them. However, an uncertainty can be calculated for two points and a line with known errors. The qualitative $R^{2}$ numerical values provide no numerical information at all about uncertainties for plotted data in between the $R^{2}$ limits of 0 and 1 . Even so, the lower the $R^{2}$ value, the greater the uncertainty. The following linear regression models are presented in terms of $U$ and $R^{2}$ as required.

\subsubsection{A Fleet Accident Prediction, a Straight-Line, First Order Model}

A straight-line model is used to predict fleet accidents, which is based on the accident data for all 11 meltdowns. Excel $^{\circledR}$ plotted the line shown in Figures. 6 and 7, and Excel ${ }^{\circledR}$ yielded the prediction of a meltdown in 2022, such that

Curve $A \rightarrow y=1.0029 \cdot x-0.8632, R^{2}=0.2805$ (Figures. 6 and 7) (12)

By substituting the number 12 (the twelfth accident / predicted accident) into this equation and adding the result to 2011.25 (The Fukushima accident date was March 2011) the meltdown prediction can be found for any equation that

\footnotetext{
${ }^{15}$ As defined in Excel $^{\circledR}, R$ equals the Pearson function and reflects the extent of a linear relationship between two data sets, and $R^{2}$ describes the proportion of the variance in $y$ attributable to the variance in $x$, i.e., the correlation between two data sets - in this case the correlation between a set of discrete data points and a curve or line.
} 
represents a meltdown prediction. For this example,

$$
\begin{array}{r}
y=1.0029 \cdot 12-0.8632=11.17 \\
\text { Meltdown prediction }=2011.25+11.17 \approx 2022
\end{array}
$$

where $y$ is the number of years between accidents, and $x$ is the number of accidents.

This equation is dismissed as being non-representative of accident predictions for the present reactor fleet since the $R^{2}$ value is so low. The errors in this equation are primarily due to the marked increase in the mean time between accidents that followed TMI-2 induced fleet improvements. Even so, this model proves that the TMI-2 actions remarkably improved accident prevention, and proves that far more frequent accidents would be expected in the absence of those actions. In fact, an accident would be due right now in the absence of earlier fleet improvements. This conclusion can also be readily reached by observing the 11 accidents that are shown in the figure. Prior to TMI-2 the longest time between meltdowns was 6 years since nuclear power plants started operations.

Higher order parabolic models were also considered for the fleet, but these models did not provide additional insight into the nuclear fleet's accident performance. For example,

$$
\text { Curve } B \rightarrow y=0.3039 \cdot x^{2}-2.34 \cdot x+4.7083, \mathrm{R}^{2}=0.5209 \text { (15) }
$$

$$
\text { Meltdown prediction }=2031
$$

\subsubsection{A Post-TMI-2 Accident Prediction, a Simplified Model}

The simplest model that can be obtained on Figure 6 neglects uncertainties and simply plots a straight line from the point at which the TMI-2 accident occurred at time $=0$ to the point at which the Fukushima accident occurred 32 years later. This prediction yields

$$
\begin{gathered}
\text { Curve } D \rightarrow y=8.305 \cdot x, R^{2}=1 \\
\text { Meltdown prediction }=2045
\end{gathered}
$$

\subsubsection{A Post-TMI-2 Accident Prediction, a Straight-Line Model}

The striking change in accident frequencies after TMI-2 requires that any modeling of future accidents cannot depend on the previous accident history of other reactors prior to TMI-2 even though that history proves that there were long term safety problems in the nuclear industry prior to TMI-2. Straight-line accident models using linear regression are legitimate and readily provide standard deviations $(\sigma)$, which can then be multiplied by student-T factors to determine the uncertainties of meltdown and explosion predictions.

A straight-line model for post-TMI-2 accidents is shown in Figures. 6 and 7, and supporting data is provided in Tables 1 and 2. Uncertainties were calculated according to (Coleman and Steele [21]) for the Standard Error of Regression $\left(S_{y}\right)$, which is the uncertainty of a straight line in the $y$ direction in Figure 6. Then,

$$
S_{y}=\left(\frac{\sum_{i=1}^{n}\left(y_{i}-m \cdot x_{i}-c\right)^{2}}{n-2}\right)^{1 / 2}
$$

\subsubsection{Straight-line Model Calculation Results}

The straight-line model for the Post-TMI-2 meltdowns is extrapolated to the next future meltdown date, and this model is reasonable based on the data, such that

$$
\begin{gathered}
\text { Curve } C \rightarrow y=7.9831 x-67.84, \mathrm{R}^{2}=0.791 \text { (Table 2, } \\
\text { Figures. } 6 \text { and } 7)
\end{gathered}
$$

The fact that $R^{2}=0.79$ indicates that the uncertainties are rather high, which is true. Even so, these equations and applicable uncertainties are valid. The time to the next power plant meltdown after Fukushima is determined from

Mean time to the next accident $=27.96$ years -15.27 years with $95 \%$ confidence, single tail probability

The uncertainty is determined by using $\sigma=6.49$ years and a student- $\mathrm{T}=2.3534$ for the four sample data set of TMI-2, Saint-Laurent, Chernobyl, and Fukushima. A normal, Gaussian distribution and a single tailed probability is assumed for this calculation (Figure 8). This data set is pertinent and includes the TMI- 2 reactor improvement effects on meltdown probabilities, and the effects of additional reactor safety improvements following Fukushima are approximated to be proportional to TMI improvement effects. In short, there is a 1 in 20 probability of a meltdown in 2123 , and there is a $50 \%$ probability that a meltdown will occur before 2039, since the

$$
\begin{aligned}
\text { Meltdown prediction }= & 2039-15 \text { years with 95\% confidence, } \\
& \text { single tail probability }
\end{aligned}
$$

The mean time to the next large release is predicted in 2067 , with a 1 in 20 probability of a large release in 2036. This prediction is determined from the fact that one out of two meltdowns results in a large release as discussed above in "Primary Accident Descriptions". For the four reactor set/group under consideration, one of two explosions and one of two large releases are caused by fluid transients. Since the LRF is a dependent probability with respect to the CDF,

The LRF in-service fleet frequency $=$ The CDF in-service fleet frequency $/ 2=0.037 / 2=0.018$ large releases $/$ year (Table

$$
\text { 1, Figure 4) }
$$

Meltdown prediction $=2067-30$ years with $95 \%$ confidence

If preventive actions are implemented to prevent explosions due to fluid transients, the mean time to the next large release can be postponed as discussed above in "Primary Accident Descriptions", since the only potential release will be caused a Chernobyl type accident. By implementing corrective actions to stop fluid transient induced explosions, the mean time to the next large release is predicted in 2067, with a 1 in 20 probability of a large release in 2025, and

The extended LRF in-service frequency= The LRF in-service frequency $/ 2=0.018 / 2=0.009$ large releases $/$ year $=$ Fukushima in-service accident frequency $=$ Chernobyl in-service accident frequency $=$ Criticality in-service accident frequency (Table 1, Figures. 4 and 9) 
Large release prediction $=2123 \pm 64$ years with $95 \%$ confidence $(26)$

However, this date is significantly distant in the future, and is therefore questionable, even though some insight is provided into how much time until a Chernobyl-type accident occurs.

A lack of regulatory control, safety culture, and developing technology have been used to differentiate between accidents in OECD and non-OECD countries (NEA [17]), and these issues have been used to discount Chernobyl effects on accident evaluations. Chernobyl is important to the limited data set under consideration, but predictions due to significant effects from Chernobyl data are primarily limited to the prediction of the next criticality accident. The prediction for the next nuclear power plant criticality is predicted as

Meltdown prediction $=2123 \pm 64$ years with $95 \%$ confidence $(27)$

This significant uncertainty is due to the fact that there is only one data point (Chernobyl) in the accident data set that is used for these calculations.

\subsubsection{A Post-TMI-2 Accident Prediction, Parabolic Models}

Two parabolic models were evaluated for meltdown predictions, i.e., a second order model and a fourth order model, where

$$
\begin{gathered}
\text { Curve } F \rightarrow y=0.0189 \cdot x^{4}-0.3161 \cdot x^{3}+1.526 \\
x^{2}-1.7809 \cdot x+1.9233, \mathrm{R}^{2}=0.8098 \\
\text { Meltdown prediction }=2057
\end{gathered}
$$

Curve $E \rightarrow y=4.4582 \cdot \mathrm{x}^{2}-76.722 \cdot \mathrm{x}+328.94, \mathrm{R}^{2}=0.9884$ (30)

$$
\text { Meltdown prediction }=2061
$$

Considering the $R^{2}$ values, the second order model provides a better curve fit. In fact, this curve fit is the best fit for any of the models considered in this work.

The Standard Error of Regression, which is the uncertainty of the parabolic curve in the $y$ direction in Figure 6 equals

$$
\begin{gathered}
S_{y}=\left(\frac{\sum_{i=1}^{n}\left(y_{i}-4.4582 \cdot x_{i}^{2}+76.722 \cdot x_{i}-328.94\right)^{2}}{n-2}\right)^{1 / 2}=7.554 \text { years } \\
U=7.554 \text { years } \cdot 2.3534=17.78 \text { years }
\end{gathered}
$$

Meltdown prediction, Single tail probability (student- $T=$ $2.3534)=2061-18$ years with $95 \%$ confidence

Meltdown prediction, Two tail probability (student- $T=3.182$, $\sigma=7.554)=2061 \pm 24$ years with $95 \%$ confidence $(35)$

Note that Eq. 34 predicts when the next meltdown will occur using a second order parabolic model, such that there is a 5\% probability of a meltdown before 2043 and a 50\% probability of a meltdown before 2061. Also, Eq. 35 predicts that there is a $95 \%$ probability of a meltdown before 2085 , i.e., there is not only an unsafe situation due to an expectation of a meltdown before 2061, but the math proves that a meltdown in the worldwide fleet is nearly certain before 2085, and this parabolic model also exceeds the $95 \%$ predictions of the straight-line model (Figure 8). In other words, there is at least a $95 \%$ probability for a meltdown before 2085 for the models considered here.

\subsubsection{Modeling Summary}

To compare the models, pertinent equation results are rewritten.

Meltdown prediction by others considering 2 accidents $=2019$ (predicted accident by others) to 2031 (Eq. 6)

Modified meltdown prediction considering 3 accidents $=2027$

$$
\text { to } 2051 \text { (Eq. 7) } \rightarrow 2039_{\text {average }}
$$

Note that Eq. 37 is endorsed rather than Eq. 36 for consistent comparative results, i.e., data from Fukushima, Chernobyl, and Saint-Laurent are evaluated for Eqs. 37, 39, and 40, and the TMI-2 accident represents time $=0$ for calculations.

Simplified meltdown prediction $=2045($ Eq. 18)

Straight-line, First order, meltdown prediction $=2039-15$ years with $95 \%$ confidence $\left(\right.$ Eq. 22) $\rightarrow 2039_{\text {average }}$

Parabolic, Second order, meltdown prediction $=2061-18$ years with $95 \%$ confidence (Eq. 34$) \rightarrow 2061_{\text {average }}$

Several meltdown predictions provide nearly the same information. Specifically, the straight-line average value specified by Eq. 39 ( $2039_{\text {average }}$ ) equals the average prediction of Eq. 37 (2039 average $)$ that was modified from the work of earlier researchers (Eq. 7), and the Eq. 37 straight-line prediction also encompasses the simplified prediction of Eq. 38 (2045). The only prediction that stands out is the parabolic prediction $\left(2061_{\text {average }}\right)$, where the mean time to a meltdown is predicted to be 22 years more than the straight-line prediction. In other words, one set of calculations predicts a meltdown in about 20 years, and another calculation predicts about 40 years to the next meltdown. Either way, a meltdown is expected in the near future.

A problem of ethics vs. engineering judgement arises. Engineering judgement provides predictions based on an engineer's experience, skill, and education, i.e., an engineering technical opinion ${ }^{16}$. On the one hand, the parabolic model is a mathematically more precise curve fit, and this second order model may actually reflect the effects of post-TMI-2 fleet improvements more accurately. On the other hand, the linear model could better suit a perception of the author's interest to magnify the importance of this research. The sooner that an accident is expected, the sooner that research needs to be completed and implemented.

However, both methods are statistically correct when uncertainties are included in the calculations (Figure $9^{17}$ ). The straight-line prediction is statistically more accurate (slightly), or correct, with respect to uncertainties, even though the parabolic model fits the data points better than the straight-line model. Additionally, a meltdown is predicted before 2085

\footnotetext{
${ }^{16}$ Engineering judgement is essential in design and operations when partial information is unknown, indeterminate, or irretrievable.

${ }^{17}$ This graph is new to the literature.
} 
with at least $95 \%$ confidence. These predictions present a wide range of approximations, and the question must be asked, is the data reasonable to be used for nuclear reactor safety? Since probability is an accepted method for safety analysis, the answer is yes. Which model approximation should be used? Since reactor safety is in question, engineering judgement and safety dictate that the more conservative model should be used, which is the straight-line model that predicts a 2039 meltdown date. For this reason, predictions for large radioactive releases and criticalities were only performed above for this model that predicted a meltdown in 2039 (Eq. 38, Table 2, and Figure 7).

Based on Figure 9, a meltdown has at least a 50\% probability between the 2039 prediction and the non-conservative 2061 prediction. However, the $50 \%$ probability of a conservative 2039 prediction is endorsed here to ensure protection of people, property, and the environment, and that prediction is coupled with a prediction that there is a $5 \%$ probability of a meltdown before 2024. That is, an accident is imminent, i.e., there is a 1 in 20 probability of a meltdown by 014 and less than a 1 in 1000 probability of a meltdown in 2020 .

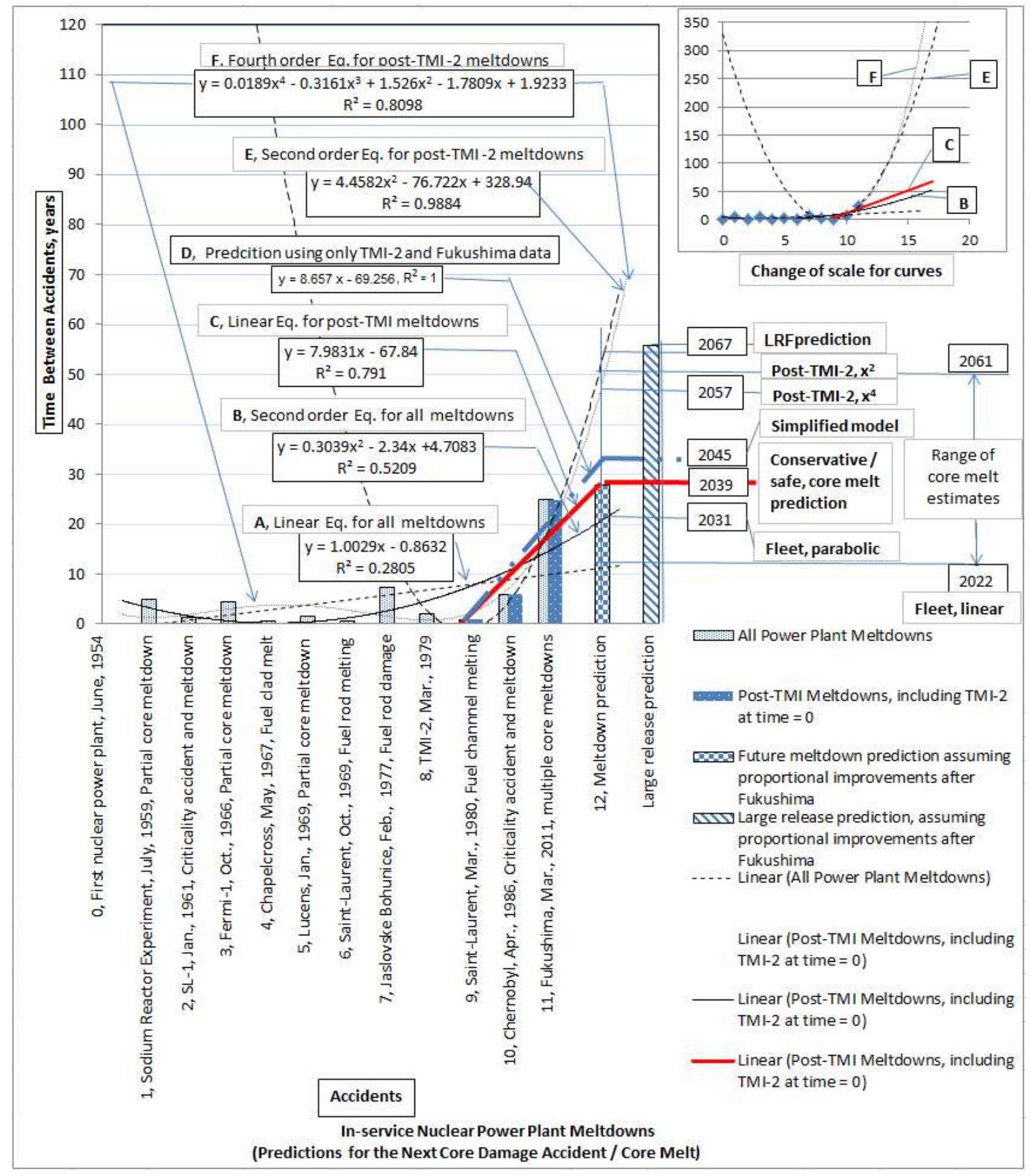

Figure 6. Nuclear power plant accident predictions ${ }^{18}$ (years per accident).

\footnotetext{
${ }^{18}$ This graph is new to the literature.
} 


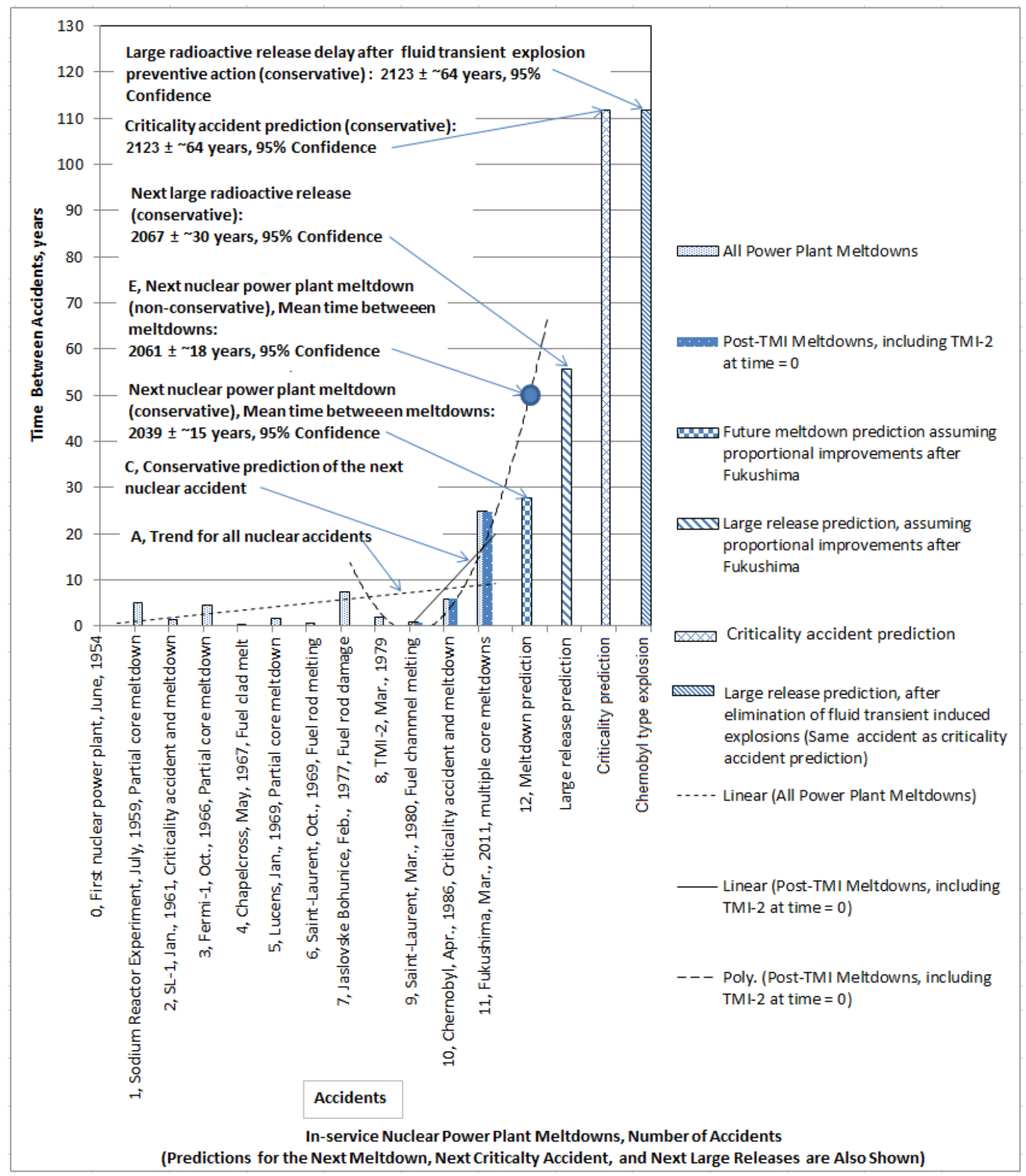

Figure 7. Nuclear power plant accident prediction results ${ }^{19}$ (years per accident).

\footnotetext{
${ }^{19}$ This graph is new to the literature.
} 


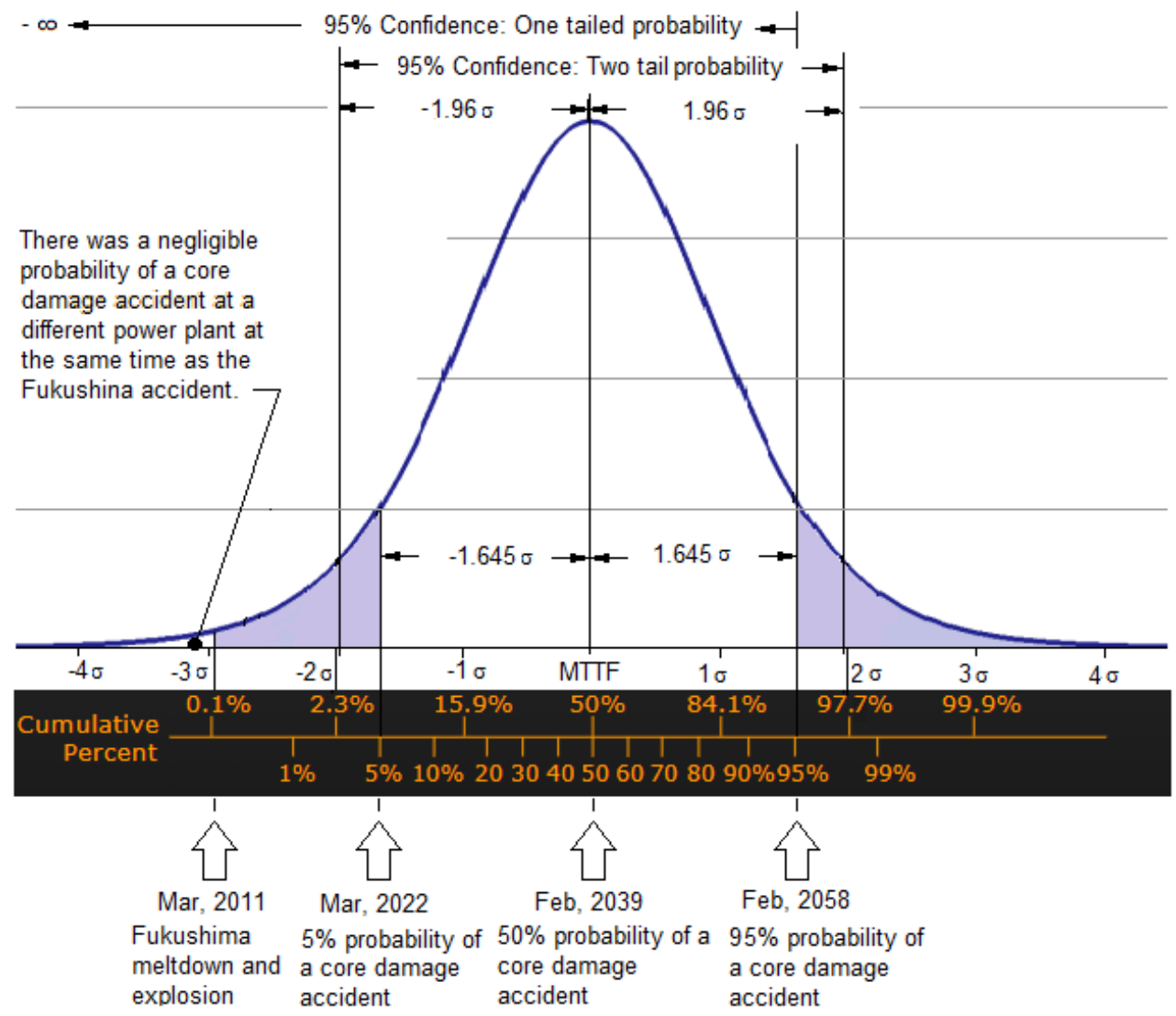

Figure 8. Probability of the next core damage accident with $95 \%$ confidence with respect to the mean time to failure for an accident using a normal distribution and a two tailed probability or one tail probability.

\subsection{Summary of In-service Fleet accidents ${ }^{20}$}

To better understand accident models, graphic displays of severe accident predictions are provided to present the new findings in this discussion (Figures 4 and 10), where technical proof is essential as a background to these significant discoveries. As shown in Figure 4, mathematical PSA values are called into question since in-service, or actual, fleet frequencies (Eqs. 2 and 3) are higher than the PSA values (Eqs. 4 and 5). In short, the in-service, fleet frequencies are based on experimental fact, i.e., these values are experimental rather than mathematical theory. Probabilistic safety analysis (PSA) data from earlier NEA accident evaluations were improved to yield new findings. Of particular interest, previous PSA fleet model results showed that the next major nuclear accident is anticipated in 2127 (Eq. 4), but this work predicts an in-service fleet accident in 2039.

However, this study of in-service nuclear accidents provides different results, where a $95 \%$ confidence interval is used to study nuclear accidents. Probabilities combined with facts show that an accidental meltdown like Three Mile Island

\footnotetext{
${ }^{20}$ Accident predictions are presented for the worldwide reactor fleet, and U.S. predictions will of course be affected by the fact that U.S. reactors comprise approximately $21 \%$ of operating reactors, since there are presently 96 operating reactors in the U.S. and 449 operating reactors around the world. That is, the probability equals $0.21 \cdot 0.5=11 \%$ for an explosion to occur in the existing U.S. fleet before 2039 .
}

may occur at any time with a small probability, and a meltdown is predicted before 2039 with a $50 \%$ probability. Similarly, the next major radioactive release like Fukushima or Chernobyl is expected to occur before 2067 with a $50 \%$ probability. Explosions also cause these major radioactive material releases, and some explosions are caused by nuclear power plant pump operations. These specific explosive blasts of radioactive dust into the air and across the globe can be stopped by controlling pump operations. Actions to stop these explosions can move the predicted Fukushima type radioactive release to 2123 with a $50 \%$ probability.

To better understand these predictions, the applied 95\% confidence level represents a one in twenty chance of an event occurring. This confidence level is commonly used throughout many industries including nuclear facility instrumentation, where this $95 \%$ confidence level was assumed here for calculations, even though a case can be made to use a $99 \%$ confidence due to the importance of the results. A $99 \%$ confidence level shows that an accident and large radioactive release is more likely to happen at any time, but the mean time to the next power plant meltdown or radioactive release remains the same. For $99 \%$ confidence calculations a student- $\mathrm{T}$ value $=4.541$ would be used instead of the 2.3534 student- $T$ value that is used in uncertainty calculations for this work. This different student-T value would then be substituted into all single-tail probability calculations above. A single-tail probability was selected since the interest is in near-term explosions, and the two-tail probability would describe both 
near-term core damage predictions and far-term predictions that would occur long after the mean time to a core damage accident and explosion. Also, the effects of Lessons Learned from Fukushima may affect this meltdown prediction, but cannot be concisely quantified. An implicit assumption is that the ongoing Fukushima Lessons Learned are as effective for future nuclear plant operations as the earlier TMI-2 Lessons Learned with respect to reactor safety improvements.

In other words, there is a reasonable probability that another
Fukushima type accident is expected a century earlier than previous PSA predictions. Again, an ethical problem arises using in-service accident data and probability theory, the expected time between accidents for the reactor fleet is once in $\sim 28$ years rather than once in 111 years for the fleet or once in 50,000 years for a single reactor design. Publicized predictions are remarkably misleading and incorrect, an accident is predicted in the near future, and misleading data provides an incredibly false sense of security and safety.

Table 2. In-service, fleet accident frequency probability calculations.

\begin{tabular}{|c|c|c|c|c|c|}
\hline $\begin{array}{l}\text { Future meltdown prediction assuming } \\
\text { proportional improvements after Fukushima }\end{array}$ & & $\begin{array}{l}\text { Large release prediction, assuming } \\
\text { proportional improvements after Fukushima }\end{array}$ & & $\begin{array}{l}\text { Large release prediction, after elimination } \\
\text { of fluid transient induced explosions }\end{array}$ & \\
\hline TMI, etc., $y=7.3581 x-68.74$, years & 27.96 & TMI, etc., $\mathrm{y}=7.9831 \mathrm{x}-67.84$ & 55.91 & TMI, etc., $\mathrm{y}=2 \cdot(7.9831 \mathrm{x}-67.84)$, years & 111.83 \\
\hline$\sigma$, years & 6.49 & $\sigma$, years & 12.98 & $\sigma$, years & 25.95 \\
\hline Student-T & 2.3534 & Student-T, Single tail & 2.3534 & Student-T, Single tail & 2.3534 \\
\hline Next meltdown prediction, year & 2039.2 & Next release prediction, year & 2067.2 & Next release prediction, year & 2123.8 \\
\hline Near term meltdown prediction, year & 2023.94 & Near term release prediction & 2036.6 & Near term release prediction, year & 2025.7 \\
\hline CDF Frequency, meltdowns/year & 0.037 & LRF Frequency, Large release/year & 0.018 & $\begin{array}{l}\text { LRF Frequency after fluid transient } \\
\text { explosion elimination, Large release/year }\end{array}$ & 0.009 \\
\hline Criticality accident frequency & 0.009 & Criticality accident frequency & 0.009 & Criticality accident frequency & 0.009 \\
\hline
\end{tabular}

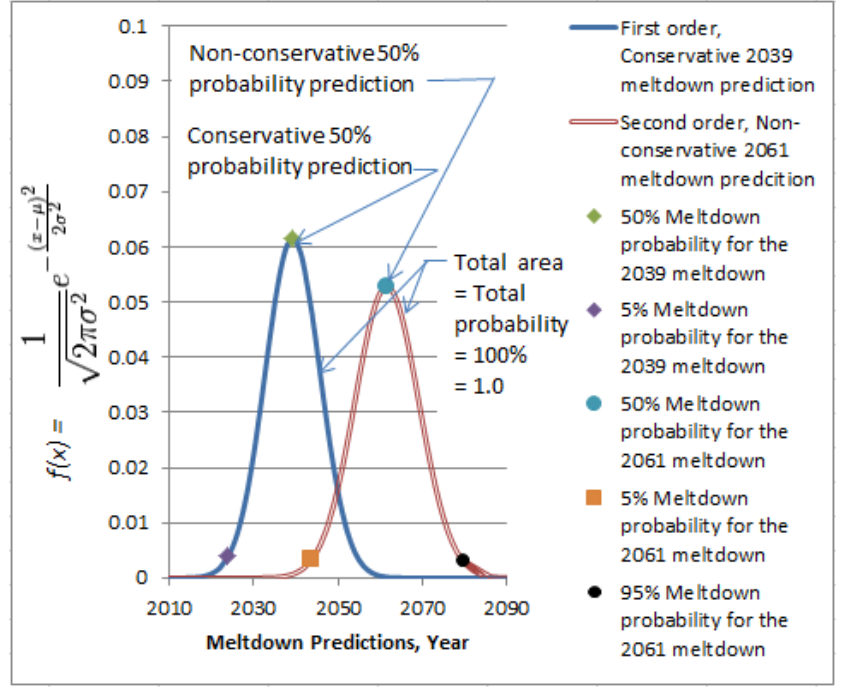

Figure 9. Comparison of first order and second order meltdown predictions.

Of particular interest to fleet accidents, the Chernobyl accident was dismissed as being applicable to meltdowns in other countries. Since the Chernobyl design was of Russian origin, the opinion was that the design was not as safe as other reactor designs, and that the Chernobyl accident was inapplicable to other safety analyses. In fact, Japanese reactor workers were taught that a reactor accident was impossible prior to Fukushima. As a result of this incompetent direction to workers, the National Industrial Safety Administration was shut down in Japan and a new organization - with greater credibility - was replaced by a new Nuclear Regulation Authority in Japan. The OECD and the U.S. NRC also promoted the opinion that any, and all nuclear accidents could not happen, which was, of course, also proven incorrect by the Fukushima explosions. In other words, Probabilistic Safety
Analysis had incorrectly proven that reactor accidents were beyond extremely unlikely, but reactor explosions occurred regardless of theory. Predictions based on what was known at that time were proven to be incorrect. We do not know what we do not know.

Two facts are certain from this research. The fluid transient cause of nuclear power plant explosions has not been considered by any government regulator or plant operator in any country that operates nuclear power plants, and the omission of facts in government reports during previous investigations has delayed this finding for decades.

\subsection{PSA Accidental Death Frequencies Versus Risks for the Energy Industry}

Previous NRC accident data [22] incorrectly and unethically showed that nuclear plants are much safer than other energy industries. To do so, NRC accident frequency data rather than risk data was used to compare nuclear power plant accidental deaths to other industrial deaths, as shown in Figure 10 where only the end points of the curves are represented here. Not only did this document misrepresent the facts, but this decision had a ripple effect throughout the nuclear industry, where NRC documents and other documents continue to use this reference. For example, an extraordinary textbook currently used for teaching nuclear engineers (Knief [23]), presents Figure 10 in the unedited format. Knief provided this information with integrity, but the NRC did not perform due diligence before publishing this misleading, and consequently unethical presentation of data. Knief's text followed the NRC path to claim that "the most likely core meltdown accident has modest consequences to the public", where consequences were not technically considered at all in the NRC report (NRC [22]). Consequently, nuclear engineers have believed this fallacy for years, which they were taught in universities, including this 
author. One may claim that the NRC may have done the best that they could, but the definition of risk has long been known, and for the NRC to ignore known technology to yield a favorable outcome is unethical.

\subsubsection{An Ethics Problem with the Use of Frequency Data Instead of Risk Data}

For example, by considering frequencies alone, Chernobyl deaths appear to have less significance than 5 deaths in the oil industry, and even the deaths of 31 workers subjected to high radiation exposures who died within three months (two died at the scene) of the Chernobyl accident have less significance than 5 deaths in the oil industry. Equating the Chernobyl accident to a pipeline accident using frequency is entirely unacceptable. The ethics issue arises due to the manipulation of data, since risk equals the accident frequency multiplied times the accident consequence. Using only the frequency half of the risk equation, a review of Figure 10 errantly concludes that the nuclear industry is far safer than any other industry. However, considering consequences as the other half of the risk equation, conclusions markedly change. Risk assessment is a well-known method to compare the importance of accidents, and the risk equation is the baseline for all risk assessments. Using only half of the risk equation to compare accidents is certainly unacceptable. In other words, the NRC not only falsified information about the TMI-2 explosion, but they falsified subsequent reports to make the reactor fleet appear to be safer than it is. These NRC actions are not only unethical, but these actions constitute malfeasance, especially when lives are at stake.

Additionally, the use of PSA risk calculations, instead of frequency calculations, effectively weights the deaths caused by accidents in different industries, where risks are more appropriate than frequencies to compare accident fatalities.

When risks are calculated instead of frequencies, nuclear power risks are comparable to risks associated with other energy industries - a much different conclusion, since reactors are not as safe as previously believed. To reach this conclusion, select risks were calculated for various energy industries, which are either part of the Organization for Economic Cooperation and Development (OECD), or not part of the OECD, which is an organization of 34 democratic member nations. Calculated using Eq. 1, risks are reported in Figure 10 to compare nuclear energy accidental death risks to risks associated with other energy industries.

\subsubsection{Cancer Risks}

Cancer risks may also be considered, since explosive, radioactive releases may cause thousands of cancer deaths. There were no deaths at the time of the TMI-2 accident, cancer risks from TMI-2 are generally considered to be negligible, and the resultant accidental death risk equals zero. Chernobyl cancer risk estimates are provided by NEA in the figure, but cancer risk estimates vary considerably as shown by the range of Chernobyl latent deaths in Figure 10 (World Health Organization [24]). The cancer death risks associated with Fukushima are widely disputed, but a reputable estimate is available, where a "discernible increase in cancer incidence ... attributed to radiation exposure from the accident is not expected, and the evacuations themselves also had repercussions for the people involved, including a number of evacuation-related deaths", but no immediate deaths attributed to the meltdown were reported (UNSCEAR [25]). Even though cancer risk data is plotted in Figure 10, the use of risk data based on cancer estimates is questionable, since approximately 288,000 deaths have been accelerated during a single year due to airborne fossil fuel particulates, according to the NEA. This statistic may lead to a different conclusion that nuclear fuels may be safer than fossil fuels with respect to cancer deaths.

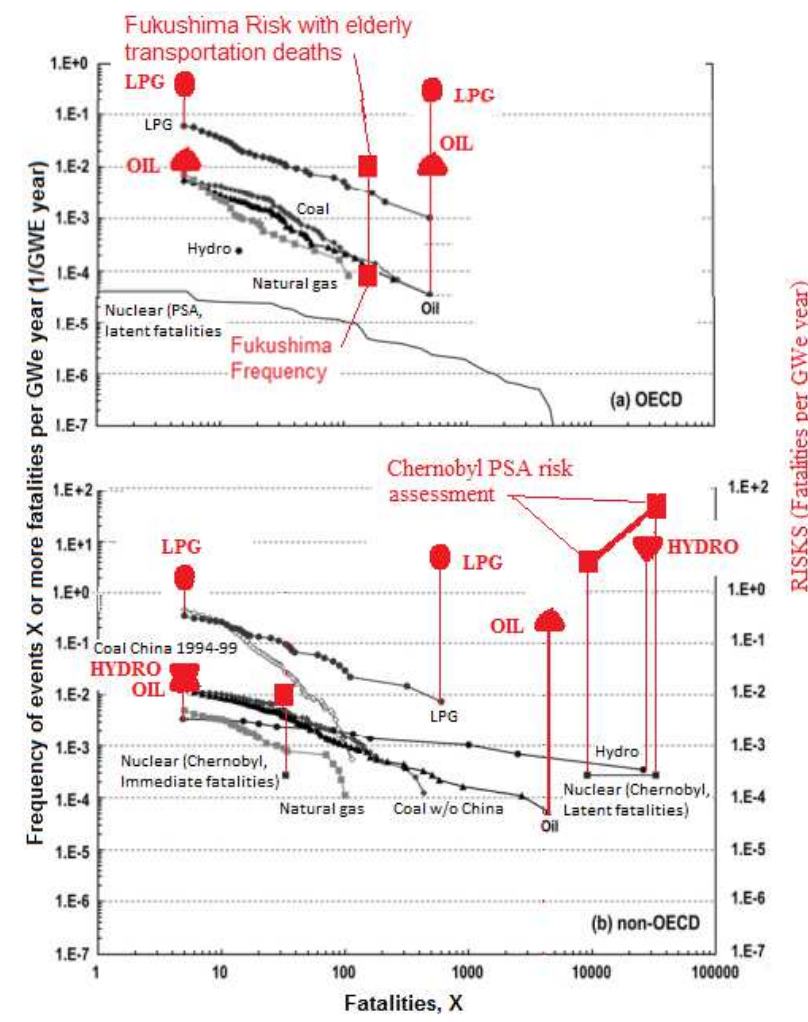

Figure 10. Frequency vs. consequences and risk vs. consequences for severe accidents $^{21}$ (Deaths $\geq 5$, only the endpoints of the curves are shown) ${ }^{22}$ (Note: All data for 1969 - 2000, 31 years, except China coal, 1994-1999, and Fukushima, 1990- 2011, 31 years. Adapted from NRC, WASH-1400 [22]. TMI-2 is not shown since fatalities did not occur, and a zero risk is undefined on a log chart.)

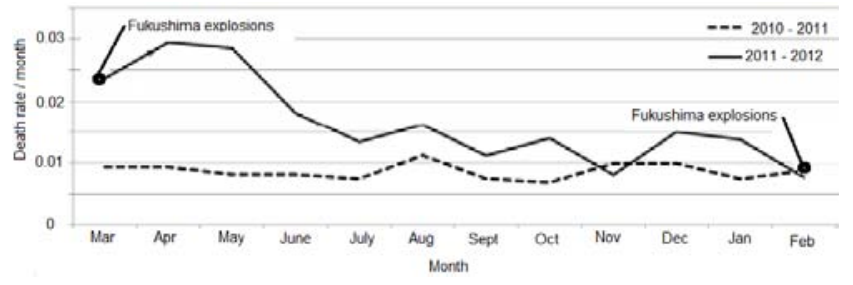

Figure 11. Mortality rate change for institutionalized elderly due to Fukushima explosions (Adapted from Yasumura [26]).

\footnotetext{
${ }^{21}$ NEA also calculated some risks that differed from risks shown in this figure, but NEA calculated nuclear risks, and risks were comparable to other industrial risks (NEA [17]).

${ }^{22}$ Revisions to this figure are new to the literature, and risks were previously not presented.
} 


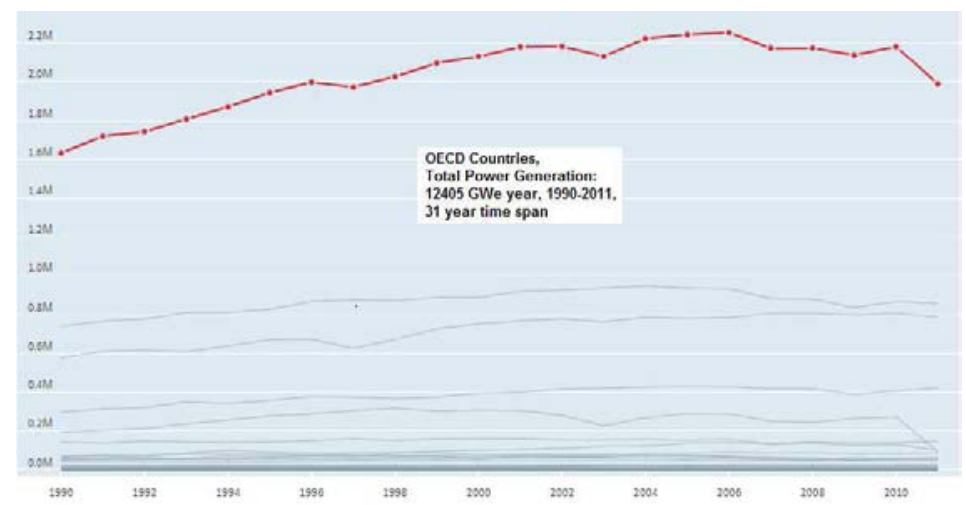

Figure 12. OECD Country energy generation, total gigawatt hours for OECD countries (NEA, [29]).

Also, NRC regulatory reactor design recommendations are depicted in Figure 13 as discussed by Leishear [30], where additional details are available (13, 14, and 18]). Again a question of ethics arises - theoretical frequencies have implied that nuclear reactors are much safer than they are. Risks are appropriate (not frequencies) for accident comparisons (NRC [31]. Another observation is that reactor design CDFs and LRFs are dependent, and as such the LRF and CDF differ by a factor of 2 yet NRC regulations require that these two values must differ by a factor of 100 as shown in Figure 13 (NRC WASH 1400 [22]. This NRC regulatory issue needs to be resolved through changes in regulations, as the NRC requirements cannot be met (Leishear [30]). Since the CDF and LRF differ by a factor of 2 , the requirement that they must differ by a factor of 10 or even 100 cannot be met as recommended by NRC documents. Even though conservative calculations by plant operators may meet this requirement, the regulations are in error and demand corrections.

\subsubsection{Dread Risks}

Figure 14 presents dread risks and a comparison of reactor risks to other risks that now changes due to technological explosion advances presented here. In this figure, "unknown risks are defined at the high end by hazards judged to be unobservable, unknown, new, and delayed in their manifestation of harm", where power plant explosion effects were unknown at the time that this figure was first created (Slovic, 1987 [32]). "Dread risks are defined at the high (right-hand) end by perceived lack of control, dread, catastrophic circumstances, and the inequitable distribution of risks, where nuclear weapons and nuclear power score highest on the factors that make up this factor." Note that Figure 14 shows that reactors have higher risks than airline travel and explosions, which in turn revises Figure 13 accordingly - hence the revised figure. Figure 13 is modified to reflect this new understanding of reactor accident explosion risks and a consequent increase in nuclear power plant risks.

Considering the change to Figure 14, nuclear accidents are one of most dreaded risks of known risks. There are no ethical concerns with respect to this figure since new technology changed this figure. Even so, an understanding of dread risk provides better insight into nuclear accidents. For example, the TMI-2 accident had a zero fatality risk since there were no deaths, but the extraordinary dread risk at the time of the accident sent shock waves throughout the industry. Dread risk about nuclear power plant explosions is still high, and the continuing lack of action by nuclear regulators to address explosion dangers raises ethical concerns as discussed throughout this paper.

\section{Discussion}

\subsection{An Overview of Ethical Theories}

Ethics has been mentioned and applied to several examples throughout this paper, and to understand ethics first consider the fundamental tenets of ethics. Ethics is the branch of philosophy that explores the nature of moral virtue and evaluates human actions using sets of moral principles and concepts to govern behavior or to conduct activities. After Martinez and Wueste [33] and Cho, et al. [34], and the National Society of Professional Engineers, a discussion of ethics follows, and the relationship between technology and ethics can be summarized by Figure 15. In this figure, morality and technical, or scientific, information overlap, where reason and logic are used to justify claims of moral truths, i.e., facts are used to determine the right thing to do. Ethics is further divided into three foundational ethical theories, which should ideally converge to the same decision or judgement.

1. Consequences: Consequentialism focuses on the potential short term and long term consequences for the greatest good for the greatest number of people, i.e., an approach to ethics that judges the morality of an action based on the action's impact on the well-being of people and the common good.

2. Rights: Deontology focuses on the act or intent of actions to treat other people with respect since they have inherent value, i.e., an approach to ethics that judges the morality of an action based on the action's adherence to rules or duties.

3. Character: Virtue Ethics focuses on being a responsible person striving for excellence, i.e., an approach to ethics that emphasizes the role of personal character and virtue in determination of morality. 

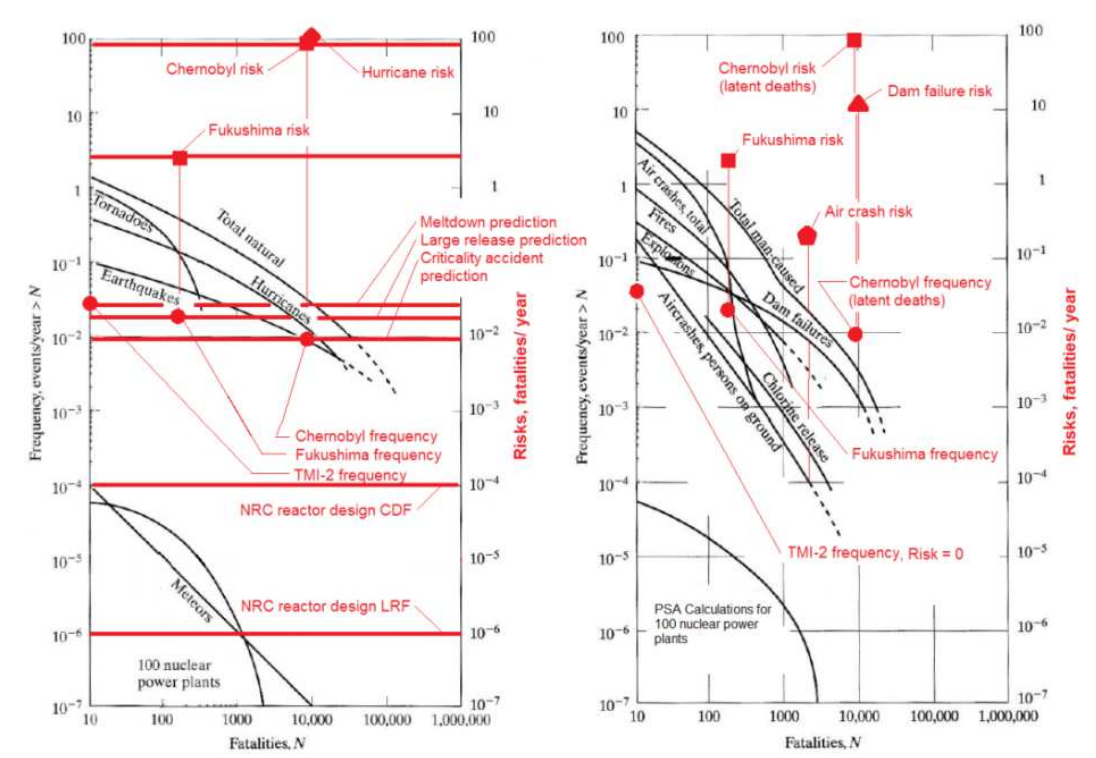

Figure 13. Comparison of nuclear power plant accidents to natural disasters.

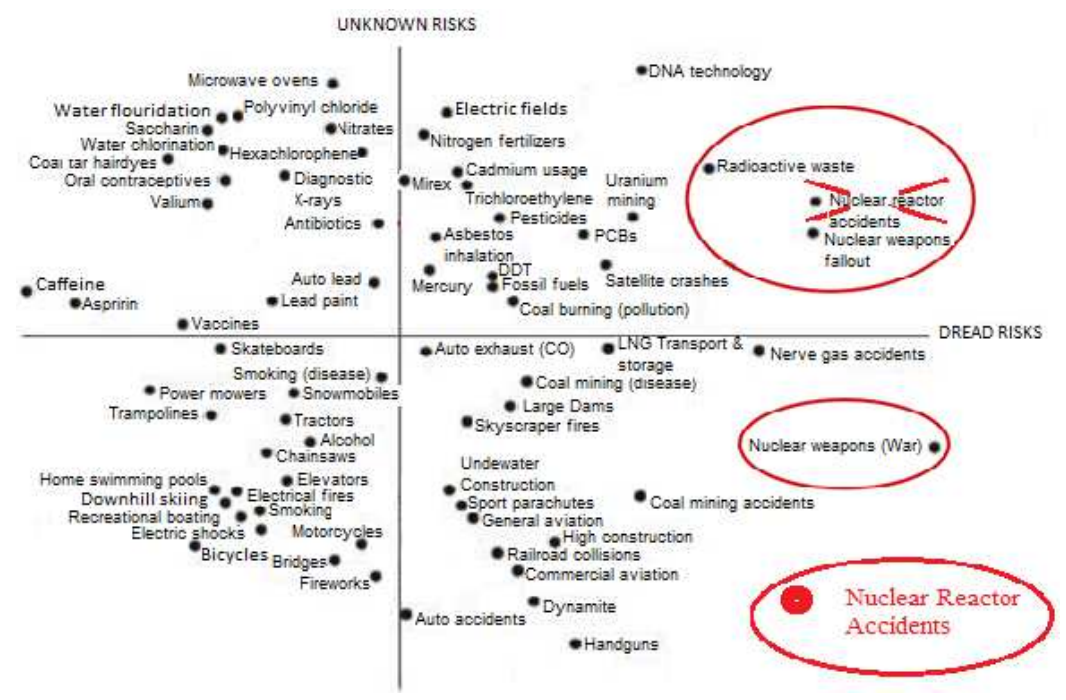

Figure 14. Comparison of nuclear power plant risks to other risks (Adapted from Slovic [32]).

\subsection{Ethics in the Radiology Business}

Radiology protection, or radiation protection, is inherent in the nuclear power industry, and "Radiological protection is not only a matter of science, but also ethics," where "the ethical foundations of the system of radiological protection ... describes the four core ethical values underpinning the present system:

Beneficence/non-maleficence, prudence, justice, and dignity. ... These core ethical values relate to the principles of radiological protection, namely justification, optimization, and limitation (International Committee on Radiological Protection (ICRP) [35])." Although nuclear power safety is paramount to this research, the ICRP recommendations for ethics are pertinent to this research since a fundamental safety problem for nuclear power plants is the release of radioactive contaminants during nuclear meltdown events, and resolving this problem is fundamental to radiological protection. In fact, much of the information used to understand and apply radiological principles was learned from the radiation exposure of people during nuclear accidents, and safety issues of concern are related to radiological dangers due to radioactive releases.

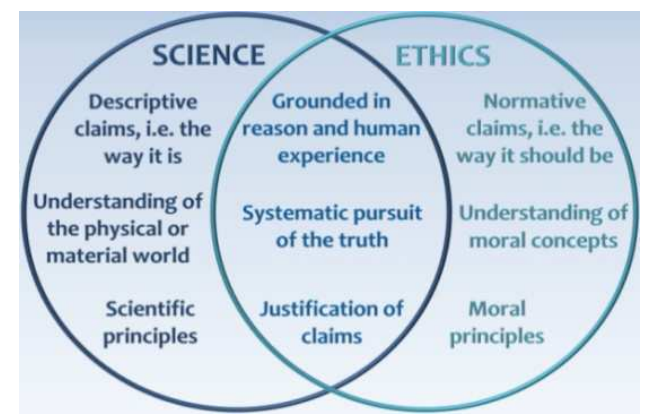

Figure 15. Technology and ethics (C) IOP Publishing. Reproduced with permission. All rights reserved).

After Martinez and Wueste [33], Ethical Principles can be 
defined as:

4. Beneficence/non-maleficence: Promoting or doing good, avoiding doing harm.

5. Prudence: Practical wisdom, making informed decisions without full knowledge of the scope and consequences of an action, e.g., the extent of explosion damages.

6. Justice: Fairness in the distribution of advantages and disadvantages.

7. Dignity: Treat people with respect/involve stakeholders, the unconditional respect that every person deserves, irrespective of personal attributes or circumstances.

Procedural Ethical Values include:

8. Accountability: The obligation of individuals or organizations who are in charge of decision making to answer for their actions to all those who are likely to be affected.

9. Transparency: Accessibility of information about the deliberations and decisions concerning potential or on-going activities, and the honesty with which this information is transmitted.

10. Inclusiveness: Ensuring that all those concerned are given the opportunity to participate in discussions, deliberations, and decision making.

\subsection{Engineering Ethics}

Next, consider the ethical responsibilities of engineers who perform research and document their findings through engineering publications. The Code of Ethics for the National Society of Professional Engineers provides guidance, which states that "Engineering is an important and learned profession. As members of this profession, engineers are expected to exhibit the highest standards of honesty and integrity. Engineering has a direct and vital impact on the quality of life for all people. Accordingly, the services provided by engineers"

11. "Require honesty, impartiality, fairness, and equity,"

12. "And must be dedicated to the protection of the public health, safety, and welfare... Engineers, in the fulfillment of their professional duties, shall: Hold paramount the safety, health, and welfare of the public."

13. "Engineers must perform under a standard of professional behavior that requires adherence to the highest principles of ethical conduct."

14. "Conduct themselves honorably, responsibly, ethically, and lawfully so as to enhance the honor, reputation, and usefulness of the profession."

\subsection{Ethics and This Research}

Finally, consider how this discussion of ethics is pertinent to the research at hand. The three theories of ethics, along with ethical principles and ethical values converge to the same conclusions, i.e., actions shall be taken to prevent nuclear power plant explosions, and the limitations of nuclear power plant safety shall be recognized.

\subsubsection{An Application of Ethical Theories}

1. Consequences: There is a potential for a nuclear accident before 2039, and there is a one in two probability of a large scale radioactive release that can explode radioactive dust into the air, which can then disperse as a radioactive dust cloud to travel around the globe as the earth rotates. Radioactive dust travelled from Japan and passed over northern Canada after the blast. Livestock in the northern United Kingdom were potentially contaminated by radioactive fallout from Chernobyl dust clouds when radioactive dust was washed to the ground by rains, but contamination has since dissipated. An old - but not recommended - adage was that the solution to pollution is dilution. By taking prompt actions, the risk of a similar blast can be extended to more than a hundred years from now.

2. Rights: Hundreds of thousands of people have been evacuated from their homes and businesses due to previous nuclear power plant explosions. During the Fukushima evacuation, more than 100 elderly people also perished due to the stresses of relocation efforts. Nearly 100,000 people are still not allowed back into their neighborhoods after $\sim 10$ years due to radioactive contamination of their homes, land, and businesses. By preventing future explosions, the rights of people through disaster protection are ensured.

3. Character: This research challenges well accepted engineering opinions. To fight uphill against the ingrained beliefs of others is a difficult and stressful process, and undertaking this fight, and not looking the other way, requires great stamina.

As an example of this stamina, this author previously published significant work that bucked normative beliefs with a clear understanding of the stress and difficulties involved. That is, the author's theory (The Leishear Stress Theory) on how fluid transients break piping (including nuclear plant piping) was, and continues to be, an uphill battle. This author spent two years writing and rewriting a Master's Thesis -10 revisions - on this topic until the Thesis advisor was convinced of this work's value. New ideas require hard work to earn acceptance. At the conclusion of that Thesis defense, the author's Adviser stated that this work was the best research that he had ever seen at the University of South Carolina, even though tempers flared on both sides during theoretical progress.

Even the Ph.D. research for the Leishear Stress Theory was fraught with difficulties to move forward. After the Dissertation was presented and accepted by a review group of four professors (my Dissertation Committee), one of the professors decided to revoke the passing grade, which violated University policies according to the Dean's office. Specifically, that professor asked that I withdraw the concept of dynamic stresses from my Dissertation, where this topic was the crux of the entire Dissertation and published papers. After discussions between Committee members, a vote was taken on whether or not to revoke my passing grade, and his recommendation was overridden, and the Ph.D. degree was granted. As noted in one of my papers, "New ideas are hard to hold on to, even by scientifically minded people", where this remark was provided by an Editor. 
Based on this research, ASME papers (Leishear [36]) were written on the topic of piping failures due to water hammer ${ }^{23}$. This work also resulted in an explanation of why nuclear power plant pipes break due to hundreds of small explosions inside of nuclear reactor piping systems, and also explained why 13 billion dollars per year in water breaks occur across North America alone (Leishear [38] $)^{24}$.

An initial editorial response to this article incorrectly claimed that this author misunderstood metallurgy and water system piping "and is denying reality". After being challenged, that author modified his response by retracting those statements before printing his article. His thoughtful technical response was also technically rebutted, and the two articles (Point / Counterpoint) were printed together (Leishear [39]).

To demonstrate skills in water main breaks, a reference for the explosions research considered herein was provided by a Senior Engineering Director for a DOE nuclear weapons plant. In regard to water main fire protection system research, he wrote that "In the weeks we worked together with other plant engineers, my previous perspective of Dr. Leishear's knowledge in fluids engineering grew exponentially. I watched him eagerly mentor young engineers in the basics of fluids engineering. As Dr. Leishear successfully completed his work for us, I was astonished with his knowledge and compassion for this field ... in solving a very complex fluid problem". We can learn and advance technology by disagreement.

The fight for ethics has a personal cost during the fight, but the benefits to others outweigh the personal costs. The personal costs for this explosions research were many stressful volunteer hours of defending engineering research to many engineers along the way - myriad hours were lost to these arguments that could have been otherwise spent with family but the benefits will be the prevention of multi-billion dollar infrastructure expenses by preventing piping failures

\footnotetext{
${ }^{23}$ Initial conference papers were refused publication, and one of the reviewers wrote "Bull****" 23 times as review comments, i.e., the reviewer adamantly disagreed with the new Leishear Stress Theory. Those papers were published after appealing the refusal decision to the Conference Chair. At the Conference, the Conference Chair stated to the engineering audience that this research had no value. Washing away this opinion, subsequent papers on this topic were designated as Honors papers in the ASME, Journal of Pressure Vessel Technology, and ASME published a book on the topic (Leishear [37]). In fact, the term Leishear Stress Theory was coined after this Dynamic Stress Theory research was published by another author in a pop-science engineering magazine. When I first read the article I thought it was good work, and a few days later it occurred to me that it was my work. That author claimed that he did not intend plagiarism, but he admitted that the work was not his own. He heard about the idea, and the concept sounded good enough to publish. This statement seemed odd since he casually remembered the mathematical simultaneous solutions to second order partial differential equations, and he overlooked the fourth order differential equation solution, where both solutions were discovered by this author. SRNL attorneys and I agreed that we did not wish to pursue this issue. I personally believed that he was trying to do the next right thing, and his article was rather well written to promote theory that needed public attention, which is afforded by a pop-science magazine.

${ }^{24}$ Also of note, the U.S. Environmental Protection Agency, which is responsible for the U.S. water supply, stated that there is no government agency responsible for ensuring that an expected trillion dollars in water main breaks during the next 25 years should be prevented. Which is worse, this agency that ignores a problem or the DOE and NRC that refuse to address a problem?
}

throughout industry. Explosions research discussed here will continue with the same rigorous defense to stop nuclear power plant explosions, but loss of life will be prevented.

In the words of a song by Chumbawamba, "I get knocked down. I get up again. You're never gonna keep me down". The quote of this lyric is not a complaint, but is an acknowledgment that doing the next right thing sometimes takes persistence and hard work to exercise personal choice. That is, the use of this quote is not a whimper of submission, but serves as a steadfast stand against indifference and refusals to accept new technology to save lives.

\subsubsection{An Application of Ethical Principles}

4. Beneficence/non-maleficence: The primary intent of this research is to help others, where more than 20,000 hours of part time volunteer research were invested over 20 years for water hammer and explosions research, and another 7000 hours of full time research have been voluntarily invested into explosions research. These hours are the equivalent of 13-1/2 years of 40 hour work weeks for unpaid volunteer research to benefit our society.

5. Prudence: This research resulted in the invention of the Leishear Explosion Theory, where new knowledge was created where knowledge did not previously exist.

6. Justice: Since the location of the next nuclear accident cannot be predicted, and since radioactive contamination can occur anywhere, these accidents affect people world-wide.

7. Dignity: A primary goal of this specific paper is to engage stakeholders, which include nuclear regulators, nuclear power plant operators, and the public at large all of whom are affected by the potential for future explosions, which can be stopped.

\subsubsection{An Application of Procedural Ethical Values}

8. Accountability: To change this paper to first person. "I am accountable for my actions, and consequently I have an obligation to accurately report the facts as I understand them, and I have a further responsibility to not just report the facts, but to provide interpretations of facts to better serve other people."

9. Transparency: This paper endeavors to clearly present the case to improve nuclear power plant safety. In fact, the Addendum presents underlying calculations for transparency of applicable theory.

10. Inclusiveness: This research affects all industrialized countries that operate nuclear power plants, where Nuclear power plants currently operate in 31 countries, and most are in South Asia, Europe, North America, and East Asia. Additionally, all countries throughout the world are potentially affected by radioactive dust clouds. The NRC and the DOE have declined opportunities to support this research or to address applicable safety concerns for the U.S. reactor fleet.

\subsubsection{An Application of Engineering Ethics}

11. Dedication to the safety, health, and welfare of the 
public: Public welfare comes first in this research, and improved safety and health will be the outcomes of this research if actions are taken in response to this research.

12. Act honorably, responsibly, ethically, and lawfully: Personal accountability and responsibility are the underlying principles of this research. Acting with integrity and honesty is a progressive, lifelong challenge and goal. We learn by mistakes.

13. Act with the highest principles of ethical conduct: Engineers are the caretakers of technology, and must act accordingly. Engineers must stand up for what they believe to be right and true to protect those who depend on the skills and competence of engineers, where a primary engineering responsibility is to ensure the safety and well-being of our citizens. The application of ethics and the difficulties to do so are discussed throughout this paper, where simply stating that one should be ethical is far easier than actually acting ethically in all business dealings. Perhaps most of us know people with great moral compasses, and we see them stray into unethical behavior to secure business interests, where rationalization can be a danger to any of us. Even so, sometimes there is good reason for people to disagree and ethics is not the issue at all, but there may be a fundamental disagreement about what is right and true. This paper endeavors to objectively discuss ethics not only for the purpose of promoting nuclear plant safety, but for the purpose of generating open discussions of ethics in the nuclear industry. Ethics are taught to nuclear workers in the business due to the immense importance of this topic, and yet a nuclear engineering journal refused to discuss these ethics issues at all. Perhaps the time has come to change this practice, and this International Journal of Philosophy paper may start this discussion.

14. Act with honesty, impartiality, fairness, and equity: There is difficulty in acting impartially, and appearing to be impartial, when contradicting the work of earlier researchers or challenging NRC ethics, since ego could trample, or appear to trample, impartiality when expressing one's own thoughts. However, the author has carefully studied and evaluated these earlier works and NRC actions as research proceeded to ensure that discussions presented here are impartial. Even so, when the opinions of others are challenged, the challenge is in fact personal, and personal feelings come into play, but there is no intent in this paper to smear reputations or hurt feelings of others in any way. The goal here is to promote our common welfare, and look at past research in a new way. Although ethics violations have been cited herein, frequently these violations were related to the dismissal of pertinent information, and the reasons for those dismissals are not clear. However, dismissal of data that does not fit a promoted opinion cannot be ethical or technically sound.

\subsubsection{Ethics and Decisions}

The principles of ethics demand that the previous understanding of nuclear reactor safety and future preventive actions for power plant explosions must be questioned and corrected. Again changing this paper to first person, I am responsible for my actions, my actions reflect my choices, and I choose to stand against current knowledge to forge an urgently needed change to the future of the nuclear reactor business - explosions can be stopped. My challenge of past theory to prevent death and destruction is a right and just action, and this paper is a written statement of that challenge. I am a dreamer, I see things that can be, and I work hard to make those dreams become fact. Nuclear plant piping explosions can be stopped; nuclear plant building explosions can be stopped; and imminent, unnecessary deaths can be stopped.

\subsubsection{Opinions Versus Facts}

Even so, an argument can be made that this author's opinion, or engineering judgement, is just one of several different technical opinions on the subject of nuclear reactor safety and power plant explosions. This paper worked to overcome this argument and demonstrate the factual competence of this theory to stop nuclear power plant explosions, and to factually prove that day to day operational safety in the nuclear power business is far less than previously endorsed. As an engineering axiom, once a problem is clearly understood that problem can be corrected, and the explosions that are discussed here can be prevented. The facts are clear that lives are at stake, major environmental damages are at stake, power plant destruction is at stake, and these problems can be stopped.

\subsection{An Ethical Dilemma in the Nuclear Industry}

All in all, there are many new questions that relate to nuclear power plant safety and ethics. Previous graphic descriptions used to demonstrate nuclear industry safety are incorrect due to explosions research discussed here that sharply change the understanding of reactor safety. Additionally, publicized, misleading nuclear data graphics challenge the principles of ethics. Harm from nuclear energy has been misrepresented, which curtails the freedom for citizens to make informed decisions about nuclear power plant safety when citizens are not aware of the actual safety conditions of the reactor fleet.

Findings presented here constitute new safety risks, some of which result in ethical issues and some of which do not. Risks throughout the oil, gas, coal, and hydro industries are widely accepted due to the common energy benefits provided by these industries, and perhaps the same level of acceptance applies to these newly identified, but comparable, risks for the nuclear industry. Whether or not these new risks are acceptable is outside the scope of this publication, but the prevention of explosions will drastically reduce future risks. Safety risks, in terms of fatalities, are comparable to other industries, but the dread risk is much higher for nuclear industries when compared to other energy industries. Even so, these explosion risks are inherent in the present operations of nuclear power plants, and as such a reasonable case could be made that the findings of this work endorse continuing safe operations. A primary goal of this 
specific publication is to change NRC and DOE actions to make our country safer through safer nuclear plants.

\subsection{Ongoing Research}

\subsubsection{Non-funded Continuing Research}

Future research to model the explosions at TMI-2 and Hamaoka is planned as continuing volunteer research. Government grants are blocked on all fronts, where the "government" is not some academic abstraction but consists of individuals who should place the interests of our society first.

Even though the NRC provides research grants, they informed this author that they do not provide such grants, and the NRC suggested the National Science Foundation, who, along with the Small Business Administration, refused grant proposals for arbitrary reasons and suggested the Department of Energy $(\mathrm{DOE})^{25}$. The Small Business Administration declined, claiming that profits would be unlikely from this research, and grants for small business are aimed to promote small business success. And, the National Science Foundation declined support by stating that even though their website claims that they support small businesses, this research would never receive support as a small business proposal since university funded research is preferred. In other words, several government agencies would not even accept a formal research proposal.

Of more importance, these agency decisions display an ongoing pattern of non-support to improve industrial explosion safety to save lives. Granted, this research is new, but novelty is not a reason to disregard loss of life. How many lives must be lost to be important enough to investigate known explosion hazards?

Subsequently, the DOE also dismissed a research grant proposal for research on "The Autoignition of Nuclear Power Plant Explosions" without any technical evaluation or consideration by stating that preventing nuclear power plant explosions does not "propose innovative technology development to improve the capability of the existing fleet". They made this statement after previously endorsing the Abstract for this same research. The DOE refused to clarify this statement, even though I informed them in a 5/5/2020 email that this statement is "patently false", and that "we can move forward together to make our country safer by improving nuclear power plant safety. ... How can this work not be important to the DOE? ... Actively preventing this research could protect previous false government reports." The DOE also refuses to answer emails that request that they, "Please answer the question of why preventing nuclear power plant

\footnotetext{
${ }^{25}$ Explosion research grants were also refused by other government agencies. The Bureau of Science and Environmental Engineering refused grant support since there were more important issues than understanding the explosion cause of offshore oil explosions like the Gulf Oil Spill [40], where the explosion cause is similar to nuclear plant explosions. The Pipeline and Hazardous Materials Safety Administration (PHMSA) turned down a grant request to investigate gas pipeline explosions by monitoring explosions, using high frequency pressure transducer technology. However, PHMSA responded to an email titled, "PHMSA Kills People", and explained that the money was gone, but their staff has been of assistance in providing information to investigate gas pipeline explosions, which are essentially the same compression and explosion process that occurs in nuclear plant explosions
}

explosions does not "propose innovative technology development to improve the capability of the existing fleet". I have asked this question several times and the basic answer has repeatedly been that it does not comply because it does not comply. My extraordinary efforts to save lives merit an answer". Not only do the stewards of this grant request refuse to discuss these issues, but the Office of the Secretary of Energy refuses to discuss these important reactor safety issues as well.

In other words, DOE not only refused to support this research, but made false statements to actively interfere with government funding for this research, and refuses to explain their actions. Together, these DOE and NRC actions constitute an ongoing cover up of explosion dangers to the public. These actions constitute a clear violation of the DOE mission "to ensure America's security and prosperity by addressing its energy, environmental and nuclear challenges through transformative science and technology solutions". This ground breaking research is transformative in the nuclear industry.

Pertinent issues were reviewed and evaluated by the DOE Office of the Inspector General, following a 5/28/2020 Allegation, titled "DOE Cover Up of Explosion Dangers in U.S. Nuclear Power Plants," [41]. This Allegation opened with the statements that "The DOE, Idaho Operations Office dismissed a research grant proposal to prevent explosions in nuclear power plants, and this decision will directly result in loss of life and disastrous environmental damages. To do so, the DOE claims that the prevention of nuclear power plant explosions does not "propose innovative technology development to improve the capability of the existing fleet" of nuclear power plants. In blocking this grant, the DOE also made false claims. These actions constitute a [continuing] cover up of an important safety issue that can result in loss of life, property damage, and major environmental damages, and this unethical DOE blockage of needed research is a threat to public safety".

These actions to hinder research and changes to nuclear regulations also constitute a clear violation of the NRC mission for "control of atomic energy ... [to] improve the general welfare, [to] increase the standard of living, ... to protect health and safety and minimize danger to life or property, [and] to promote efforts which will prevent or eliminate damage to the environment and biosphere and stimulate the health and welfare of man". All of these expectations are violated when NRC and DOE inaction and direct actions implicitly permit explosions to continue.

\subsubsection{Flawed Ethics Investigation}

The DOE Office of the Inspector General closed this investigation without action to continue the cover up of nuclear safety violations, where none of the concerns that were raised in the complaint to DOE were addressed at all (HQ-2021-00078-F). That is, DOE refused to clarify this statement even in response to a formal investigation by their own DOE Office of the Inspector General, where the same, exact, initial DOE claim was repeated, and all allegations were completely ignored. Essentially, DOE still tacitly contends that safety is inapplicable to the U.S. reactor fleet. A letter was sent to DOE stating that "As I fight to make the world a little 
better place to live, I am extremely disappointed that people disregard loss of life. Granted, new technology is difficult to accept, but how can people just look the other way and allow nuclear accidents to continue? How can safety not be applicable to the U.S. nuclear reactor fleet?"

Not a single one of the following allegations were addressed by DOE during their investigation. "The DOE, Idaho Operations Office improperly, unethically, and dishonestly dismissed a research grant proposal to prevent explosions in nuclear power plants, and this decision will directly result in loss of life and disastrous environmental damages, i.e., this DOE decision can kill people and spew radioactive contamination across U.S. property. To dismiss this research proposal, the DOE falsely claimed that the prevention of nuclear power plant explosions does not "propose innovative technology development to improve the capability of the existing fleet" of nuclear power plants. That is, in blocking this grant, the DOE made this false claim and other false claims (dishonest, untruthful actions) to support their errant decision that violated their own procedures, i.e., Funding Opportunity Announcement (an improper action). These actions constitute a cover up (an unethical action and lack of integrity) of an important safety issue that can result in loss of life, property damage, and major environmental damages, and this unethical DOE blockage of needed research is a threat to public safety. The issues are described as follows.

1. U.S. NRC malfeasance with respect to nuclear power plant explosions is discussed in detail ...

2. I have voluntarily spent the past four years investigating nuclear power plant explosions to prove that explosions have a common preventable cause. This research has been voluntary at a personal cost of more than $\$ 130,000$ for pertinent publication and training costs to perform and document this research.

3. DOE approved an Abstract to perform this research in accordance with their Funding Opportunity Announcement (FOA) (DE-FOA-0001817, U.S., Industry Opportunities for Advanced Nuclear Technology Development, Application ARD 20.2-21608).

4. The original proposal included experimental explosion testing to better understand explosion theory and explosion prevention, and I spent several months designing explosion test equipment.

5. DOE nonfeasance caused the explosions contractor to withdraw from this research.

6. Accordingly, the scope of the research changed, and details of planned computer modeling were modified to ensure that results could be reasonably validated without explosion tests. Future experimental research was recommended in the final Grant Proposal.

7. The intent of preventing explosions and saving lives was not changed at all.

8. The completed grant proposal was submitted.

9. DOE dismissed the entire proposal claiming that it did not meet the FOA, where DOE had already approved this research plan with respect to FOA compliance. DOE refuses to explain this decision, which blocks important research to prevent nuclear power plant explosions in the U.S. False claims were made to support their decision.

10. This unethical DOE malfeasance is tantamount to a cover up of U.S. nuclear power plant explosion dangers.

11. These actions constitute fraud, waste, and abuse due to mismanagement"

These allegations are discussed in detail in the DOE allegations and DOE responses (Leishear [40]).

\subsubsection{A Question of Ethics}

Is there an ethical conflict of interest concerning this author's comments about the DOE and NRC? This question is important to the writings presented here. One could opine that an interest to earn profit drives this discussion, which is not the case. While earning money is certainly a benefit, the planned use of grant funding would have been to support future experimental research to better understand and prevent explosions. As a matter of fact, the initial Abstract for this research included experimental work, but DOE nonfeasance cancelled that part of the research, where Merriam-Webster defines nonfeasance as the failure or omission to do something that should be done or especially something that one is under a duty or obligation to do. DOE refused to answer the simple question of how payments would be made for grant research, and an explosives range contractor interested in performing the explosions withdrew from the research until payment procedures are known and a first contract is received and performed. The grant proposal Abstract was then revised to keep the intent of explosion prevention the same, but explosion tests were dropped from consideration. Much personal money has been invested into this research to make our country safer, but paying contractors out of pocket to perform explosions research is out of the question. Effectively any experimental research was blocked by DOE, but computer modeling as requested in the dismissed grant proposal will be performed by this author to make our country safer. Furthermore, the likelihood of any funding to this author for this research after publishing this paper would be astonishing, and no proposals are planned.

As volunteer research continues, the fight to do the next right thing continues for the sole purpose of stopping death and destruction. Two more years of planned voluntary research, at an additional personal cost of more than $\$ 70,000$ will be well worth the effort. "I get knocked down. I get up again. You're never gonna keep me down". Research continues regardless of funding.

\subsection{Ethics Take Time}

Even though the NRC and DOE have failed to take action for years on this issue to save lives and property, the NRC has taken a step to address this major explosion hazard. That is, the NRC supported partial research on water hammer and resultant explosions. Coronel, et al. [42] performed small scale research to prove that fluid transients autoignite explosions in piping, which is another step forward for this research. In the Introduction to their experimental research, 
Coronel, et al noted that "Pressure waves created by the ignition of a vapor bubble or region can propagate into the surrounding liquid explosive and initiate a propagating explosion or decomposition wave with highly destructive consequences. This mechanism has been proposed by Leishear [1] as being relevant to accidents in nuclear power plants". They concluded that "Our system size is small in comparison to industrial facilities and our method of producing pressure pulses creates a limited range of pressure histories. Industrial facilities such as nuclear power plants have much higher operating pressures and temperatures which have to be taken into account in evaluating the critical conditions for ignition. Despite the significant differences in scale and pressure pulse parameters between our tests and industrial facilities, we anticipate that some of our findings will be universally applicable".

Coronel's research provides an important step in the understanding of nuclear power plant and gas pipeline explosions, and the Leishear Theory explains a fundamental mechanism of gas explosions in piping, but explosion modeling and research at a larger scale is extremely important to nuclear plant safety, i.e., finite element explosion models, pilot scale explosion testing, and pressure measurements in reactor plants are recommended.

\section{Ethics, Technology, and Politics}

\subsection{Government Politics}

Politics, technology and ethics are intertwined throughout industry and government. Technology funding typically occurs through government agencies. Politics and ethics drive funding and publications. Technology may advance society, but politics are the drivers that implement technology. Unless politics are addressed in various parts of society, technology can be stymied, which can of course be a conscious choice. Technology is a conscious choice based on quality of life issues. In fact, the discussion of ethics presented here is a step toward changing political decisions to improve quality of life in our society, or safety versus a perceived dread risk, where past political and ethical decisions are vehemently challenged here.

For example, discussions in this paper considered DOE funding for research to stop explosions. DOE disallowed this research, where DOE basically claimed that safety research did not apply to new research for nuclear power reactor operations. A detailed Allegation was submitted to the DOE Office of the Inspector general, and the DOE response was identical to the original statement, and all allegations for the "DOE Cover Up of Explosion Dangers in U.S. Power Plants" were dismissed without acknowledgment or comment for numerous specific concerns.

Although DOE decisions were not affected by congressional support, a meeting was held with U.S. Congressman Joe Wilson of South Carolina in Washington, D.C., and he provided a letter of endorsement to DOE for this research. Senator Lindsay Graham declined support since he wrote that this research would lead to more government regulations, and he supports deregulation of industry. He is correct, where standing regulations for control of hydrogen generation in reactor systems to control explosions have recently been cancelled, and a primary goal of this research is to establish regulatory controls to prevent reactor system explosions. Politics were instrumental in NRC and DOE decisions, where unethical decisions were enforced by bureaucratic processes.

\subsection{Publication Politics}

Even publications are embroiled in politics. Prior to this publication, this paper was turned down by a reputable nuclear engineering journal (The ASME Journal of Nuclear Engineering and Radiation Science). When the paper was submitted, the Associate Editor strongly endorsed a discussion of ethics in this Journal. This paper was initially reviewed by two reviewers. The paper was accepted pending revisions, where one reviewer had more than 70 technical comments, one reviewer stated that "we need this kind of paper to stimulate professional and scientific dialogue", and both reviewers demanded additional details on ethics to specify individuals who acted unethically. In response, this paper quadrupled in length to add graphs, equations, and detailed discussions of NRC and DOE correspondence, which was not provided in the first draft of this paper. All reviewer comments were addressed.

The inclusion of DOE and NRC discussions of reactor safety were certainly controversial. Nine potential reviewers recused themselves from reviewing this paper at all, i.e., they refused to review this paper that challenged nuclear industry regulations and industry norms.

Three new reviewers agreed to review the paper, and again all technical comments were addressed when reviews were completed. Two of the three reviewers recommended that this paper should not be published since ethics did not belong in this paper. One reviewer even stated that a discussion of ethics did not even belong in a nuclear engineering journal.

Their recommendations were appealed to the Journal Editor, and the decision was confirmed that the paper would not be published, where the Editor wrote that "I think that it is very dangerous to make any predictions on any accidents including severe ones plus such statement will be immediately used against nuclear-power industry!" In response, a follow up letter included the statement that "the decision to not publish "Nuclear Power Plants are Not So Safe... by R. A. Leishear was, in itself, a question of ethics and censorship".

\subsection{Politics and Technology}

Perhaps opponents of nuclear energy may use this new information to promote their interests, but prevention of the loss of life should be paramount. Although politics were the underlying reason for an earlier refusal to publish new technology in a Nuclear Engineering Journal, once the technical facts are fully considered, political, regulatory, and corporate decisions can be made to decide if the low numbers of fatalities are acceptable, where such decisions are commonly outside the purview of engineers. 
Consequently, by taking action with respect to the operating nuclear reactor fleet, risks from explosions can be cut in half, since Fukushima type explosion risks can be eliminated, but Chernobyl type explosion risks cannot be eliminated by the research presented here. Thirty-one deaths were directly attributed to the Chernobyl explosion in Ukraine, many more died from cancer (Figure 10), and a radioactive dust cloud spread across the globe. Even so, a Chernobyl type explosion is far in the future with a $50 \%$ probability before 2123 .

Accordingly, elimination of hydrogen explosions can stop nuclear accidents for the next one hundred years, where the uncertainty of this estimate is questionable since much can happen in a hundred years. However, the possibility of a hydrogen explosion before 2067 is realistic as a near term event. In short, imminent hydrogen explosions are the primary concern arising from this research, and this type of nuclear power plant explosion, and smaller, continuing explosions, can be stopped if preventive actions are taken.

\subsection{Ethics and Statistics}

Another important question is whether or not the available statistics have been stretched too far to obtain results and reach conclusions (See Addendum), which would, of course, be a breach of ethics? The data analysis performed for this work is all that is available until the next accident, calculations are consistent with probability theory, and the stakes are too high to ignore this research.

\subsection{Financial Costs and Ethics}

If actions are taken in response to this research, there will be significant costs. For example, the costs to perform a safety analysis for a change to a reactor, changes to procedures, and changes to hardware can be expensive. For example, an OECD class taught that a revision to a safety basis, or the required safety documentation for operations, for a commercial reactor costs one million dollars, which does not include the costs to modify reactor systems. More than offsetting that cost, OECD also taught that each commercial reactor has an income of about one million dollars per day, plants cost approximately four to five billion dollars to build, U.S. plant life extensions from 40 to 60 years are common, and 80 year plant licenses are likely, where plant retirements are also possible. In short, a million dollars is a lot of money, but the cost of a safety basis change is one day of income from a nuclear plant's operations. Incidentally radiation damage is known to shorten component life in reactor systems, but water hammer induced small explosions also reduce system life as well by accelerating fatigue damage.

Careful decisions need to be made by others on the actions that should, or should not, be taken to address the hydrogen explosion risk. Accordingly, very careful consideration has been given to technical decisions in this work.

\subsection{Project Management and Ethics}

Also ethics related, the discipline of Project Management has wide acceptance throughout industry. A primary premise is that a team of professionals is better suited to manage a project than one or two strong willed individuals. In fact, strong willed stubborn individuals are frequently considered to be detrimental to a project. A tacit assumption is that a multi-membered team that uses technical resources as a supplemental requirement will outperform the performance of any single individual. Although this approach has much success, if a team member stands up for an ethical issue, team work may become very difficult and uncomfortable to pursue. Ethics are not even mentioned as a consideration in a comprehensive text book that teaches 49 distinct Project Management Processes (Crowe [43]). Perhaps ethics should be a $50^{\text {th }}$ process, since ethics can lead to greater project success.

Also, the idea that new inventions can be legislated by a group of managers may fall short of success. For example, this explosions research has used Project Management principles to guide this work, but this researcher is not considered to be a team player by the primary stakeholders, such as the DOE and the NRC. Following DOE and NRC recommendations, this work would have been dismissed years ago, but this important work continues.

The new theories that were invented as part of this research have been overlooked by project engineers all over the world for nearly 70 years. Although the advent of nuclear technology itself was the result of colossal teamwork (Leishear [30]), Project Management teams cannot necessarily create new knowledge. If this research had been embraced by nuclear industry personnel in 2010, the explosions at Fukushima could have been prevented.

\subsection{New Ideas and Research}

New ideas have been considered by some people to have three phases. First, the idea is said to have no merit, and no time should be spent on this research. Second, the research is said to be interesting, but no time should be spent on this research. And third, everybody knows that these findings are fact, and no time should be spent on this research.

However, this research is time well spent, and things are not that simple. For example, even though there is great resistance by some to this research, a professor who has provided assistance with this research recently commented that my nuclear plant explosions research is "a logical application of what is already pursued in the literature". That is, my years of painstaking research conclusions are impossible to some and obvious to others. Accordingly, the phrase of the Leishear Explosion Theory was coined herein, where fluid transients cause high pressures to autoignite flammable gases to explode in gas pipelines and nuclear power plants. Since there are no wages for this work, credit for this new discovery seems reasonable.

As learned from many years as a researcher, new facts require a lot of hard work to prove, even though the facts may seem obvious when the work is done. Also noted, assumed facts are occasionally assumed without data to support those supposed facts. One good experiment or model can destroy a lot of assumed facts. Additional experiments or modeling will yield better insights into these complex explosion processes and preventive actions. 


\subsection{The Future of This Research}

Even though additional voluntary research is planned by this author, the future of the new ideas presented here is uncertain. Hopefully, opinions will change, and other researchers will follow this work.

However, as a result of this research, attacks against personal integrity, credentials, personality, and experience are expected as the first defense against these new ideas when facts are inadequate to defeat new ideas. In the absence of a legitimate opposition to new ideas, slander is a convenient and often effective, yet unethical, defense. Defense against such attacks has been, and will be, a remarkably unpleasant part of doing the next right thing ${ }^{26}$, which is not always the easiest path to follow. Acting honorably can have a hard price.

Perhaps legal actions will be the ultimate means to address the ethical lapses discussed here that lead to deaths and destruction. Now that the risks of nuclear operations have been clarified, inaction by regulators and corporations may be interpreted as negligence in the courts. At a minimum, formal requests are planned to be submitted to the NRC to evaluate changes to reactor safety regulations, where this request is planned for submission after scheduled explosion modeling is performed. Computer graphics of explosions and videos of computer generated explosions should help support such a request.

Others may look the other way, but deaths and destruction can be stopped, and turning away does not serve public interests, integrity, or ethics. Unless someone stands up against false statements ingrained in the nuclear industry, misinformation will be part of the standards by which this industry operates with respect to explosions and meltdowns, even though safety is a major part of the nuclear industry. Being first is hard as this new technology is promoted. "I get knocked down, I get up again, they're never gonna keep me down".

\section{Synopsis of Findings}

Probability and statistics are widely used to assess nuclear plant operations and safety, and probability and statistics along with factual nuclear accident data are used here to prove several primary discoveries.

1. There is an imminent risk of another nuclear accident. A conservative, or safer, model predicts a reactor core meltdown in 2039, and a non-conservative model

\footnotetext{
${ }^{26}$ For example, a book contract is under consideration to document this research on completion. Although author credentials and publications were listed in the book proposal, one of the reviewers falsely wrote that this author had no experience in nuclear accidents or explosions, and that reviewer further stated that a book written by this author "would be an embarrassment to the ASME". This dishonest, malicious, and vicious comment was not supported by any facts provided by that reviewer. Understanding people who act so hateful and disrespectful is difficult. Also, industry professionals with similar thoughts are a reason that credentials are provided to support this paper. At the end of modeling research, a book is still planned. In a recent response to this book proposal, the Manager of ASME Press wrote that "ASME Press looks forward to having the opportunity to publish this important research, and your books have sold very well, and we would be happy to consider any updates or new books for publication."
}

predicts a meltdown in 2061.

2. The 2039 meltdown prediction is endorsed here, and there is a one in two probability of a large radioactive release at that time.

3. Using this assumption, there is also a $50 \%$ probability that a reactor building explosion will occur before 2067. A more conservative, less uncertain, approximation of 2053 may also be predicted, where there is a $4 \%$ probability of a release in 2021.

4. Correcting the fluid transient problem can extend the predicted $50 \%$ probability of a criticality plus explosion date to 2123, a hundred years from now. A more conservative, less uncertain, approximation of 2095 may also be predicted.

5. Even so, reactor shutdowns and new technology may extend explosion and meltdown predictions, where Pioro, et al. [44] discusses predictions for future reactor operations, where an important assumption here is that reactor operations will be similar in the future. As reactors are removed from service, the accident predictions presented here will be extended.

6. Whether future predictions are affected or not, meltdowns and explosions can happen at any time, where actions to minimize the possibility of explosions must be implemented.

7. Frequency predictions for nuclear reactor accidents were previously estimated to be once in 50,000 years for individual reactor designs and about once in 200 years for the U.S. reactor fleet (Figure 4), but consideration of the TMI-2, Chernobyl, and Fukushima accidents leads to a frequency prediction for a nuclear reactor meltdown of once every 28 years - a remarkable difference.

8. Every other meltdown accident - every 55 years - is expected to result in a large radioactive release, similar to Chernobyl or Fukushima.

9. Accidental death risks are roughly equivalent to other industrial, man-made, and natural event death risks, contrary to previous misleading publications.

10. Fluid transients are the common cause of nearly all nuclear power plant explosions, where hydrogen is compressed in piping systems due to pump and valve operations, which in turn heats hydrogen to autoignite explosions. The complex processes to do so in nuclear power plants are described by the Leishear Explosion Theory, i.e., fluid transients compress flammable gases to autoignition to cause explosions.

11. Gas pressures at the ends of pipes can double during pump pressure startups for large gas volumes, and pressures can be even higher for small gas volumes, and calculations are available (Leishear [37]), and experimental validation confirmed this theory (Zhoul, et al. [45]). NRC reports claim that this type of calculation is impossible, and incorrectly concluded, and continue to assert, that water hammer, rather than explosions ignited by water hammer, occur in nuclear power plants. High gas pressures autoignite flammable hydrogen and oxygen. 
12. A critical assumption for this work is that fluid transients are a common cause for explosions, and that this commonality validates the use of statistics to relate various accidents with very different initiating events.

13. A discussion of ethics was presented to consider the ethics of this research, the ethics of some previous research, and the ethics of government agencies that thwart this research.

14. What engineers ethically think as they work is as important as the work that they do since lives are often at stake.

15. Ethical decisions can be costly to engineers, and the costs to this author are discussed by way of example.

16. Acting ethically frequently has a cost, but the cost is worth the effort.

17. Some previous publications are grossly inadequate, where skewed data has incorrectly led people to believe that nuclear reactors were remarkably safe, when they are not.

18. The risks of future accidents can be minimized if explosion prevention is better incorporated into nuclear power plant operations.

19. The U.S. NRC and the DOE refused for years to act on these explosion findings, and the actions of these organizations endanger public safety in general, the lives of our citizens in particular, and the environment around us. Even so, the NRC has started to support new research on water hammer and explosions theory.

\section{Conclusions}

This research paper provides a two-fold discussion of nuclear reactor safety, and tells the story of a years-long fight against government agencies to save lives and stop environmental disasters. On the one hand, the dangers of an imminent nuclear power plant explosion are considered, where the basic explosion mechanism has been proven. On the other hand, the unethical misrepresentation of technical information in the nuclear industry for several decades by government agencies prevented earlier detection of this explosion peril and perpetuates a reckless, irresponsible, and dangerous cover up.

Contrary to previous research by others, significant claims about nuclear power plant safety perils are established here, and the arguments to do so are logically sound and backed by facts. Since new risks that were developed during this research have not been addressed in other studies, government publications, and regulatory publications, the danger of another nuclear reactor accident is high. One may claim that safety analysis prevents such nuclear power plant explosions, but a safety analysis did not prevent Fukushima. One may claim that explosions like Fukushima or Chernobyl cannot happen again since much has been learned, but only recently a discovery was made that TMI-2 experienced an explosion rather than a fire in 1979, and Fukushima reports do not yet acknowledge the correct autoignition cause of explosions that fired radioactive dust into the air and around the earth (Figs.
16 and 17). More importantly, prior to every meltdown and every explosion, governing authorities believed and publicly claimed that accidents were impossible, which is another common thread that connects all nuclear accidents. Until and unless explosion risks are acknowledged, understood, and fully addressed, these risks are not likely to be resolved, and the probability of a near-term, preventable explosion due to a nuclear accident will continue.

Specifically, the Fukushima explosions could have been prevented since this "new" explosion theory was already published in 2010. While watching the televised Fukushima explosions in 2011, I turned to my wife and said that "They just turned on the pumps", which is exactly what happened to autoignite the explosions. In short, the misrepresentation of facts following TMI-2 explosions thwarted technological advances that could have better prepared the nuclear industry to prevent the Fukushima explosions, where the discovery and publication of the fundamental explosion mechanism in nuclear power plants was delayed until a year before the Fukushima disaster (Leishear [46]). Impending similar explosions can be prevented, and ongoing research to stop future explosions is required to understand preventive actions.

Additionally, the U.S. NRC and DOE continue to cover up nuclear power plant explosion dangers, which started with the 1979 Three Mile Island explosions, which were falsely promoted to be fires and not explosions. Also, smaller explosions continue to occur, and continue to be misdiagnosed by the U.S. NRC and other government agencies (Figure 18).

Requests to correct these disaster potentials through a grant proposal for new hydrogen explosions research were answered with a response that the DOE claims that the prevention of nuclear power plant explosions does not "propose innovative technology development to improve the capability of the existing fleet" of nuclear power plants. This decision that safety is inapplicable to nuclear plant operations continues the cover up of explosion dangers.

Continuing this cover up, the DOE Office of the Inspector General performed an investigation in response to a detailed allegation of a "cover up (an unethical action and lack of integrity) of an important safety issue that can result in loss of life, property damage, and major environmental damages, and this unethical DOE blockage of needed research is a threat to public safety". DOE ignored each and every allegation and again concluded that new research to improve reactor safety does not "propose innovative technology development to improve the capability of the existing fleet" of nuclear power plants. That is, no answer was provided to any allegations by this U.S. citizen, and the cover up continues for this 10 year dispute with U.S. government agencies to change policies and regulations to improve nuclear power plant explosion safety.

Another finding that provides a false perception of nuclear safety is engrained in previous reports that compare nuclear plant safety to other industries and natural disasters. In published reports that have been promoted for decades, the frequency of accidents was used rather than the risks for those accidents. The graphic end results errantly showed that 31 deaths at Chernobyl were of far less significance than 4 or 5 
deaths in the oil or hydro industries. Appropriately considering risk, which equals the frequency multiplied times consequence, nuclear industry risks are comparable to, or higher than, other industrial risks. Previous graphs also promoted that nuclear energy was orders of magnitude safer than natural disasters like hurricanes or tornadoes, but the use of risk instead of frequency showed that nuclear risks are similar or higher than the risks due to natural disasters. The use of frequencies instead of risks to describe accidents is technically inappropriate and unethical. Even if one disagrees with the predictions provided here, the identified explosion hazards present clear and present dangers, and explosion risks can be massively reduced.

A primary ethical question for this author was whether or not to publish these major new discoveries that challenge nuclear industry experts. Ethically, how can I not publish the facts that I know to be true when lives are at stake? The nuclear industry has stringent safety regulations (NRC [47]) and, all in all, the nuclear industry is as safe as other industries, but the nuclear industry is not as safe as it has been claimed to be, and current regulations are inadequate with respect to new and proven explosion theory.

In fact, the dread risk, or perceived risk by the public, for nuclear power plant accidents is exceeded only by the dread of nuclear war and radioactive fallout, where fallout follows both nuclear explosions and nuclear power plant explosions. In other words, the fact that nuclear power safety is comparable to other industries is important to the perception of nuclear safety, bur the dread of a nuclear accident is far more important to citizens in their day to day lives.

In conclusion, a forty year cover up of explosion hazards in nuclear power plants continues to threaten the safety of the public. Recent research proves that a phenomenon known as water hammer compresses flammable hydrogen-oxygen mixtures in nuclear reactor power plants to heat and ignite those gases and cause explosions. Explosions occurred at Three Mile Island in 1979, and data was omitted from investigations that would have proven that explosions occurred in the U.S. This intentional omission of information thwarted earlier research that could have prevented the explosions at Fukushima. Additionally, smaller water hammer induced explosions have occurred in nuclear power plants since the 1950s, and these ongoing explosions have been misdiagnosed in the U.S. and abroad.

As written to a DOE Deputy Secretary of Energy, "What happens when the next explosion occurs and people are killed, knowing that explosions can be prevented." The DOE presently refuses to act to address this specific explosion concern, which constitutes an ongoing cover up of a radiation and explosion hazard to citizens across the globe.

All of these accidents are related to water hammer, and nuclear power plant safety can be improved to save lives, property, and the environment. These new findings constitute potential inadequacies in the safety analyses of the entire world-wide reactor fleet. Government agencies have the authority to accept explosion risks, but they do not have the authority to ignore and cover up explosion risks. Nuclear power plant explosions can be stopped!

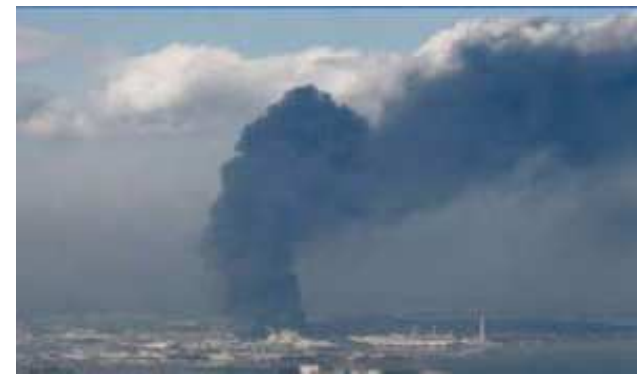

Figure 16. 2011Fukushima explosions (U.S. NRC).

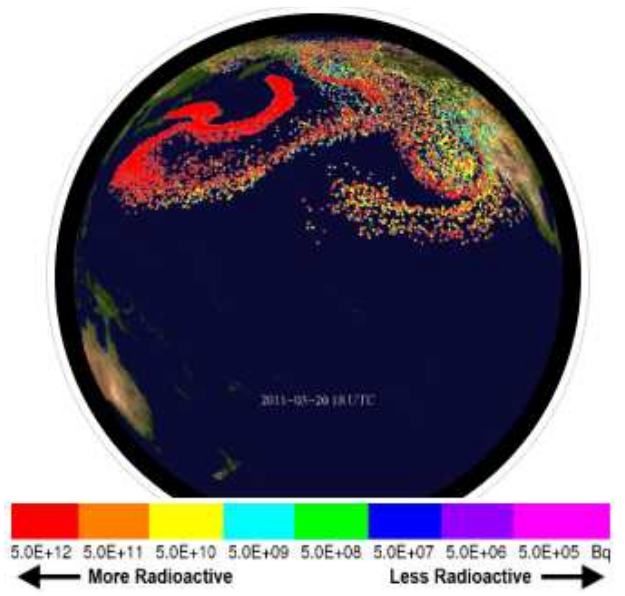

Figure 17. A radioactive dust cloud circled the earth due to the Fukushima explosions (Draxler, et al. [49]).

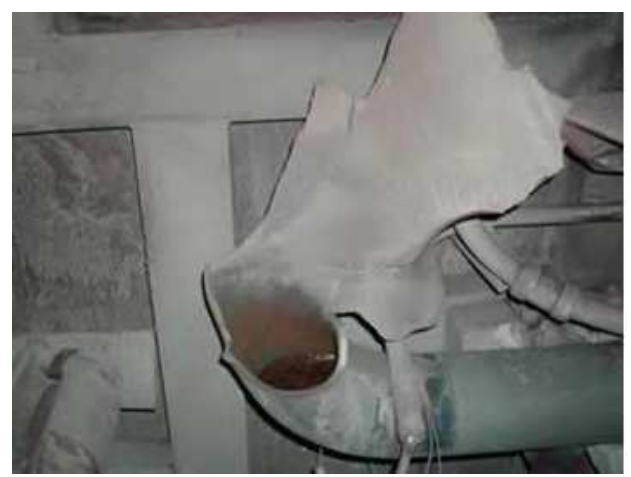

Figure 18. 2001 Hamaoka, Japan piping explosion due to water hammer (U.S. $N R C)$

\section{Addendum: Criticalities, Explosions, and Statistics}

\subsection{Criticality Accidents}

Criticalities typically affect industrial personnel safety more than the safety of the general public, where accidents that affect personnel are classified as Safety Significant and off-site consequences are Safety Class. Although criticality accidents are outside the primary scope of this paper, they provide some insight into the random nature of nuclear accidents. 
A comprehensive study was performed for criticality accidents before 2000 (McLaughlin, et al. [48]), and additional criticalities since 2000 were not noted in a literature review. Calculations are not presented here for experimental research reactor criticalities. Results for different types of process plants in different countries are summarized in Figure 19, where the mean time between accidents continually increased since 1953.

Most of these accidents were related to the mishandling of liquids, where quantities exceeded the controlled mass quantities mandated to prevent uncontrolled reactions. The next industrial criticality accident can happen at any time, and cannot be predicted with any certainty since the last criticality occurred 21 years ago due to safety improvements in the industry, and the scatter of criticality data prior to the last criticality is prohibitive to accurate accident predictions.

Also of interest, more than one explosion occurred for each of the Chernobyl and SL-1 reactors, where an intentional explosion due to a criticality at the Borax-1 National Reactor Test Station is shown in Figure 20. Note that the original Borax-1 investigation did not consider pertinent hydrogen explosions as conceived in this research (Leishear [1]), where hydrogen - steam explosions caused the blast rather than steam explosions alone as incorrectly believed since 1955 .

\subsection{Statistical Approximations for Criticality Predictions}

Are the accident processes statistically random? Can a normal random distribution be assumed for calculations and accident predictions? To address these questions, first consider criticality accidents. Note that the word "accident" is questionable throughout this paper and the nuclear industry since most of these "events" are preventable. Specifically, explosion events are preventable, and explosion events should therefore not be referred to as accidents. Even so, the term accident is so ingrained into the nuclear industry that the term is used in this paper, and the word accident can be used as a general term to encompass small inconsequential events to large scale disasters, i.e. an accident is considered to be a non-voluntary event.

The safety culture in the nuclear industry continues to improve, and this fact is evidenced by an increase in the mean time between criticality accidents over time, as gleaned from Figure 19. Uncertainty calculations for this set of data show that there is $99.9 \%$ probability that another criticality should have occurred before 2020, which did not occur. This probability was calculated for the most recent accidents between 1978 and 1999, similar to the calculations above for the explosion and meltdown accidents that followed TMI-2. In general, the average time between accidents increases, and there is a continuing increase in time between accidents as observed for meltdowns.

Also of importance, there were many near misses that happened during that time. Between 2000 and 2013, there were no Level 1 criticality accidents, but there were 62 Level 2 events and 28 Level 3 events in the U.S, where definitions of Level 1, 2, and 3 events follow (Hodges and Sander [50]).
"Level 1 events are accidents where an accident occurred but where criticality did not occur due to criticality parameters not being met. Level 1 is followed by Level 2 events determined to be those where one control of double contingency was lost but criticality potential was prevented through successful employment of a second control. Lastly, Level 3 is delineated for events related to identification of shortcomings before they would lead to loss of controls required for double contingency".

In other words, the facts that no criticality accidents occurred since 2000 were, in fact, purely random events, since there were occasions where specified safety limits for nuclear material quantities were exceeded, and accidents could have occurred.

Consequently, if near misses were included in calculations, statistical predictions would have improved for criticality predictions. Even so, the variability in criticality accident frequencies is significant. Note that extraordinary efforts have been performed in the nuclear industry to control explosions, but the effort to stop criticalities, while significant, does not match the responses to accidents like Three Mile Island and Chernobyl, where thousands of pages of reports document research from more than one hundred countries.

Similarly, there have been reactor operational near misses that could have caused reactor meltdowns as documented in the literature, and there have been many small explosions that were inadequate to cause reactor system failures (Leishear [1]). The models presented here are simplifications of reality to better understand reactor safety. In other words, the extent of meltdowns and explosion magnitudes vary, and only the largest accidents were the focus of this study.

\subsection{A Choice of Statistical Calculations}

Now consider the validity of statistical calculations for meltdown and explosion predictions, where statistics are commonly accepted for predictions of random events. Statistical data for explosions do not have nearly as much scatter as data from criticality accidents, as observed by comparison of Figures 6 and 19. The criticality accident frequencies are extremely scattered, presumably since the criteria in many cases for distinguishing between a near miss and an accident is the volume of liquid accumulated before that accumulation is detected, either by operations personnel or by a criticality occurrence. For plant explosions, near misses also occur, but explosions are the measures of failure, which are concise indicators of failure. Explosion events are not nearly as scattered with respect to frequency as criticality events.

Numerous predictions were performed for CDFs and LRFs with different assumptions, where the costs are loss of life and environmental disasters. The less conservative approximations delay some accident predictions, but these extreme hazard predictions that have been calculated are only pushed out in time if the math is incorrect. The explosions are still on the way. The only question is when these explosions will arrive.

Even so, the limited data set of four accidents is extremely 
important. As already noted, student-T values are a well-accepted method for evaluating small data sets. Of particular interest to these calculations, TMI-2 is included in this data set to obtain a 2067 prediction for a large radioactive release and a 2132 prediction of a Chernobyl type accident. This set of accidents was selected to determine the impact of TMI-2 corrective actions on nuclear plant safety. Should TMI-2 be included in the data set since this accident cannot be affected by its own corrective actions? At a minimum the TMI-2 accident is required at time, $t=0$, since the time between TMI- 2 and the next accident at Saint Laurent is essential to the accident predictions. Once TMI-2 is included as the starting point for this predictive data set, it may, or may not, be considered as an inclusive accident, where TMI-2 can be considered as an accident that does not release radioactivity and does not involve a criticality.

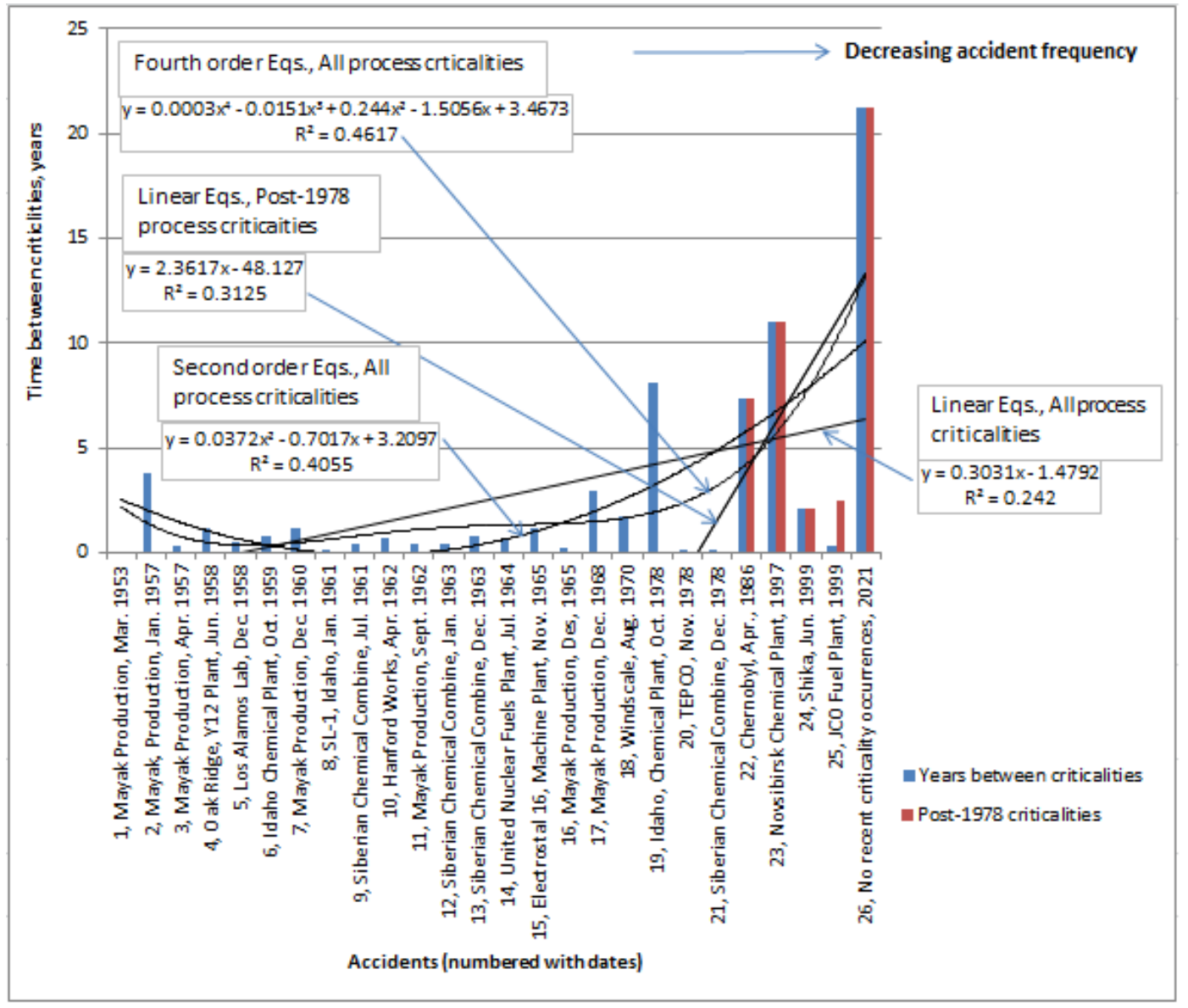

Figure 19. Process criticality accidents (years per accident) - experimental reactor criticalities are not shown.

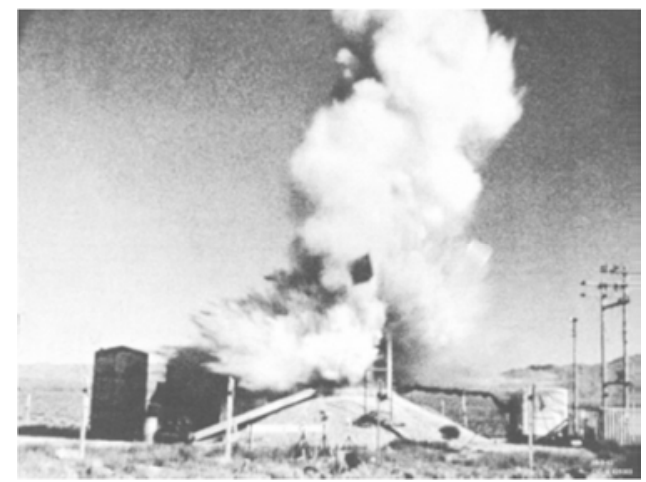

Figure 20. Borax-1 criticality and explosion test in 1955resulted in a much larger explosion than expected due to previously unknown hydrogen explosion effects (McLaughlin, et al. [49]).

This decision affects explosion predictions since there are four accidents to be used for calculations rather than three. A decision to include three accidents in prediction calculations, rather than four accidents, results in a more conservative prediction of $2053 \pm 37.9$ years rather than $2067 \pm 30.5$ years for a $50 \%$ probability of a large release, and a $4 \%$ probability of a release in 2021 (Figure 21), and the Chernobyl type explosion prediction is reduced to $2095 \pm 80$ from $2132 \pm 64$ years. The 2039 prediction for the next accident is unaffected,.i.e., the prediction is the same for either three or four accident assumptions.

An effective argument can be made to support either Figure 7 or Figure 21 predictions, where the predictions are similar. This decision was more technical than ethical. Including the TMI- 2 accident as a placeholder at time $=0$ seemed prudent, and the less conservative results of Figure 7 are endorsed. Even so, either set of estimates can be justified. The primary reason that Figure 7 is endorsed is that the uncertainties of Figure 7 are smaller, albeit less conservative, than those of Figure 21, where fewer data points result in a greater uncertainty for Figure 21 calculations. 


\section{Acknowledgements}

Although this work is claimed to be a one-man research project, the help of others was essential to promote the nuclear safety theory presented here. Not only did this author invest extraordinary efforts to perform this important research, but his wife, Janet Leishear, sacrificed much over many years to support this research by serving as a reviewer for all publications and providing unbelievable day to day support to ensure that this research continued.

Also, the opportunity to publish new ideas in this Journal is greatly appreciated, and comments from the many reviewers, both pro and con, improved the quality of this work. As a matter of fact, reviewers who opposed the conclusions of this work as documented in previous letters and publications - forced a better and stronger defense and discussion of this work.

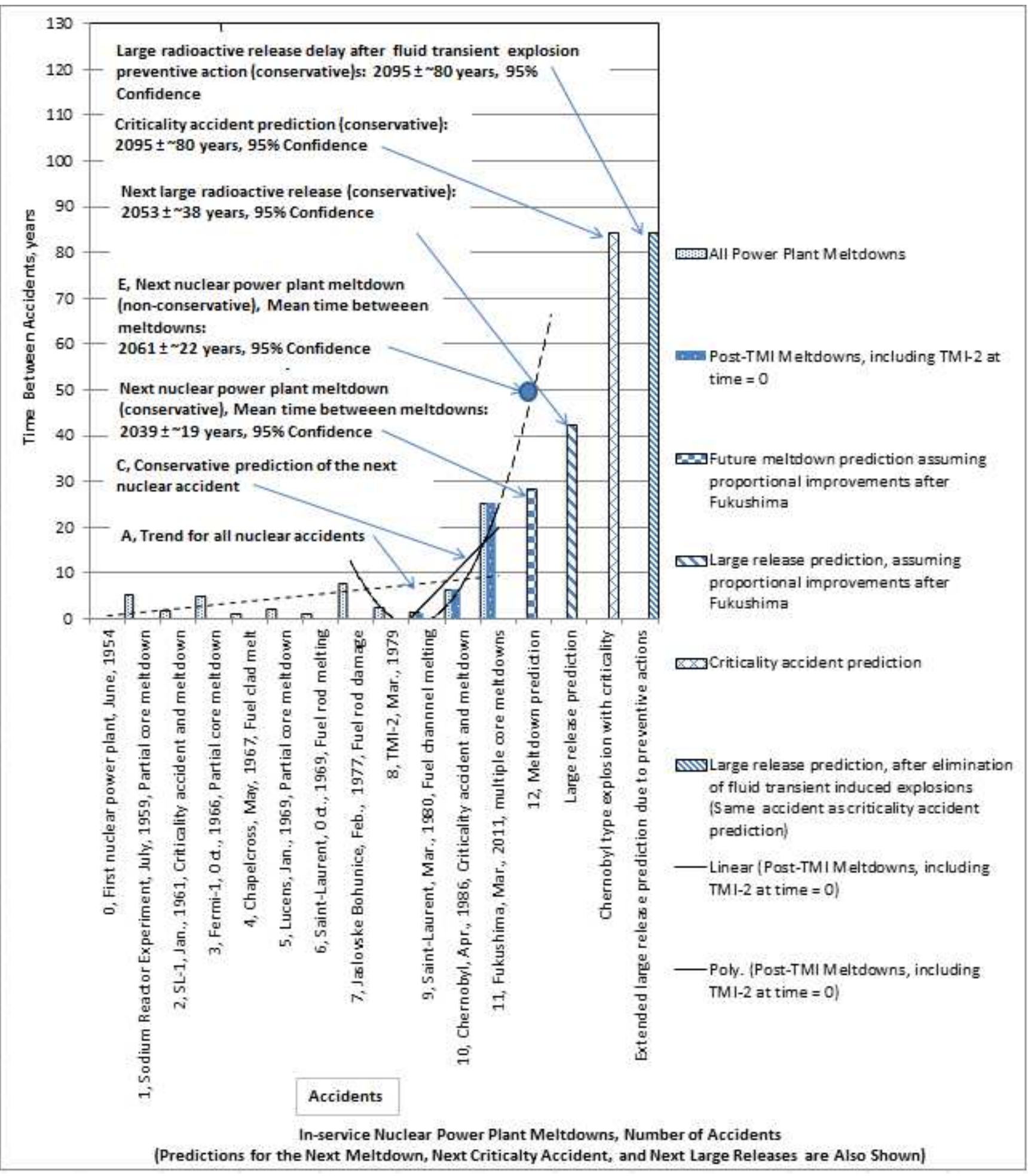

Figure 21. Nuclear power plant accidents, three accident model prediction results (years per accident). 


\section{Nomenclature}

$\begin{array}{ll}\text { CDF } & \text { core damage frequency } \\ \text { DOE } & \text { U.S. Department of Energy } \\ \text { GWe } & \text { gigawatt, electric } \\ \text { IAEA } & \text { International Atomic Energy Agency } \\ \text { ICRP } & \text { International Committee on Radiological Protection } \\ \text { IRPS } & \text { International Radiological Protection School } \\ \text { NEA } & \text { Nuclear Energy agency, OECD } \\ \text { NRC } & \text { U.S. Nuclear Regulatory Commission } \\ \text { LRF } & \text { large release frequency } \\ \text { MD } & \text { management directive } \\ \text { MWe } & \text { megawatt, electric } \\ \text { NOAA } & \text { National Oceanic and Atmospheric Administration } \\ \text { OECD } & \text { Organization for Economic Development and Cooperation } \\ \text { PSA } & \text { probabilistic safety analysis, probabilistic risk assessment } \\ \text { R } & \text { Pearson function } \\ \text { RCWS } & \text { reactor coolant water system } \\ \mathrm{S}_{\mathrm{y}} & \text { Standard Error of Regression } \\ \text { TMI } & \text { Three Mile Island } \\ \text { WHO } & \text { World Health Organization } \\ \mathrm{U} & \text { uncertainty } \\ \text { UNESCO } & \text { United Nations Educational, Scientific and Cultural Organization } \\ x & \text { number of accidents } \\ y & \text { number of years between accidents } \\ \sigma & \text { standard deviation }\end{array}$

\section{References}

[1] Leishear, R., 2020, "The Autoignition of Nuclear Power Plant Explosions", Journal of Nuclear Engineering and Radiation Science, ASME, N. Y., N. Y., pp. 1-22.

[2] Leishear, R., 2019, "The TMI-2 Explosion”, ANS Nuclear News Magazine, Le Grange Park, Illinois, 1 p.

[3] Leishear, R., 2017, "Nuclear Power Plant Fires and Explosions, I, Plant Design and Hydrogen Ignition", Pressure Vessels and Piping Conference, ASME, N. Y., N. Y., 9 pps.

[4] Leishear, R., 2017, "Nuclear Power Plant Fires and Explosions, II, Hydrogen Ignition Overview", Pressure Vessels and Piping Conference, ASME, N. Y., N. Y., 11 pps.

[5] Leishear, R., 2017, "Nuclear Power Plant Fires and Explosions, III, Hamaoka Piping Explosion", Pressure Vessels and Piping Conference, ASME, N. Y., N. Y., 9 pps.

[6] Leishear, R., 2017, "Nuclear Power Plant Fires and Explosions, IV, Water Hammer Ignition Mechanisms", Pressure Vessels and Piping Conference, ASME, N. Y., N. Y., 7 pps.

[7] Leishear, R., 2017, "Nuclear Power Plant Fires and Explosions, Accident Overviews", ANS 22950, American Nuclear Society, N. Y., N. Y., pp. 1-4.

[8] Henrie, J. and Postma, A., "Analysis of Three Mile Island Hydrogen Burn", 1983, U.S. Nuclear Regulatory Commission, Washington, D. C., pp. 1-50.

[9] Leishear, R., "From Water Hammer to Ignition, The Spark That Ignited Three Mile Island Burst from a Safety Valve, Mechanical Engineering Magazine”, 2013, ASME, N. Y., N. Y., pp. 46-49.

[10] Leishear, R., "PRE-GI-015, Hydrogen Fires and Explosions in Nuclear Reactors, ML15245A508", 2015, U.S. Nuclear Regulatory Commission, NRC, Washington, D.C., 12 pps.

[11] "U.S. Nuclear Regulatory Commission Management Directive, MD 8.8 Management of Allegations DT-16-05", U.S. Nuclear Regulatory Commission, Washington, D. C., pp. 3-13.

[12] Boyce, T. H., "Response to PRE-GI-015: ML15191A397, ML15191A398, ML16007A181, ML16007A182, ML16063A320", 2015, U.S. Nuclear Regulatory Commission, Washington, D.C., 15 pps.

[13] Dube, D., "ML082400370, Comparison of New Light-water Reactor Risk Profiles", 2008, U.S. Nuclear Regulatory Commission, Washington, D.C., pp. 1-12.

[14] "ML992930056, The Core Damage Frequency Objective to a Fundamental Commission Safety Goal", 1997, U.S. Nuclear Regulatory Commission, Washington, D.C., pp. 1-7.

[15] "Nuclear Power Plants, World-wide", 2018, European Nuclear Society, Brussels Belgium, http://www.euronuclear.org/info/encyclopedia/n/nuclear-powe r-plant-world-wide.htm, p.1.

[16] Modarres, M., Kaminsky, M., Kristov, V., An Introduction to Reliability Engineering and Risk Analysis, 2010, A Practical Guide, CRC Press, New York, New York, pp. 12-70.

[17] NEA, "Comparing Nuclear Accident Risks with Those from Other Energy Sources", OECD, Paris, France, https://www.oecd-nea.org/ndd/reports/2010/nea6861-compari ng-risks.pdf, pp.1-52.

[18] "NUREG-2201, Probabilistic Risk Assessment and Regulatory Decisionmaking: Some Frequently Asked Questions", 2016, U.S. Nuclear Regulatory Commission, Washington, D. C., pp. 17-49. 
[19] Max-Planck-Gesellschaft, "Severe Nuclear Reactor Accidents Likely Every 10 to 20 Years, European Study Suggests", 2012, Max Planck Institute, Science Daily, Rockville, Maryland, p.1.

[20] "Safety of Nuclear Power Reactors", 2019, https://www.world-nuclear.org/information-library/safety-and -security/safety-of-plants/safety-of-nuclear-power-reactors.asp x, World Nuclear Association, London, United Kingdom, p.1.

[21] Coleman, H., Steele, W., Experimentation, Validation, and Uncertainty Analysis for Engineers, 2009, John Wiley and Sons, Hoboken, New Jersey, pp. 240-245.

[22] NRC, "WASH-1400, NUREG KM -0010, "The Reactor Safety Study, The Introduction of Risk Assessment to the Regulation of Nuclear Reactors", 1975, NRC, Washington, D.C. pp. 23-24.

[23] Knief, A., Nuclear Engineering, Theory and Technology of Commercial Nuclear Power, 2008, American Nuclear Society, La Grange Park, Illinois, pp. 395-396.

[24] "Health Effects at the Chernobyl Accident, an Overview", 2006 World Health Organizations, Geneva, Switzerland, p.1

[25] "Sources, Effects and Risks of Ionizing Radiation, UNSCEAR Report", 2013, Vol. 1, United Nations Technical Committee on the Effects of Atomic Radiation, New York, New York, pp. $1-311$.

[26] Yasumura, S., 2014, "Evacuation Effects on Excess Mortality Among Institutionalized Elderly After the Fukushima Daiichi Nuclear Power Plant Accident", Fukushima, J. Med. Sci., 6, No. 2, Fukushima Medical University, Japan, pp. 192-195.

[27] Wheatley, S., Benjamin K. Sovacool, Didier Sornette, "Reassessing the Safety of Nuclear Power", 2016, Energy Research \& Social Science, Amsterdam, Netherlands, 15, pp. 96-100.

[28] Duffey, R., "Extreme Events: Causes and Prediction", 2015, Sun Valley, Idaho, April 26-30, 2015, pp.318-324.

[29] "Electricity, Generation", 2018, OECD, NEA, Paris, France, https://data.oecd.org/energy/electricity-generation.htm\#indicat or-chart, p.1.

[30] Leishear, R., 2018, "Pump Startups Ignite Nuclear Power Plants, History, Law and Risks", British Hydraulic Research Group, Cranfield, Bedfordshire, United Kingdom, 16 pps.

[31] NUREG-1860, "Feasibility Study for a Risk-Informed and Performance-Based Regulatory Structure for Future Plant Licensing", 2007, Volume 2, Appendix D, U.S. Nuclear Regulatory Commission, Washington, D.C., pp. D-1 to D-6.

[32] Slovic, P. "Perception of Risk Science", 1987, 236, The American Association for the Advancement of Science, Washington, D.C., pp. 280-285.

[33] Martinez, N., Wueste, D., "Balancing Theory and Practicality: Engaging Non-Ethicists in Ethical Decision Making Related to Radiological Protection,” 2016, J. Radiol. Prot. 36, 832-841.

[34] Cho, K., Cantone, M., Kurihara-Saio, C., Le Guen, B., Martinez, N., Oughton, D., Schneider, T., Toohey, R., Zölzer, F. "Ethical Foundations of the System of Radiological Protection", 2018, ICRP Publication 138, Ann. ICRP 47(1), pp. 1-65.

[35] "Annals of the ICRP, ICRP Publication 138, Ethical Foundations of the System of Radiological Protection", 2018, International Commission on Radiological Protection,
Thousand Oaks, California, p. 7.

[36] Leishear, R., Rhodes, C., Alford, L., "Dynamic Pipe Stresses During Water Hammer", I, A Finite Element Analysis", 2002, Young, Pressure Vessel and Piping Conference, ASME, N. Y., N. Y., pp. 1-10.

[37] Leishear, R., Fluid Mechanics, Water Hammer, Dynamic Stresses, and Piping Design, 2013, ASME, N. Y., N. Y., pp. 1448.

[38] Leishear, R., "We Can Stop Nearly \$1.7 Trillion in Water Main Breaks", 2020, NACE, Materials Performance Magazine, National Association of Corrosion Engineers, Houston Texas, pp. 1-6.

[39] Leishear, R., "Of Course We Can Stop Nearly \$1.7 Trillion in Water Main Breaks", 2020, NACE, Materials Performance Magazine, National Association of Corrosion Engineers, Houston Texas, pp. 20-24.

[40] Leishear, R., "Explosions: A Fresh Look at Chernobyl, Three Mile Island, the Gulf Oil Spill, and Fukushima Daiichi”, 2013, Mensa World Journal, Mensa International Limited, Caythorpe, United Kingdom, p. 6.

[41] Leishear, R., "DOE Cover Up of Explosion Dangers in U.S. Nuclear Power Plants and DOE Responses," 2020, Leishear Engineering, LLC Aiken, S.C., leishearengineeringllc.com.

[42] Coronel, S. A., Veilleux, J., Shepherd, J., "Ignition of Stoichiometric Hydrogen-Oxygen by Water Hammer", Proceedings of the Combustion Institute, Elsevier Press, Cambridge, Massachusetts, pp. 1-8.

[43] Crowe, A., The PMP Exam, How to Pass on Your First Try, 2018, Velociteach.com, pp. 1-735.

[44] Pioro, I., Duffey, R., Kirillov, P., Pioro, R., Zvorykin, A., Machrafi, A., "Current Status and Future Developments in Nuclear-Power Industry of the World", 2019, Journal of Nuclear Engineering and Radiation Science, ASME, N. Y., N. Y., pp. 1-27.

[45] Zhoul, F., Hicks, F., Steffler, P., "Transient Flow in a Rapidly Filling Horizontal Pipe Containing Trapped Air", 2002, 128, Journal of Hydraulic Engineering, American Society of Civil Engineers, Reston, Va., p. 629.

[46] Leishear, R., "Hydrogen Ignition Mechanism for Explosions in Nuclear Facility Pipe Systems", 2010, ASME, Pressure Vessel and Piping Conference, pp. 1-12.

[47] "10 CFR, Part 50, Code of Federal Regulations, Domestic Licensing Of Production And Utilization Facilities", U.S. NRC, Washington, D.C.

[48] McLaughlin, T., Shean, P. Monahan, S., Pruvost, N., "A Review of Criticality Accidents", 2000, Los Alamos National Laboratory, Lo Alamos, New Mexico, pp. 1-142.

[49] Draxler, R., "Fukushima Radioactive Dispersion Model", 2011, National Oceanic and Atmospheric Administration, https://sos.noaa.gov/datasets/fukushima-radioactive-aerosol-di spersion-model/

[50] Hodges and Sanders," Nuclear Criticality Safety, Near Misses and Classification", 2014, Cambridge, Massachusetts, Elsevier Press, pp. 88-99. 